IZA DP No. 5014

Earnings Dynamics and Inequality among Men in Luxembourg, 1988-2004:

Evidence from Administrative Data

Denisa Maria Sologon

Cathal O'Donoghue

June 2010 


\title{
Earnings Dynamics and Inequality among Men in Luxembourg, 1988-2004: Evidence from Administrative Data
}

\author{
Denisa Maria Sologon \\ Maastricht University, MGSoG \\ and IZA \\ Cathal O'Donoghue \\ Teagasc Rural Economy Research Centre, \\ NUI Galway, ULB and IZA
}

\section{Discussion Paper No. 5014 \\ June 2010}

\author{
IZA \\ P.O. Box 7240 \\ 53072 Bonn \\ Germany \\ Phone: +49-228-3894-0 \\ Fax: +49-228-3894-180 \\ E-mail: iza@iza.org
}

Any opinions expressed here are those of the author(s) and not those of IZA. Research published in this series may include views on policy, but the institute itself takes no institutional policy positions.

The Institute for the Study of Labor (IZA) in Bonn is a local and virtual international research center and a place of communication between science, politics and business. IZA is an independent nonprofit organization supported by Deutsche Post Foundation. The center is associated with the University of Bonn and offers a stimulating research environment through its international network, workshops and conferences, data service, project support, research visits and doctoral program. IZA engages in (i) original and internationally competitive research in all fields of labor economics, (ii) development of policy concepts, and (iii) dissemination of research results and concepts to the interested public.

IZA Discussion Papers often represent preliminary work and are circulated to encourage discussion. Citation of such a paper should account for its provisional character. A revised version may be available directly from the author. 


\title{
ABSTRACT \\ Earnings Dynamics and Inequality among Men in Luxembourg, 1988-2004: Evidence from Administrative Data
}

\begin{abstract}
Starting with the late 1980s and intensifying after early 1990s, Luxembourg evolved from an industrial economy to an economy dominated by the tertiary sector, which relies heavily on the cross-border workforce. This paper explored the implications of these labour market structural changes for the structure of earnings inequality and earnings mobility. Using an extraordinary longitudinal dataset drawn from administrative records on professional career, we decomposed Luxembourg's growth in earnings inequality into persistent and transitory components and explored the extent to which changes in cross-sectional earnings inequality between 1988 and 2004 reflect changes in the transitory or permanent components of earnings. Thanks to the richness of the Luxembourgish data set, we are able to estimate a much richer model that nests the various specifications used in the US, Canadian and European literature up to date, thus rejecting several restrictions commonly imposed in the literature. We find that the growth in earnings inequality reflects an increase in long-term inequality and a decrease in earnings instability, and is accompanied by a decrease in earnings mobility. Thus in 2004 compared with 1988, low wage men in Luxembourg are worst off both in terms of their relative wage and in terms of their opportunity of improving their relative income position in a lifetime perspective.
\end{abstract}

JEL Classification: $\quad$ C23, D31, J31, J60

Keywords: panel data, wage distribution, inequality, mobility

Corresponding author:

Denisa Maria Sologon

Maastricht Graduate School of Governance

Maastricht University

Kapoenstraat 2

6211 KW Maastricht

The Netherlands

E-mail: denisa.sologon@maastrichtuniversity.nl 


\section{INTRODUCTION}

Understanding the source of the growth in earnings inequality has become a major topic in economics over the past two decades, fuelled mainly by the rise in earnings inequality experienced by many developed countries during the 1980s and 1990s.

Starting with the US and Canada, followed by UK and Europe, recent studies on earnings dynamics have stressed the importance of decomposing the growth in earnings inequality into permanent and transitory components, due to their implications for long-run differentials. An increase in cross-sectional earnings inequality triggered by an increase in the permanent component signals an increase in lifetime earnings differentials, suggesting a worsening of the relative lifetime earnings position of the chronically poor. An increase in cross-sectional earnings differentials triggered by an increase in earnings instability signals an increase in earnings mobility, implying an increased opportunity for the poor to improve their relative income position in a lifetime perspective.

In Europe, the advancement and the full potential of this research in understanding the structural changes in inequality has been limited, due to insufficiently long panels. Our study aims to fill part of this gap.

The contribution of this study to the literature on earnings dynamics and inequality is twofold. First, it aims to expand the research regarding the possible implications of the labour market structural changes on the structure of earnings inequality and earnings mobility. The specific context of the Luxembourgish labour market, which underwent significant structural changes during the last decades, makes Luxembourg a relevant case for studying the structural changes in earnings inequality and the implications for lifetime earnings differentials. This study is the first of its kind in Luxembourg. Following the tradition of previous studies we focus on men to avoid the problem of selection bias characterising female earnings.

Starting with the late 1980s and intensifying after early 1990s, Luxembourg evolved from an industrial economy to an economy dominated by the tertiary sector, which relies heavily on the cross-border workforce. Moreover, Luxembourg recorded a large increase in the number of active population, both residents and cross-borders, which more than doubled in 2004 compared with 1988. The change in the structure of the labour market by occupation status (Figure 1), 
reveals an increase in the share of white collars and civil servants, and a decrease in the share of blue collars. The change in the labour market structure by the sector of activity (Figure 2) reveals a significant increase in the share of the service sector and a decrease in the share of the industry sector. The evolution of the labour market age distribution (Figure 3, upper panel) reveals a clear shift in men's labour market behaviour due to the education system: from a high concentration of active men around ages 20-25 in 1988 to a high concentration around ages 25-45 in 2004. The change in the labour market behaviour is confirmed also by the cumulative age distribution (Figure 3, bottom panel), which shifted towards higher ages: e.g. the share of people present in the labour market until age 25 is almost double in 1988 than in 1996 or 2004. Following these changes cross-sectional earnings inequality increased.

What are the implications of these changes for the structure of earnings inequality and earnings mobility? Using 17 years of longitudinal earnings information drawn from the administrative data on the professional career, we decompose Luxembourg's growth in earnings inequality into persistent and transitory components. We explore the extent to which changes in cross-sectional earnings inequality in Luxembourg between 1988 and 2004 reflect changes in the transitory or permanent components of earnings.

On the one hand, did the increases in cross-sectional wage inequality result from greater transitory fluctuations and a higher degree of earnings mobility? Or does it reflect increasing permanent differences between individuals with mobility remaining constant or even falling? On the other hand, did mobility influence falls in cross-sectional inequality? Understanding the contributions of the changes in permanent and transitory inequality to increased cross-sectional inequality is useful therefore in evaluating alternative structural changes hypotheses and for determining the potential welfare consequences of rising inequality. (Katz and Autor, 1999)

Second, we exploit our extraordinary dataset to achieve some methodological advances at the EU level. The limited scale of most European panels has forced EU researchers to rely on simple country models, which impose economically implausible restrictions. For example, the 7 ECHP waves available for Luxembourg have forced Sologon and O'Donoghue (2009b, 2009a, 2009c) to impose the assumption of invariant permanent component with no permanent shocks (age specific or not), no life-cycle variation in the variance of transitory earnings shocks and no MA process in the transitory variance. Due to our long panel, we are able to estimate much richer 
models that nest the various specifications used in the US, Canadian and European literature up to date.

Unlike previous studies, we decompose the analysis by 36 birth cohorts composed of people born in a certain year. This small age window allows the precise identification of the two components at different lifecycle stages. Equally weighted minimum distance methods are used to estimate the covariance structure of earnings, decompose earnings inequality into a permanent and a transitory component, estimate earnings mobility and conclude about their evolution.

\section{LiteratURE REVIEW}

The existing literature on earnings dynamics is predominantly based on US data. Atkinson, Bourguignon et al. (1992) provide a comprehensive survey of the literature on earnings dynamics until 1992. Earlier work focused on fitting statistical models to the earnings process. E.g. Lillard and Willis (1978), Lillard and Weiss (1979), MaCurdy (1982), Abowd and Card (1989) fitted models to the autocovariance structure of earnings and hours, but they did not account for the changes in the autocovariance structure of earnings over time.

Later work, Moffitt and Gottschalk (1995, 1998, 2002) used PSID to estimate the permanent and transitory components of male earnings and how it evolved over time. In Moffitt and Gottschalk (1998), the earnings process was fit by a permanent component, modelled as a random walk in age and a highly persistent serially correlated transitory component, with weights on these components for each year. They found that the increase in the cross-sectional inequality of individual earnings and wage rates in the U.S. between 1969 and 1991 has been roughly equally composed of increases in the variances of the permanent and transitory components of earnings, with little change in earnings mobility rates. Since most of the theoretical explanations for the increase in inequality have been aimed at explaining increases in the variance of the permanent component of earnings (e.g. increases in the price of skills), they found their result surprising and unexpected. Therefore, in their most recent study, Moffitt and Gottschalk (2008) estimated the trend in the transitory variance of male earnings using PSID from 1970 to 2004. They found that the transitory variance increased substantially in the 1980's and remained at the same level until 2004, for both less and more educated workers. Moreover, the transitory variance appears to 
have a strong cyclical component: its increase accounts for between $30 \%$ and $65 \%$ of the rise in the overall inequality, depending on the period.

Using the PSID, Baker (1997) compared two competing specifications for the permanent component of earnings: the "profile heterogeneity or the random growth model" and the "random walk model". In spite of the increased popularity of the latter, Baker (1997) proved that the profile heterogeneity model provides a better representation of the data.

Baker and Solon (2003) decomposed the growth in earnings inequality into its persistent and transitory components using longitudinal income tax records from Canada. The earnings process was fit by a permanent component, modelled as a mixed process composed of a random growth and a random walk in age and a highly persistent serially correlated transitory component, with weights on these components for each year. They found that growth in earnings inequality reflects both an increase in the long-run inequality and an increase in earnings instability.

Up until recently, little work has been carried out in Europe on the dynamic nature of individual earnings. Dickens (2000b) analysed the pattern of individual male wages over time in UK using the New Earnings Survey (NES) panel data set for the period 1975-1995. This study divided the data into year birth cohorts and analysed the auto-covariance structure of hourly and weekly earnings for each cohort. In the tradition of Moffitt and Gottschalk (1998), the earnings process was fit by a permanent component, modelled as a random walk in age and a highly persistent serially correlated transitory component, with weights on these components for each year. The innovative element of their model was the extension of the random walk to a specification that allows for age-specific innovation variances until age 40 and a random effects model thereafter. The results showed that about half of the rise of the overall cross-sectional inequality can be explained by the rise in the permanent variance and the rest by the rise in the persistent transitory component.

Ramos (2003) analysed the dynamic structure of earnings in UK using the British Household Panel Study for the period 1991-1999. The earnings specification followed a similar specification with Baker and Solon (2003). Using information on monthly earnings of male fulltime employees, this study decomposed the covariance structure of earnings into its permanent and transitory components and concluded that the increase in inequality over the 1990's was due to increased in earnings volatility. Moreover, the relative earnings persistency was found to 
decline over the lifecycle, which implies a lower mobility for younger cohorts. These findings are at odds with the previous literature on earnings dynamics both for UK and the OECD. Unlike previous literature, this study considered also for the effect of observed characteristics and found that human capital and job related characteristics account for nearly all persistent earnings differences and that the transitory component is highly persistent.

Kalwij and Alessie (2003) examined the variance-covariance structure of log-wages over time and over the lifecycle of British men from 1975 to 2001, controlling for cohort effects. Their model follows closely the specification used by Abowd and Card (1989), Dickens (2000b) and Baker and Solon (2003) accounting also for cohort effects. They showed that the increase in the cross-sectional inequality was caused mainly by an increase in the transitory component of earnings and to a lesser extent by an increase in the permanent wage inequality. Thus the increase in cross-sectional inequality was accompanied by an increase in earnings mobility.

Cappellari (2003) used the Italian National Social Security Institute for the period 1979-1995 and decomposed the male earnings autocovariance structure into its long-term and transitory components using a model specification similar with Moffitt and Gottschalk (1995) and Backer (1997). The model included a permanent component, modelled as a random growth in age and a highly persistent serially correlated transitory component, with weights on these components for each year and cohort. The findings showed that growth was determined by the long-term earnings component. Other evidence on the contribution of permanent and transitory earnings components to cross-sectional inequality has become available in recent year in Sweden. Gustavson (2004a, 2009b) used a hybrid model between Baker and Solon (2003) and Dickens (2000b) and concluded that the decrease in earnings inequality was due to a decrease in the permanent component.

Most recently, Sologon and O'Donoghue (2009a, 2009b, 2009c) used the 8 waves of ECHP for 14 EU countries to explore the dynamic structure of individual earnings and the extent to which changes in cross-sectional earnings inequality reflect transitory or permanent components of individual lifecycle earnings variation. Overall, the decrease in inequality resulted from a decrease in transitory differentials in Germany, France, UK and Ireland, in permanent differentials in Belgium and Spain and in both components in Denmark and Austria. The increase in inequality reflects an increase in permanent differentials in Luxembourg, Italy, 
Greece and Finland, and an increase in both components in Portugal and Netherlands. The decrease in inequality was accompanied by an increase in mobility only in Denmark, Belgium and Spain. Except for Netherlands and Portugal, all countries recording an increase in inequality experienced also a decrease in mobility.

\section{THEORETICAL MODEL OF THE DETERMINANTS OF WAGE DIFFERENTIALS}

The theoretical and methodological specifications in this section follow closely Sologon and O’Donoghue (2009a, 2009b, 2009c).

\subsection{Determinants of earnings inequality}

As pointed out by Katz and Autor (1999), the existing literature contains many explanations for the rise in earnings inequality experienced by many developed countries during the 1980s and 1990s. One approach for explaining changes in wage differential is to decompose overall wage inequality into permanent inequality and transitory inequality.

Following the terminology introduced by Friedman and Kuznets (1954), individual earnings are composed of a permanent and a transitory component, assumed to be independent of each other. The permanent component of earnings reflects personal characteristics, education, training and other systematic elements. The transitory component captures the chance and other factors influencing earnings in a particular period and is expected to average out over time. Following the structure of individual earnings, overall inequality at any point in time is composed from inequality in the transitory component and inequality in the permanent component of earnings. The evolution of the overall earnings inequality is determined by the cumulative changes in the two inequality components.

The rise in the inequality in the permanent component of earnings may be consistent with increasing returns to education, on-the-job training and other persistent abilities that are among the main determinants of the permanent component of earnings, meaning enhanced relative earnings position of the highly skilled individuals. (Mincer, 1957, 1958, 1962, 1974; Hause, 1980).

The increase in the inequality of the transitory component of earnings may be attributed to the weakening of the labour market institutions (e.g. unions, government wage regulation, and 
internal labour markets), increased labour market instability, increased competitiveness, a rise in the temporary workforce which increase earnings exposure to shocks. A period of skill-biased technological change with the spread of new technologies can on the one hand increase the demand for skills, and on the other hand it can increase earnings instability. (Katz and Autor, 1999). Rodrik (1997) argued that also globalization and international capital mobility can increase wage instability. Overall, the increase in the return to persistent skills is expected to have a much larger impact on long-run earnings inequality than an increase in the transitory component of earnings. (Katz and Autor, 1999; Moffitt and Gottschalk, 2002)

\section{Alternative model specifications for the permanent and transitory components}

Next we introduce several models of earnings dynamics that have been dominating the literature on permanent and transitory earnings inequality over the past 30 years. To begin with, we introduce the simplest specification, which in spite of its simplicity provides a very intuitive insight into the decomposition of earnings into their permanent and transitory components. Based on this specification earnings are being decomposed as follows:

$$
Y_{i t}=\mu_{i}+v_{i t}, \quad \mu_{i} \sim \operatorname{iid}\left(0, \sigma_{\mu}^{2}\right), \quad v_{i t} \sim \operatorname{iid}\left(0, \sigma_{v}^{2}\right), \quad t=1, \ldots, T_{i}, \quad i=1, \ldots, N
$$

where $\mu_{i}$ represents the permanent time-invariant individual specific component and $v_{i t}$ represents the transitory component, which is independent distributed both over individuals and time. This model imposes very rigid restrictions on the covariance structure of earnings:

$$
\operatorname{Cov}\left(Y_{i t}, Y_{i s}\right)= \begin{cases}\sigma_{\mu}^{2}+\sigma_{v}^{2}, & t=s \\ \sigma_{\mu}^{2}, & t \neq s\end{cases}
$$

Because $\mu_{i}$ is assumed to incorporate the effect of lifetime persistent individual specific characteristics such as ability, the variance of the permanent component $\sigma_{\mu}^{2}$ represents the persistent dispersion of earnings or the inequality in the permanent component of earnings. The transitory shocks are captured by the transitory variance $\sigma_{v}^{2}$ and are assumed to persist only one year.

This model facilitates the understanding of the inequality decomposition into its permanent and transitory components. The variance of earnings at a certain point in time, $\sigma_{y}^{2}$, as a measure of 
earnings dispersion, is composed both from a permanent and transitory dispersion $\left(\sigma_{\mu}^{2}+\sigma_{v}^{2}\right)$. The covariances, on the other hand, are determined solely by the permanent component $\left(\sigma_{\mu}^{2}\right)$. Therefore, the assessment of the relative importance of the two components in the overall earnings dispersion is straightforward: the ratio $\sigma_{\mu}^{2} / \sigma_{y}^{2}$ captures the relative importance of the permanent component, whereas the ratio $\sigma_{v}^{2} / \sigma_{y}^{2}$ captures the relative importance of the transitory component.

Notwithstanding its attractive features, the empirical evidence rejected the rigid restrictions imposed by model (1). One of the main drawbacks of model (1) is that it does not allow for changes in earnings inequality over time. (Lillard and Willis, 1978; Lillard and Weiss, 1979; MaCurdy, 1982; Abowd and Card, 1989) Other studies (Katz, 1994; Moffitt and Gottschalk, 1995; Sologon and O'Donoghue, 2009b, 2009a, 2009c) took the model complexity further by allowing the covariance structure of earnings to vary over time. To account for these time effects, these models considered also time specific loading factors or shifters on both components, which allow the parameters of the process to change with calendar time.

$Y_{i t}=\lambda_{1 t} \mu_{i t}+\lambda_{2 t} v_{i t}$

$\lambda_{k t}, k=1,2$ are time-varying factor loadings on the permanent and transitory components of earnings. The variance of $Y_{i t}$ implied by this model takes the form:

$\operatorname{Var}\left(Y_{i t}\right)=\lambda_{1 t}^{2} \sigma_{\mu}^{2}+\lambda_{2 t}^{2} \sigma_{v}^{2}$

An increase in either time loading factors generates an increase in the cross-sectional earnings inequality. The nature of the change in inequality depends on which of the loading factors changes. On the one hand, a persistent rise in $\lambda_{1 t}$ increases the permanent or long-run inequality (inequality in earnings measured over a long period of time, such as lifetime earnings). As $\lambda_{1 t}$ can be interpreted as time-varying return to skills or skill price, its increase suggests that the relative labour market advantage of high skill workers is enhanced. In this situation, the autocovariances grow in greater proportion that than the variance, causing the autocorrelation to increase. As a consequence, the increase in overall cross-sectional inequality is accompanied by a decrease in mobility. On the other hand, an increase in $\lambda_{2 t}$ without a change in $\lambda_{1 t}$ increases 
cross-sectional earnings inequality by increasing the transitory inequality, but without any impact on long-run or permanent inequality. In this situation the rise in the variances is not accompanied by a rise in the autocovariances, hence autocorrelations decrease and the increase in the overall inequality is accompanied by an increase in mobility. (Baker and Solon, 2003) As pointed out by Katz and Autor (1999), $\lambda_{1 t}$ maintains the rank of the individuals in the earnings distribution, but causes a persistent increase in the spread of the distribution and an increase in $\lambda_{2 t}$ changes the rank of the individual in the short-run. In other words an increase in the time parameters associated with the permanent component of earnings indicates a growing earnings inequality with no impact on the relative position of individuals in the distribution of permanent earnings, whereas an increase in the transitory time parameters indicates an increase in earnings mobility.

Although model (2) incorporates changes over time in the permanent and transitory components of earnings inequality, it disregards other important features of earnings dynamics. Firstly, it disregards the cohort effects. As argued by Katz and Autor (1999), the increased wage inequality may arise from increased dispersion of unobserved labour quality within recent entry cohorts, resulting from unequal school quality. Some studies brought evidence against the hypothesis that the return to education is the same for different cohorts. These changes could be attributed either to the cohort effects or to the larger impact of the labour market shocks on younger than on older cohorts of workers. In the same line of thought, Freeman (1975) put forward the "active labour market" hypothesis, which postulates that changes in the labour market conditions, such as changes in the supply and demand for skills, affect mainly new entrants in the labour market. To account for these cohort effects, these models considered also cohort specific loading factors or shifters on both components, which allow the parameters of the process to change with cohort. (Cappellari, 2003; Kalwij and Alessie, 2003; Sologon and O'Donoghue, 2009b, 2009a, 2009c)

$Y_{i t}=\gamma_{1 c} \lambda_{1 t} \mu_{i t}+\gamma_{2 c} \lambda_{2 t} v_{i t}$

where $\gamma_{j c}, j=1,2$ are cohort specific loading factors. ${ }^{1}$

Secondly, regarding the permanent component, some studies brought evidence in favour of the "random growth rate model" or the "profile heterogeneity model": (Hause, 1977; Lillard and

\footnotetext{
${ }^{1}$ This model represents the starting point of our model, which is developed in Section 5.
} 
Weiss, 1979; MaCurdy, 1982; Baker, 1997; Cappellari, 2003; Sologon and O'Donoghue, 2009b, 2009a, 2009c)

$\mu_{i t}=\mu_{i}+\varphi_{i} a g e_{i t}, \quad \mu_{i} \sim \operatorname{iid}\left(0, \sigma_{\mu}^{2}\right), \quad \varphi_{i} \sim \operatorname{iid}\left(0, \sigma_{\varphi}^{2}\right), \quad E\left(\mu_{i}, \varphi_{i}\right)=\sigma_{\mu \varphi}$

According to this model, which is consistent with labour market theories such as human capital, and matching models, each individual has a unique age-earning profile with an individual specific intercept (initial earnings $\mu_{i}$ ) and slope (earnings growth $\varphi_{i}$ ) that may be systematically related. The variances $\sigma_{\mu}^{2}$ and $\sigma_{\varphi}^{2}$ capture individual heterogeneity with respect to time-invariant characteristics and age-earnings profiles. The covariance between $\mu_{i}$ and $\varphi_{i}, \sigma_{\mu \varphi}$, represents a key element in the development of earnings differentials over the active life. A positive covariance between $\mu_{i}$ and $\varphi_{i}$ implies a rising inequality in the permanent component of earnings over the life cycle. This is consistent with the school-matching models where the more tenure one individual accumulates, the more is revealed about his ability. Thus highly educated people are expected to experience a faster growth in their earnings as the quality of the match is revealed to their employers. A negative covariance implies that the two sources of heterogeneity offset each other, which is consistent with the on-the-job training hypothesis (Mincer, 1974; Hause, 1980). A negative covariance is expected to generate mobility within the distribution of the permanent component of earnings. (Cappellari, 2003)

This structure is equivalent to a random coefficient model where the intercept and the coefficient on age in model (5) are randomly distributed across individuals. Therefore, because earnings evolve along an individual specific age profile, a good prediction of future earnings requires additional information besides the current earnings.

An alternative/additional specification for the permanent component of earnings is the "random walk model" or the "unit root model", which is used in the literature to accommodate earnings shocks that might have permanent effects: (MaCurdy, 1982; Abowd and Card, 1989; Moffitt and Gottschalk, 1995; Dickens, 2000; Wilke, 2005; Sologon and O'Donoghue, 2009a, 2009b, 2009c).

$u_{i a}=u_{i, a-1}+\pi_{i a}, \quad \pi_{i a} \sim i i d\left(0, \sigma_{\pi}^{2}\right), \quad E\left(u_{i, a-1}, \pi_{i a}\right)=0$

Equation (6) specifies the random walk process, where the current value depends on the one from the previous age and an innovation term $\pi_{i a}$, which represent white-noise non-mean- 
reverting shocks to permanent earnings. In other words, $\pi_{i a}$ accommodates any permanent reranking of individuals in the earnings distribution. As argued by Baker (1997), the intuition for this model is not obvious, but the high persistency of the unit root model might result from low rates of depreciation of human capital investments or labour market conditions through implicit contacts. In this model, current earnings are a sufficient statistic for future earnings. Most studies forced the innovation variance to be lifecycle invariant, except for Gustavsson (2004b) and Dickens (2000b).

Thirdly, regarding the transitory component of earnings, previous research has brought evidence that transitory earnings might be serially correlated. Therefore, a more general autocorrelation structure is called for, that relaxes the restriction on $v_{i t}{ }^{\prime} s$ from the canonical model. For the construction of such a structure, longitudinal studies on earnings dynamics turned to error processes from the literature on time series analysis. Based on MaCurdy (1982), the structure of the transitory component, $v_{i t}$, is assumed to follow an $\operatorname{ARMA}(\mathrm{p}, \mathrm{q})$ process:

$\sum_{j=0}^{p} \rho_{j} v_{i t-j}=\sum_{j=0}^{q} \theta_{j} \varepsilon_{i t-j}, \quad \varepsilon_{i t} \sim \operatorname{iid}\left(0, \sigma_{\varepsilon}^{2}\right), \quad v_{i 0} \sim\left(0, \sigma_{0, c}^{2}\right)$,

$\varepsilon_{i t}$ is assumed to be white noise with mean 0 and variance $\sigma_{\varepsilon}^{2}$. The variance $\sigma_{0, c}^{2}$ measures the volatility of shocks at the start of the sample period and $\sigma_{\varepsilon}^{2}$ the volatility of shocks in subsequent years. $\rho_{j}$ is the autoregressive parameter with $\rho_{0}=1$, which measures the persistence of shocks. $\theta_{j}$ is the moving average parameter with $\theta_{0}=1$, which accommodates sharp drops of the lag-j autocovariance compared with the other autocovariances. In this model, the autoregressive and moving average parameters are assumed to be constant over time. Additionally, some studies have found that the variance of the transitory shocks, $\sigma_{\varepsilon}^{2}$, varies over the lifecycle and incorporated a polynomial in age in the transitory component. (Backer and Solon, 2003; Gustavson, 2004b)

\subsection{Earnings Mobility}

Another aspect relevant for the evolution of earnings differentials is earnings mobility, defined by Katz and Autor (1999) as the rate at which individuals shift positions in the earnings distribution. Earnings mobility is closely related to the importance of the permanent and 
transitory components in earnings variation. A large contribution of the permanent component implies that individual earnings are highly correlated over time and individuals do not change their income position to a large extent experiencing low rates of earnings mobility. Therefore, the changes in earnings mobility are determined by the extent to which changes in cross-sectional inequality are driven by changes in the permanent or transitory variance.

Earnings mobility is a very complex phenomenon, and the ways of measuring it are diverse. We look at the degree of immobility, measured by the ratio between permanent and transitory inequality, following Kalwij and Alessie (2003). This measure offers also a summary of the evolution in the structure of inequality: a(n) decrease (increase) in the immobility ratio indicates an increase (decrease) in earnings mobility, equivalent with a(n) decrease (increase) in the relative share of permanent differentials in the overall inequality. This mobility index captures non-directional earnings movements and can be interpreted as the opportunity to improve one's position in the distribution of lifetime earnings.

An increase in cross-sectional inequality accompanied by a decrease in earnings mobility is expected to have negative implications for long-run or lifetime earnings differentials, as it shows that over time low wage men get worse off both in terms of their relative earnings position and in terms of their opportunity to escape low wage trap. Thus it is reasonable to expect that crosssectional earnings differentials will be enhanced in a lifetime perspective.

An increase in cross-sectional inequality accompanied by an increase in earnings mobility has uncertain implications for long-run or lifetime earnings differentials. Over time low wage men get worse off in terms of their relative earnings position, but better off in terms of the opportunity to escape low wage trap in a lifetime perspective. Thus earnings mobility could either enhance or decrease lifetime earnings differentials compared with the cross-sectional ones.

A decrease in cross-sectional inequality accompanied by an increase in earnings mobility is expected to have positive implications for lifetime earnings differentials, as over time low wage men better their relative earnings position and their opportunity to escape low wage trap in a lifetime perspective. Thus, lifetime earnings differentials are expected to be reduced compared with annual differentials.

A decrease in cross-sectional inequality accompanied by a decrease in earnings mobility has uncertain implications for lifetime earnings differentials, as over time low wage men get better 
off in terms of their relative earnings position, but worse off in terms of their opportunity to escape low wage trap in a lifetime perspective. Thus, lifetime earnings differentials could be either reduced or enhanced compared with annual differentials.

It becomes obvious that the question regarding the link between earnings mobility and earnings inequality does not have a straight forward answer and mobility is not always beneficial. It depends on the underlying factors: "changes in earnings mobility could either work to offset or to increase changes in cross-sectional dispersion", with very different implications for permanent earnings inequality. Dickens (1999) Nonetheless, no controversy surrounds the fact that mobility is beneficial when it helps low paid individuals to improve their income position in the long-term or lifetime income distribution.

\section{DATA}

The study is conducted using the administrative input data file on the professional career coming from the Social Security Institutions in Luxembourg. In Luxembourg each person with a gainful occupation must be affiliated to the social security system in the beginning of his professional career. The file contains detailed information on the professional career characteristics such as gross annual labour income, months, days or hours worked per year, occupational status, over the period 1950 and 2004. Important limitations of this file are that income from property is not recorded, wage income is known up to 4 times the minimum wage until 1991, and 5 thereafter, and white collars' hours or days worked per year before 1988 are missing.

The chosen measure of earnings is real log gross hourly wage. Hourly wage is computed by dividing the capped gross annual income ${ }^{2}$ by the total number of hours worked. Given the missing information for white collars' hours of work prior to 1988, the study is restricted to 17 years of panel: 1988-2004. The monetary values recorded in the data set are at the "nombre indice 100" (price index) and at the wage level of 1984. In order to get these values at the price and wage level of 2004 they are multiplied by $6.2463 * 1.337^{3}$. Overtime hours and multiple jobs are disregarded from the analysis, therefore the total number of hours worked is capped at 12 multiplied by 173 for white collars and 176 for the rest. The values of hourly wage below the

\footnotetext{
${ }^{2}$ Capped annual income was computed based on the capped monthly wage.

${ }^{3}$ n.i. 2004: 624.63 , wage level $+33,7 \%$
} 
minimum wage are set to the minimum wage ${ }^{4}$. Individuals with gross hourly wage above 100 Euro at 2004 level or who worked less than 1 hour per year are excluded from the analysis.

To avoid biases several filters are applied. Following the tradition of previous studies, the analysis focuses only on men to avoid the problem of selection bias characterising women's earnings. We choose individuals born between 1940 and 1975, with ages between 20 and 57, recorded working at least once during 1988 and 2004. Individuals that experienced at least five years of inactivity gaps because of disability or who retired before the age of 57 with a disability benefit are dropped from the analysis.

The resulting sample is an unbalanced panel, consisting of 270240 men. The individuals are allowed to exit and (re)enter the panel. The choice of using unbalanced panels for estimating the covariance structure of earnings is motivated by the need to mitigate the potential overestimation of earnings persistence that would arise from balanced panels where the estimation is based only on people that have positive earnings for the entire sample period.

For the empirical analysis, individuals are categorized into 36 birth cohorts formed from men born in a particular year, with ages between 20 and 57 . We selected only cohorts observed for at least 10 years over the period 1988-2004, which allows exploring the earnings covariance structure for individuals of the same age, followed through time. Table 1 offers an overview of the sample size, the years observed and age range for each cohort. The evolution of the variance and mean of log hourly earnings is captured in Figure 4, which reports an increase earnings inequality and economic growth over the sample period. The evolution of the variance and mean earnings records a jump between 1991 and 1992. This jump is partially artificial because of a change in legislation: before 1992 the threshold for reporting wage was 4 times the minimum wage and 5 times thereafter. The highest jump in the evolution of mean wage is observed between 1998 and $1999^{5}$, which is most probably due to the increase of $8 \%$ in the gross wage of civil servants as a measure to finance social contributions. Around the same time a small increase is observed also in the variance of earnings.

\footnotetext{
${ }^{4}$ The number of hours is recalculated accordingly.

51999 marks also the year when there was a change in the pension law for civil servants, and as a consequence some civil servants were included in the sample only starting with 1999. This effect is seems to affect the most the oldest cohorts.
} 
The Luxembourgish labour market went through structural changes which started at the end of the 1980's and intensified after 1995, resulting in a large increase in the active population after 1988. We present an overview of the sample following these structural changes. First, the number of active men more than doubled in 2004 compared with 1988, reaching a value of 160,315 in 2004. Second, the evolution of the composite of the sample ${ }^{6}$ by occupation status and sector (Figure 5 and Figure 6) resembles the one for the whole population illustrated in Figure 1 and Figure 2: there is a clear shift in the structure, with white collars and civil servants, and the tertiary sector recording a significant increase in their share over time. Thirdly, as illustrated in Figure 7, the evolution of the composite of the sample by age is affected slightly by the filters applied, but maintains similar characteristics as the whole population (Figure 3).

${ }^{6}$ Provided upon request from the author 


\section{ECONOMETRIC SPECIFICATION AND ESTIMATION METHOD OF COVARIANCE STRUCTURES}

The aim of this section is to fit a parsimonious model to the autocovariance structure of earnings for all cohorts. This model is use to explore the changes in the permanent and transitory components of earnings over the sample period and their impact on overall earnings inequality.

\subsection{Econometric Earnings Specification}

In order to differentiate lifecycle dynamics from secular changes in earnings inequality, the earnings differentials are analysed within the 36 cohorts defined in the previous section. The first step is to de-trend earnings for each cohort. The empirical specification of earnings follows the structure:

$Y_{i c t}=\overline{Y_{c t}}+r_{i c t}, \quad t=1, \ldots, T_{i}, i=1, \ldots, N_{c}$

where $Y_{i c t}$ is the natural logarithm of real hourly earnings of the $i$-th individual, from the $c$-th cohort in the $t$-th year, $\overline{Y_{c t}}$ is the year-cohort specific mean and $r_{i c t}$ is an error term which represents the individual-specific deviation from the year-cohort specific mean. The demeaned earnings $r_{i c t}$ are assumed to be independently distributed across individuals, but autocorrelated over time. Earnings differentials within each cohort can be characterised by modelling the covariance structure of individual earnings $\operatorname{Var} \operatorname{Cov}\left(Y_{i c t}\right)=E\left(r_{i c t}, r_{i c t-s}\right), s=0, \ldots, T_{c}-t_{0 c}{ }^{7}$

This study approaches the problem of choosing a longitudinal process for the demeaned earnings, $r_{i c t}$ following the methodology used by MaCurdy(1981) and MaCurdy (1982), meaning in a similar manner with time series. The inspection of the covariance structure of earnings, which is presented in the following section, suggests the following features of the data:

(i) the elements of the autocovariance structure decrease with the lag at a decreasing rate and

(ii) they converge gradually at a positive level ${ }^{8}$;

(iii) the lag-1 autocovariance drops to a larger extent compared with higher order autocovariances, which decline more gradually;

\footnotetext{
${ }^{7} T_{c}$ and $t_{0 c}$ represent the total number of years and the first year observed for each cohort. ${ }^{8}$ convergence with increasing lags
} 
(iv) the autocovariances and mean earnings vary over the sample period, so they cannot be assumed to be stationary over sample period;

(v) the autocovariances vary with age controlling for the period effect, hence they cannot be assumed to be stationary over the life cycle;

(vi) the variance covariance structure appears to be cohort specific.

Feature (i) suggests the presence of an $\mathrm{AR}(1)$ process, but the presence of feature (iii) calls for a more complex $\operatorname{ARMA}(1,1)$ or $\operatorname{ARMA}(1,2)$ process. Feature (ii) can be captured by the presence of the permanent component. Feature (vi) is captured by incorporating period specific parameters, meaning that the permanent individual component and the transitory component of earnings are allowed to vary with time. The life cycle non-stationarity of the autocovariance structure of earnings mentioned in feature (v) is captured by modelling the permanent individual component as random walk and/or random growth in age. Cohort heterogeneity is incorporate by parameters that allow the permanent and transitory components to vary between cohorts. Additionally, unlike most studies, we allow for age-specific innovation variance and age-related heteroskedasticity in the transitory shocks.

We started with a general model specification that encompasses all the relevant aspects of earnings dynamics considered above. We employed preliminary data analysis procedures to choose among competing specifications in order to avoid choosing a model which is broadly inconsistent with the data. After much experimentation, the following general specification of equation (4) is found to best fit the data.

$$
\begin{aligned}
& Y_{i c t}-\overline{Y_{c t}}=r_{i c t}=\gamma_{1 c} \lambda_{1 t} u_{i a t}+\gamma_{2 c} \lambda_{2 t} v_{i t} \\
& u_{i a t}=u_{i, 20} \sim i i d\left(0, \sigma_{u_{20}}^{2}\right) \quad \text { if } \quad a=20 \\
& u_{i a t}=u_{i, a-1, t-1}+\pi_{i a} \quad \text { if } \quad 21 \leq a \leq 40, \quad \pi_{i a} \sim \operatorname{iid}\left(0, \sigma_{\pi_{a}}^{2}\right), \quad E\left(u_{i, a-1, t-1}, \pi_{i a t}\right)=0 \\
& u_{i a t}=u_{i, 40} \sim i i d\left(0, \sigma_{u_{40}}^{2}\right) \quad \text { if } \quad a>40 \\
& v_{i t}=\rho v_{i t-1}+\varepsilon_{i t}+\theta \varepsilon_{i t-1}, \quad \varepsilon_{i t} \sim\left(0, \sigma_{\varepsilon_{t}}^{2}\right), \quad v_{i 0} \sim\left(0, \sigma_{0, c}^{2}\right), \quad c=1945, \ldots, 1975 \\
& \sigma_{\varepsilon_{t}}^{2}=\beta_{0}+\beta_{1}\left(\text { age }_{t}-20\right)+\beta_{2}\left(\text { age }_{t}-20\right)^{2}+\beta_{3}\left(\text { age }_{t}-20\right)^{3}+\beta_{3}\left(\text { age }_{t}-20\right)^{4}
\end{aligned}
$$


We refer to the model in equation (9)-(12) as our "base model". According to equation (9), earnings can be decomposed into a permanent component $\gamma_{1 c} \lambda_{1 t} u_{i a t}$ and a transitory component $\gamma_{2 c} \lambda_{2 t} \nu_{i t}$. The permanent component $u_{\text {iat }}$ (Equation (10)) specifies a random walk in age in earnings growth after age 20 up to age 40 , where $\pi_{i a} \sim \operatorname{iid}\left(0, \sigma_{\pi_{a}}^{2}\right)$ is the innovation at each age, and after that a random effects model with the distribution of the effects fixed at that implied by the random walk. Previous research forced the innovation variance $\sigma_{\pi_{a}}^{2}$ to be the same over the lifecycle. Our rich data allowed us to estimate age specific innovation variances. The model with age-specific innovation variances until the age of 40 was found to fit the data the best. This decision is backed up also by Figure 9. We also estimate the variance of an initial permanent shock (assumed to be at age 20, which is also the lowest age observed in our dataset), denoted $\sigma_{u_{20}}^{2}$. Thus the permanent earnings variance within a cohort rises with age up until age 40, after which it remains at its current level. Consistent with many matching and human capital models, whereby human capital or ability is revealed for the first 20 years of labour market experience after which the permanent differentials start shrinking, We expect larger permanent shocks at younger age. (Jovanovic, 1979)

Equation (11) specifies the transitory component of earnings which evolves as an ARMA(1,1) process, where the serial correlation $\rho$ parameter captures the decreasing rate of decay of the covariances with the lag, the moving-average parameter $\theta$ captures the sharp drop of the lag-1 autocovariance compared with the other autocovariances, and $\varepsilon_{i t}$ are white-noise mean-reverting transitory shocks. The variance $\sigma_{0, c}^{2}$ measures the volatility of shocks at the start of the sample period, $\sigma_{\varepsilon_{t}}^{2}$ the volatility of shocks in subsequent years and $\rho$ the persistence of shocks. Measurement error in this model is captured by this transitory component. Additionally, equation (12) allows the variance of $\varepsilon_{i t}$ to change over the lifecycle, as a polynomial of order 4 in age.

The non-stationary pattern of earnings is accommodated using time specific loading factors, both on the permanent and transitory component of earnings, $\lambda_{k t, k=1,2 ; t=0,16}$, normalized to 1 in the first 
wave for identification ${ }^{9}$. Cohort heterogeneity is accommodated by allowing both the permanent and the transitory component to vary with the cohort. $\gamma_{j c}, j=1,2$ are cohort loading factor, normalized to 1 for the cohort born in 1945 for identification.

\subsection{Specification of the Covariance Structure of Earnings}

When working with $\operatorname{ARMA}(\mathrm{p}, \mathrm{q})$ processes in the context of panel data, MaCurdy (1981), MaCurdy (1982) and Anderson and Hsiao (1982) underlined the need for a treatment of initial conditions $^{10}$. As illustrated in equations (14) and (15), the autoregressive process induces a recursive structure in the moments: the variance-covariance in year $t$ depends on the transitory variance-covariance in year $t$ - 1 . If one tracks the recursion back to the first sample year for each cohort, this raises the question of what is the transitory variance for each cohort in that year. In the earlier stage of the literature on earnings dynamics, it was common to restrict the initial transitory variance to be the same for all cohorts. In line with the most recent literature on earnings dynamics, our model acknowledges that earnings volatility varies across cohorts because they illustrate different stages of the lifecycle and they have experienced different period effects. Therefore such a strong assumption is untenable.

Following MaCurdy (1981), MaCurdy (1982), we treat the initial transitory variances of the 36 cohorts as 36 additional parameters to be estimated. The covariance structure for the first sample period takes the form:

$$
\begin{gathered}
\operatorname{Var}\left(Y_{i c 0}\right)=E\left(r_{i c 0} r_{i c 0}\right)=\sigma_{\mu_{20}}^{2}+\sum_{a=21}^{a_{0}} \sigma_{\pi_{a}}^{2}+\operatorname{Var}\left(v_{i 0}\right) \quad \text { if } t=0 \text { for } a_{0} \leq 40, \\
=E\left(r_{i c 0} r_{i c 0}\right)=\sigma_{\mu_{20}}^{2}+\sigma_{u_{40}}^{2}+\operatorname{Var}\left(v_{i 0}\right) \quad \text { if } t=0 \text { for } a_{0}>40,
\end{gathered}
$$

The covariance structure for subsequent years can be expressed as follows:

\footnotetext{
${ }^{9} 1994$ refers to $\mathrm{t}=0$

${ }^{10}$ See Macurdy(1982, page 92/93)
} 
$\operatorname{Var}\left(Y_{i c t}\right)=$

$=E\left(r_{i c t} r_{i c t}\right)=\gamma_{1 c}^{2} \lambda_{1 t}^{2}\left[\sigma_{\mu_{20}}^{2}+\sum_{a=21}^{a_{t}} \sigma_{\pi_{a}}^{2}\right]+\gamma_{2 c}^{2} \lambda_{2 t}^{2}\left[\rho^{2} \operatorname{Var}\left(v_{i t-1}\right)+\sigma_{\varepsilon_{t}}^{2}\left(1+2 \rho \theta+\theta^{2}\right)\right] \quad$ if $t>0$ for $a_{t} \leq 40$

$=E\left(r_{i c t} r_{i c t}\right)=\gamma_{1 c}^{2} \lambda_{1 t}^{2}\left[\sigma_{\mu_{20}}^{2}+\sigma_{u_{40}}^{2}\right]+\gamma_{2 c}^{2} \lambda_{2 t}^{2}\left[\rho^{2} \operatorname{Var}\left(v_{i t-1}\right)+\sigma_{\varepsilon_{t}}^{2}\left(1+2 \rho \theta+\theta^{2}\right)\right] \quad$ if $t>0$ for $a_{t}>40$,

where $\sigma_{u_{40}}^{2}=\sum_{a=21}^{40} \sigma_{\pi_{a}}^{2}$

$\operatorname{Cov}\left(Y_{i c t} Y_{\text {ict-s }}\right)=$

$=E\left(r_{i c t} r_{i c t-s}\right)=\gamma_{1 c}^{2} \lambda_{1 t}^{2}\left[\sigma_{\mu_{20}}^{2}+\sum_{a=21}^{a_{t-s}} \sigma_{\pi_{a}}^{2}\right]+\gamma_{2 c}^{2} \lambda_{2 t} \lambda_{2 t-s}\left[\rho \operatorname{Cov}\left(v_{i t-1}, v_{i t-s}\right)\right] \quad$ if $t>0 \& s>1$ for $a_{t-s} \leq 40$

$=E\left(r_{i c t} r_{i c t-s}\right)=\gamma_{1 c}^{2} \lambda_{1 t}^{2}\left[\sigma_{\mu_{20}}^{2}+\sigma_{\mu_{40}}^{2}\right]+\gamma_{2 c}^{2} \lambda_{2 t} \lambda_{2 t-s}\left[\rho \operatorname{Cov}\left(v_{i t-1}, v_{i t-s}\right)\right] \quad$ if $t>0 \& s>1$ for $a_{t-s}>40$

where $\sigma_{\mu_{40}}^{2}=\sum_{a=21}^{a_{t-5}} \sigma_{\pi_{a}}^{2}$

$\operatorname{Cov}\left(Y_{i c t} Y_{i c t-1}\right)=E\left(r_{i c t} r_{i c t-1}\right)=$

$\left.=\gamma_{1 c}^{2} \lambda_{1 t}^{2}\left[\sigma_{\mu_{20}}^{2}+\sum_{a=21}^{a_{t-1}} \sigma_{\pi_{a}}^{2}\right]+\gamma_{2 c}^{2} \lambda_{2 t} \lambda_{2 t-1}\left\{\rho \operatorname{Var}\left(v_{i t-1}\right)+\theta \sigma_{\varepsilon_{t-1}}^{2}\right)\right\} \quad$ if $t>0 \quad \& \quad s=1$ for $a_{t-1} \leq 40$

$\left.=\gamma_{1 c}^{2} \lambda_{1 t}^{2}\left[\sigma_{\mu_{20}}^{2}+\sigma_{\mu_{40}}^{2}\right]+\gamma_{2 c}^{2} \lambda_{2 t} \lambda_{2 t-1}\left\{\rho \operatorname{Var}\left(v_{i t-1}\right)+\theta \sigma_{\varepsilon_{t-1}}^{2}\right)\right\} \quad$ if $t>0 \quad \& \quad s=1$ for $a_{t-1}>40$

where $\sigma_{\mu_{40}}^{2}=\sum_{a=21}^{a_{t-1}} \sigma_{\pi_{a}}^{2}$

\subsection{Estimation of Covariance Structures}

Covariance structures are models that specify a structure for the covariance matrix of the regression error. They can be used to model structures for error dynamics and measurement error. The goal is to estimate the parameters of the covariance structure of earnings for all cohorts. This can be used to analyse the changes in the permanent and transitory components of earnings over the sample period.

The parameters of the models are fit to the covariance structure for each cohort using equally weighted minimum distance methods of estimation. The methodology used is the same as that utilized by Cappellari (2003), Baker and Solon (2003), Ramos (2003), Kalwij and Alessie 
(2003), Dickens (2000), Baker (1997), Abowd and Card (1989), Cervini and Ramos (2006), Sologon and O’Donoghue (2009a, 2009b, 2009c).

Following Sologon and O'Donoghue (2009a, 2009b, 2009c), for each cohort $\boldsymbol{c}$ and individual $\boldsymbol{i}$, define a vector which identifies the presence for each individual in the respective cohort and year:

$$
\mathbf{d}_{\mathrm{ic}}=\left(\begin{array}{c}
d_{i c t_{1}} \\
\vdots \\
d_{i c t_{c}}
\end{array}\right)
$$

where $d_{i c t}$ is an indicator variable that is equal to 1 if the individual from cohort $c$ is present in year $t$ of the panel and $t_{c}$ is the total length of the panel for each cohort. Similarly, the vector containing the cohort earnings residuals can be represented as follows:

$$
\mathbf{R}_{\mathbf{i c}}=\left(\begin{array}{c}
r_{i c_{1}} \\
\vdots \\
r_{i t_{c}}
\end{array}\right)
$$

where $r_{i c t}$ are the earnings residuals for individual $i$ belonging to cohort $c$ in year $t$ in mean deviation form for each cohort and year. The elements of the $\mathbf{R}_{\text {ic }}$ corresponding to missing years are set to 0 . The variance-covariance matrix of the earnings is computed separately for each cohort, $\mathbf{C}_{\mathbf{c}}$. The elements of the variance-covariance matrix for cohort $\mathrm{c}, \mathbf{C}_{\mathrm{c}}$, which is of dimension $\left(t_{c} \times t_{c}\right)$ are computed follows:

$m_{c}[k, l]=\frac{\sum_{i=1}^{n_{c}} r_{i c k} r_{i c l}}{\sum_{i=1}^{n_{c}} d_{i c k} d_{i c l}}(17)$

where $n_{c}$ is the total number of individuals in cohort $c, k, l=\left\{1, \ldots, t_{c}\right\}$. Conformably with $m_{c}$, $m_{c i}$ represent the distinct elements of the individual cross-product matrix $\mathbf{R}_{\mathrm{ic}} \mathbf{R}_{\mathrm{ic}}^{\prime}$. Then $m_{c}[k, l]=\frac{\sum_{i=1}^{n_{c}} m_{c i}[k, l]}{\sum_{i=1}^{n_{c}} d_{i c k} d_{i c l}}$. 
The matrix $C_{c}$ is symmetric with $\left(\frac{t_{c}\left(t_{c}+1\right)}{2} \times 1\right)$ distinct elements. Let $\operatorname{Vech}\left(\mathbf{C}_{\mathbf{c}}\right)$ be a column vector of dimension $\left(\frac{t_{c}\left(t_{c}+1\right)}{2} \times 1\right)$ which stacks all the elements of the variance covariance matrix $\mathbf{C}_{\mathbf{c}}$ for cohort $\mathbf{c}$. The aggregate vector of moments for all cohorts is denoted by: $\mathbf{m}=\left(\operatorname{Vech}\left(\mathbf{C}_{1}\right)^{\mathrm{T}}, \ldots, \operatorname{Vech}\left(\mathbf{C}_{4}\right)^{\mathrm{T}}\right)^{\mathrm{T}}$, which is a column vector of dimension $\left(\sum_{c=1}^{36} \frac{t_{c}\left(t_{c}+1\right)}{2} \times 1\right)=(N \times 1)$. In this paper, $\mathrm{N}=4668$.

To estimate the error components of the structural model illustrated by equations (9), (10) and (11), the elements of $\mathbf{m}$ are fit to a parameter vector $\boldsymbol{\theta}$, so that $\mathbf{m}=f(\boldsymbol{\theta}), f(\boldsymbol{\theta})$ takes the form of equations (14), (15), (16) and (13). Minimum distance estimation requires minimising the weighted sum of the squared distance between the actual covariances ( $\mathbf{m}$ ) and a function of the parameter vector $(f(\boldsymbol{\theta}))$ which encapsulates the covariance structure implied by the error component model. Therefore, minimum distance estimation involves the following quadratic form: $D(\boldsymbol{\theta})=[\mathbf{m}-f(\boldsymbol{\theta})] \mathbf{W}[\mathbf{m}-f(\boldsymbol{\theta})]^{\prime}$, where $\mathbf{W}$ is a positive definite weighting matrix. Minimum distance estimator chooses $\hat{\boldsymbol{\theta}}$ to minimise the distance function $D(\hat{\boldsymbol{\theta}})$.

Based on Chamberlain (1984), the asymptotic optimal choice of $\mathbf{W}$ is the inverse of a matrix that consistently estimates the covariance matrix of $\mathbf{m}$, which leads to the optimum minimum distance estimator (OMD). However, Clark (1996) and Altonji and Segal (1994) provided Monte Carlo evidence that OMD is biased in small samples because of the correlation between the measurement error in the second moments and forth moments. Instead, they proposed using the identity matrix as a weighting matrix. This approach, often called "equally weighted minimum distance estimation" (EWMD), involves using the standard nonlinear least squares to fit $f(\boldsymbol{\theta})$ to $\mathbf{m}$. The same procedure is followed in this paper.

For estimating the asymptotic standard errors of the parameter estimates, we apply the delta method. Following Chamberlain (1984), the asymptotic variance-covariance matrix of the estimated parameters is obtained from the following formula:

$$
\operatorname{Asy} \operatorname{Var}(\theta)=\left(G^{\prime} W G\right)^{-1} G^{\prime} W V W G\left(G^{\prime} W G\right)^{-1}
$$


where $\mathbf{G}$ is the Jacobian of the transformation $f(\boldsymbol{\theta})$ evaluated at $\boldsymbol{\theta}=\hat{\boldsymbol{\theta}}$. $\mathbf{G}$ has dimension $\left(t_{m} \times p\right)$ and rank $\mathrm{p}$, where $t_{m}$ is the sum across cohorts of $\left(\frac{t_{c}\left(t_{c}+1\right)}{2} \times 1\right)$ and $\mathrm{p}$ is the number of parameters. $\mathbf{W}$ is the identity matrix and $\mathbf{V}$ the matrix of fourth sample moments.

Chamberlain (1984) showed that under some fairly general regularity assumptions, the independence of $\mathbf{R}_{\mathbf{i c}}$ implies that the sample mean of $m_{c i}$ has an asymptotic normal distribution $m_{c} \sim N\left(m_{c}^{*}, \mathbf{V}_{c}^{*}\right)$, where $m_{c}^{*}$ is the expectation of $m_{c i}$, meaning the true covariance matrix of earnings, and $\mathbf{V}_{c}^{*}$ is the variance-covariance matrix, which can be estimated consistently by computing the sample moment matrix of the $\operatorname{Vech}\left(\mathbf{C}_{\mathbf{c}}\right)$ vector, $\mathbf{V}_{\mathbf{c}}$. The elements of the variance covariance $\mathbf{V}_{\mathbf{c}}$ can be written as follows:

$$
\begin{gathered}
\operatorname{Cov}\left(m_{c}[k, l], m_{c}[p, q]\right)=\frac{\sum_{i=1}^{n_{c}} d_{i c k} d_{i c l} d_{i c p} d_{i c q}}{\sum_{i=1}^{n_{c}} d_{i c k} d_{i c l} \sum_{i=1}^{n_{c}} d_{i c p} d_{i c q}}\left(m_{c}[k, l, p, q]-m_{c}[k, l] m_{c}[p, q]\right), \\
\text { where } m_{c}[k, l, p, q]=\frac{\sum_{i=1}^{n_{c}} r_{i c k} r_{i c l} r_{i c p} r_{i c q}}{\sum_{i=1}^{n_{c}} d_{i c k} d_{i c l} d_{i c p} d_{i c q}}
\end{gathered}
$$

The variance-covariance matrix of $\mathbf{m}$ was denoted by $\mathbf{V}$, where $\mathbf{V}$ is the block diagonal matrix which is constructed from all the $\mathbf{V}_{\mathbf{c}}$ matrices.

\subsection{Strategy for model specification}

The strategy for model specification follows Sologon and O'Donoghue (2009a, 2009b, 2009c). The chi-squared goodness of fit statistic is computed following Newey(1985):

$$
\chi=[\mathbf{m}-f(\hat{\boldsymbol{\theta}})] \mathbf{R}^{-1}[\mathbf{m}-f(\hat{\boldsymbol{\theta}})]^{\prime}
$$

where $\chi$ follows a chi-squared distribution with degrees of freedom equal to $\sum_{c=1}^{36} \frac{t_{c}\left(t_{c}+1\right)}{2}-p=N-p, \quad \mathbf{R}^{-1}=\left(\mathbf{W V W} \mathbf{W}^{\prime}\right)^{-1}$ and $\mathbf{W}=\mathbf{I}-\mathbf{G}\left(\mathbf{G}^{\prime} \mathbf{A} \mathbf{G}\right)^{-\mathbf{1}} \mathbf{G}^{\prime} \mathbf{A}$. The majority of the existing studies estimating the covariance structure of earnings used this general form of specification test to assess the goodness of fit of the model. However, in most cases, all models have been rejected. Baker and Solon (2003), Baker (1997), Leamer (1983) criticized these type 
of tests for several reasons. First, Baker and Solon (2003) and Leamer (1983) underlined that "diagnostic tests such as goodness-of-fit tests, without explicit alternative hypothesis, are useless, since if the sample size is large enough, any maintained hypothesis will be rejected. Such tests therefore degenerate into elaborate rituals for measuring the effective sample size." Second, as pointed by Baker and Solon (2003), an additional problem is that these specification tests have inflated size in small samples and the inflation is positively related with the number of overidentifying restrictions. For example, Baker (1997) revealed through a Monte Carlo study, that for a test with fewer than 150 overidentifying restrictions, the critical values are $40 \%-50 \%$ greater than the critical values based on the asymptotic theory. Therefore, we decided to report this statistic as a reference, but not to use it to assess the goodness of fit of our model. Instead we employed the SSR as a measure of fit.

To test between nested models, we could use Preposition 3' in Chamberlain (1984) or the LR test. Based on Preposition 3' in Chamberlain (1984), assuming that the general model has p parameters, to test between two nested models, one in which $k_{1}$ parameters are restricted to 0 ( $\left.\chi_{p-k_{1}}\right)$ and one in which $k_{2}{ }^{11}$ parameters are restricted to $0\left(\chi_{p-k_{2}}\right)$, Chamberlain (1984) showed that the incremental chi square statistic $\chi=\chi_{p-k_{1}}-\chi_{p-k_{2}}$ follows a chi-squared distribution with $k_{1}-k_{2}$ degrees of freedom. The LR test takes the following form: $L R=N \log \frac{S S E_{R}}{S S E_{U}}$. Under the null hypothesis, LR is follows a chi-square distribution with d.o.f equal to the number of restrictions $k_{1}-k_{2}$. To test between non-nested model, we use the BIC and the AIC criterion.

$$
A I C=\frac{S S E \cdot e^{2 k / N}}{N-k} \quad \text { or } \quad B I C=\frac{S S E \cdot N^{k / N}}{N-k}
$$

The smaller the value of BIC and AIC are the better the fit is. The difference between the two is that BIC incorporates a higher penalty for additional parameters than AIC and is recommended as the first choice.

${ }^{11} k_{1}=k_{2}$ 


\section{THE DYNAMIC AUTOCOVARIANCE STRUCTURE OF HOURLY EARNINGS}

To begin with, it is informative to have a description of the dynamic structure of individual log hourly earnings. The autocovariance structure of earnings is computed for each cohort, adding up to 4668 sample moments. The autocovariance structure by cohorts is displayed in Figure 8. Based on these trends we establish the main characteristics of the model aimed to fit the autocovariance structure of earnings for all cohorts.

In all countries, the autocovariances display different patterns across cohorts, supporting the hypothesis of cohort heterogeneity with respect to individual earnings dynamics. The general picture reveals that the variance of log hourly earnings increased for all cohorts between 1988 and 2004, but the rate of increase and the magnitude differs among cohorts. Similarly with Dickens' (2000b) results for UK, the younger the cohort the faster the rise in the autocovariances. The absolute magnitude of the autocovariance structure appears to have a hump-shaped pattern: the lowest values are recorded by the youngest cohorts, followed by the oldest cohorts and lastly by the middle-age cohorts.

For all cohorts, all lags autocovariances show a similar pattern as the variance. They are positive and evolve parallel with the variance. The distance between autocovariances at consecutive lags falls at a decreasing rate. The biggest fall is registered by the lag-1 autocovariance, after which the covariances appear to converge gradually at a positive level. Variances reflect both the permanent and the transitory components of earnings, whereas higher order covariances reflect the permanent component of earnings. Therefore, for all cohorts, the evolution of covariances, at all orders, suggests the presence of a permanent individual component of wages and a transitory component which is serially correlated. In addition, the magnitude of the longer lag covariances relative to the variances is higher the older the cohort.

One possible explanation for these trends is given by the theory on matching models, which sustains that the more experience an individual accumulates, the more information is revealed on the individual's ability. (Jovanovic, 1979) Therefore, permanent wage dispersion and implicitly overall inequality within a cohort is expected to rise as the cohort ages.

To look at the life cycle effects more clearly it is necessary to control for the period effect which is present in the within-cohort covariances. Thus we keep year constant and illustrate the life 
cycle autocovariances by age. Figure 9 presents the variance-covariance structure by age for the selected years.

All lags autocovariances of log real gross hourly earnings show a similar pattern as the variance. They are positive and evolve parallel with the variance, at different rates over the life cycle. They rise sharply over the life cycle until the late 30s and early 40s, after which they have a rather stable evolution up until late 50s. The diminishing rate of increase of all lags autocovariances observed from the age of 20 until the late $50 \mathrm{~s}$ is consistent with the presence of a permanent component of earnings that rises with age at a diminishing rate. (Dickens, 2000b)

Comparing across years, the life cycle profile of the auto-covariances of log gross hourly earnings appears to become steeper over time. The slope of the life cycle profile can be interpreted as the returns to the permanent complement of earnings. Therefore, steeper slopes in later years imply increasing returns to the permanent component of earnings over time.

To sum up, the description of the dynamic structure of individual earnings for men suggests five main features of the data, which were incorporated in our model, as mentioned previously:

- First, the covariance elements are not the same at all lags. They decrease with the lag at a decreasing rate and converge gradually at a positive level, suggesting the presence of a transitory element, which is serially correlated, and of a permanent individual component of earnings.

- Second, as the autocovariances and mean earnings vary over the sample period, they cannot be assumed to be stationary over sample period. The stationarity assumption was tested and rejected using the methodology introduced by MaCurdy (1982).

- Third, as autocovariances vary with age controlling for the period effect, they cannot be assumed to be stationary over the life cycle.

- Lastly, the variance-covariance structure appears to be cohort specific. 


\section{RESUlts OF COVARIANCE STRUCTURE ESTIMATION}

\subsection{Error component model estimation results}

To investigate these patterns more formally, we proceed to the GMM estimation of the earnings dynamics model described in Section 5. Table 2 shows the resulting estimates. The first three columns show the parameter estimates and the associated SE estimates for the base model outlined in equations (9)-(12). All the parameter estimates are highly significant. Recall that this model incorporates a persistent component, composed of terms capturing a random walk after age 20 until age 40, with age-specific innovation variances, and a random effects model after age 40 with the distribution of the effects fixed at that implied by the random walk, plus a transitory component following an $\operatorname{ARMA}(1,1)$ process with age-based heteroskedastic innovations. Furthermore, the persistent and transitory components are allowed to shift over time and over cohort by separate year-specific and cohort-specific factor loadings.

The significant estimates of $\sigma_{u_{20}}^{2}$ and $\sigma_{\pi_{a}}^{2}$, show that the variance of the initial permanent shock at age 20 and the random walk with age-specific innovation variances until age 40 play a significant role in the formation of the persistent component. As each cohort ages, the permanent component increases by the innovation variance, $\sigma_{\pi_{a}}^{2}$, which records the highest values at younger ages and declines with age. The pattern of the permanent variance, holding time and cohort shifters constant is captured in Figure 10. This pattern indicates that the persistent inequality increases over the lifecycle, but at a diminishing rate. Hence, within a cohort, the persistent variance increases with age until age 40, remaining at the same level thereafter. The same result is also found by Dickens (2000b) for the UK between 1975 and 1995.

Table 2 (base model) reports next the estimates of the year-specific loading factors on the persistent component. For identification, the parameter for 1988 is normalized to 1. The estimated factor loadings are significant and above one in all years, except 1990. Their pattern is captured in Figure 11. Except for the slight decrease in 1990, the factor loadings increase between 1988 and 2004, suggesting that the returns to the systematic earnings components, such as education, ability, increased over time in Luxembourg. Thus the permanent component is expected to play a relative large role in the increase in earnings inequality over this period. This 
is consistent with the trend estimated by Sologon and O'Donoghue (2009a, 2009b, 2009c) for Luxebourg between 1995 and 2001.

Next, Table 2 (base model) reports the cohort-specific factor loadings. For identification, the parameter for the cohort born in 1940 is normalized to 1. All parameters are significant and lower than 1. Their pattern is displayed in Figure 12: the permanent component plays a larger relative role in earnings differentials the older is the cohort. This is expected given that younger cohorts experience higher earnings volatility than older cohorts due to temporary contracts. The cohorts born between 1973 and 1975, appear to have a higher return to education than the cohorts born between 1967 and 1972. The overall trend is consistent with the trend estimated by Sologon and O'Donoghue (2009b, 2009a, 2009c) for Luxembourg between 1995 and 2001. Opposite trends are obtained by Gustavsson (2004a, 2004b) for Sweden.

Further on, Table 2 (base model) reports the estimated parameters for the transitory component, which reveal that the initial cohort-specific variances, the $\operatorname{ARMA}(1,1)$ process, the age-based heteroskedactic transitory shocks after age 20, the time and cohort-specific loading factors contribute significantly to earnings volatility in Luxembourg.

The pattern of the estimates of the cohort-specific initial variances, which capture the accumulation of the transitory process up to the start of the sample period for each cohort is illustrated in Figure 13: the older the cohort the higher the initial variance. The pattern evolves monotonically as a U-shape until the cohort born in 1948, and with spikes for the oldest cohort. The estimated initial variances for the cohorts born in 1968 through 1975 show how the accumulation of the transitory process changed for the 20 -year-old over the period. The variance estimate more than doubled from 1988 (cohort 1968) to 1995 (cohort 1975), suggesting that dispersion has been increasing over time. A similar trend in the initial variances is obtained, for example, by Baker and Solon (2003) for Canada between 1976 and 1992.

Next, Table 2 (base model) shows the estimates of the $\operatorname{ARMA}(1,1)$ process. The large autoregressive parameter, $\hat{\rho}=0.964$, suggests that shocks are persistent, and the negative sign of $\hat{\theta}=-0.206$ implies that the autocovariances decline sharply over the first period, confirming the trends observed in the description of the autocovariance structure of earnings. The estimates suggest that $75.8 \%$ of a transitory shock is still present after 1 year, and $0.9 \%$ is still present after 
17 years. our estimates for the $\operatorname{ARMA}(1,1)$ process are similar with Dickens's $(2000 \mathrm{~b})$ and Gustavsson's (2004a, 2004b) most comparable estimates for the UK and Sweden.

$\mathrm{Next}^{12}$, we turn to the parameters that allow for age-related heteroskedasticity in the transitory shocks. The sign of the parameter estimates is consistent with those obtained by Baker and Solon (2004) for Canada and Gustvason (2004a, 2004b) for Sweden. The estimates of the age quadratic function determine the pattern illustrated in Figure 14. There is an initial decline in the variances of the innovations in early twenties, followed by a slow increase until early forties, and an accelerated increase thereafter. This pattern points to the importance of accounting for the systematic influence of age on the variance of the transitory earnings innovations.

Finally, we report the estimates of the period and cohort-specific loading factors for the transitory component. For identification, the factor loadings for 1988 and for the cohort born in 1940 were normalized to unity. The pattern of the year-specific loading factors is captured in Figure 11, which illustrate a monotonic decrease over the period. Thus the relative share of the transitory component appears to decrease over the sample period. The divergence observed in the trends of the time factor loading of the two components (Figure 11), suggest that the structural labour market changes favoured a rise in the returns to skills over time and a decrease in earnings instability.

Figure 12 captures the pattern of the cohort-specific loading factors for the transitory earnings, which reveals that earnings volatility is higher for younger cohorts, confirming the pattern observed in the dynamic description of the autocovariance structure of earnings, where autocovariances were found to be lower for younger cohorts. This is expected, given the more frequent job changes and less stable earnings of younger workers. A similar trend was obtained by Sologon and O'Donoghue (2009a, 2009b, 2009c) for Luxembourg.

Our base model nests and extends most of the specification used in the US, Canadian, and European studies. The studies based on relatively small-scale panel surveys imposed often economically implausible restrictions. We tested whether some of these restrictions hold in our data. The Wald test and the p- values for testing these restrictions are reported in Table 3.

\footnotetext{
${ }^{12}$ Table 2 (base model)
} 
Some studies assumed away the heterogeneity in earnings growth rates and/or the existence of earnings shocks with permanent effects. Backer and Solon (2003) and Ramos (2003) were able to incorporate both in the permanent component. Our model, however incorporates only the random walk process, as a specification with both components leads to identification problems for two parameters of the random growth model.

We extended the specification of the permanent component to follow a random walk process with age-specific innovation variances until age 40, and a random effects model with the distribution of the effects fixed at that implied by the random walk thereafter. These features were incorporated only by Dickens (2000b) for the UK. Another study which did a similar attempt is Gustavsson (2004b), but he constrained the innovation variance to be the same for two adjacent ages between 28 and 53 .

If we assume away the random walk until age 40 in the permanent component, the Wald test on this restrictions clearly rejects the null $\left(\chi^{2}=10326.6302, \mathrm{df}=31\right)$. If we assume away the agespecific innovation variance until age 40, keeping all the other specifications of the base model, the Wald test on this restrictions rejects the null $\left(\chi^{2}=2463.3344, \mathrm{df}=21\right)$ with a p-value equal to 0.0001 .

Except Baker and Solon (2003) and Gustavsson (2004b), previous studies imposed the restriction of invariant variance of the transitory shocks, which was rejected by the Canadian and Swedish data. Our study proves once again that assuming away the presence of age-related heteroskedastic transitory shocks, meaning that $\beta_{1}=0, \beta_{2}=0, \beta_{3}=0, \beta_{4}=0$, is statistically indefensible: the p-value for the Wald test is 0.0001 , clearly rejecting the null hypothesis in the Luxembourgish data.

In order to see the implications of imposing some of these restrictions on the inequality decomposition, we estimated a restricted model, where the permanent component follows a standard random walk in age with the variance of the first period shock at age 20 fixed at 0 , and the transitory component follows an $\operatorname{ARMA}(1,1)$ process with cohort-specific initial variances, with time and cohort loading factors on both components. The estimation results are displayed in Table 2, columns 4-6. 


\subsection{Inequality Decomposition into Permanent and Transitory Inequality}

We now use the parameters estimates from the error component models to decompose earnings inequality into permanent and transitory inequality, assess their absolute and relative contribution to the evolution of overall inequality and estimate earnings mobility over the sample period. In interpreting the findings one has to keep in mind that there is a fundamental conceptual underidentification of time, life-cycle, and cohort effects due to the exact multicollinearity of time, age, and birth year. Thus two effects will always be confounded. In order to provide a more comprehensive picture, we perform first the inequality decomposition by cohort over time, second the decomposition of the cross-sectional age-inequality profile in four selected years, and third the inequality decomposition by selected age groups over time.

\subsubsection{Inequality decomposition by cohort over time}

We start with the decompositions by cohort over time, which reveals how the structure of inequality and earnings mobility evolved between 1988 and 2004 for people born in each birth cohort considered. This decomposition enables to see whether the labour market structural changes had a different impact depending on the birth year. This decomposition controls for the cohort effect, but confounds age and period effects.

\section{$\underline{\text { Absolute decomposition }}$}

Figure 15 illustrates the absolute decomposition of the variance, together with the actual and predicted variance of earnings by cohort for the base model. The predicted variance follows closely the evolution of the actual variance, confirming the fit of the base model.

In a longitudinal view, over the sample period, earnings differentials increased for all cohorts. Overall, the increase in cross-sectional inequality is the result of increasing permanent differentials, trend consistent across cohorts. This finding is consistent with the results obtained by Sologon and O'Donoghue (2009b, 2009a, 2009c) for Luxembourg between 1995 and 2001. More heterogeneity is observed in the evolution of the transitory variance, which increased for the oldest cohorts 1940-1945 and for the youngest cohorts 1964-1975, and decreased for the rest. Thus the cohorts 1940-1945 experienced an increase in their earnings instability between ages 43 (for the youngest) and 48 (for the oldest) until age 57. Similarly, earnings instability increased 
for cohorts 1964-1975 between early 20s until late 30s and 40s. For the middle cohorts, earnings instability decreased between age 25 and 57 .

The trends of the two components present some similarities across cohorts. For most cohorts permanent variance was lower than transitory variance in the beginning of the sample, and then surpassed it in 1993 for cohorts 1940-1963, in 1991 for cohorts 1964-1967, in 1992 for cohorts 1968-1970, in 1995 for cohort 1971-1973, in 1996 for cohort 1974, and in 1997 for cohort 1975. Thus the structural change appears to affect the cohorts born in 1940-1943 around their 50s, the cohorts born between 1944-1953 around their 40s, the cohorts 1954-1962 around their 30s, the cohorts 1963-1965 around their late 20s, and finally the cohorts 1966-1975 around their early 20 s.

Given that for most cohorts the changes occur around mid 1990's, suggest that the trends observed are not age effects, but the result of the changes in the structure of the labour market, which intensified beginning with early 1990's. This explanation is sustained by the evolution of the occupation structure for each cohort, which reveals a common trend: they all record an increase in the share of the white collars and civil servants, accompanied by a reduction in the share of blue collars. Similarly, the share of the tertiary sector increases for all cohorts over time. Moreover, these trends are more pronounced for younger compared with older cohorts. ${ }^{13}$

An explanation for the slightly delayed effect for the cohorts born 1971-1973, which record an intensification of their permanent differentials in 1995, meaning around age 22-23 could be the evolution in the education and in the occupation structure. Younger cohorts tend to spend longer time in education and thus highly educated men enter the labour market after the age of 22, exacerbating permanent differentials. This effect coupled with the evolution towards a service economy results in an increasing share of men entering the labour market as highly educated white collars and civil servants. Similarly, for the youngest two cohorts, the structural change kicks in two years after their entrance into the labour market, meaning at 22, when also highly educated men join the labour market, probably as white collars or civil servants. For example, looking at the cohort born in 1975, the share of people working in the financial sector doubled in

\footnotetext{
${ }^{13}$ The tables can be provided upon request from the author.
} 
1997, and quadrupled in 2004 compared with 1995. Similarly, the share of white collars almost doubled in 1997 and more than tripled in 2004 compared with $1995 .{ }^{14}$

Except for the youngest six cohorts, the persistent dispersion tends towards overall inequality during the last years of the panel and diverges from the trend of the transitory component, suggesting a general diffusion of earnings persistence for mid-career (older than 35) and older workers.

Following these trends, the contribution of the two components to the growth in overall inequality differs across periods and across cohorts. The inequality growth until 1992 was determined by an increase in both components for the cohorts 1940 through 1965, and by an increase in the permanent component counteracted by a decrease in the transitory component for the other cohorts. The increase between 1992 and 1997 was due to the increase in the permanent component counteracted by the decrease in the transitory component for most cohorts, except the cohorts born in 1963 through 1970. For the rest of the sample period, the growth in inequality was due to an increase in earnings persistency accompanied by a decrease in earnings instability for the cohorts born in 1940 through 1968, and by an increase in both components for the cohorts born in 1969 through 1975.

1997 appears to be an important period in the evolution of both components, marking the moment when the two components accentuated their fanning out pattern. First, permanent dispersion intensified its increase for all cohorts. This is what we expect given the increasing shares of white collars and civil servants, which for the youngest cohorts is equivalent also to an increasing share of highly educated people. Second, the intensification of the structural changes appears to have decreased transitory dispersion for older workers and increased it for the young. This might be linked with the increased ability of younger workers of adapting to the new economy as opposed to older workers, first due to their higher level of education and second due to their availability for flexible work contracts. The reduction in the transitory component for older workers might signal their reduced ability of adapting to the new economy.

\footnotetext{
${ }^{14}$ The tables can be provided upon request from the author.
} 


\section{$\underline{\text { Relative decomposition }}$}

In order to assess how the structure of inequality evolved over time for each cohort, we computed the relative share of the two components in the overall predicted variance of earnings. Figure 16 illustrates the share of the two components over time by cohort.

The evolution of the structure of inequality reveals common and diverging patterns across cohorts. First, all cohorts recorded an overall increase in the share of the permanent component. The evolution however was not monotonic. The cohorts born 1940 through 1959 have a similar pattern in the evolution of the share of the permanent inequality, which decreased until 1990 at a decreasing rate the younger the cohort, then increased at an increasing rate until 1993 - when they turned between 52 and 34 years old -, slowed down until 1997, accelerated its increase towards 1999 and slowed down towards 2004. For these cohorts, the share of the permanent component was between roughly $40 \%-60 \%$ in the beginning of the sample - when they were between 42 and 29 years old -, and 65\%-75\% in 2004 - when they were between 57 and 45 year old.

For the cohorts born in 1960 through 1968 the share of the permanent component increased at a higher rate the younger the cohort until 1993, when they turned between 33 and 25 years old. Until 1997, the share increased for the cohorts 1960-1963 at a decreasing rate the younger the cohort, remained constant for the cohort 1964 and decreased for the other cohorts at an increasing rate the younger the cohort. After 1997, the share increased at a decreasing rate the younger the cohort, ranging between $15 \%-42 \%$ in 1988 - when they were between 28 and 20 years old - to $65 \%-74 \%$ in 2004 - when they were between 44 and 36 years old -, with the highest rates belonging to the oldest cohorts.

The youngest seven cohorts appear to have a different profile compared with the older cohorts, which might be due to the stronger age effects coupled with the change in the educational behaviour of younger cohorts and with the maturation of the labour market structural changes. Unlike the older cohorts where the changes in the structure of inequality occurred around a specific year, e.g. 1993, the changes in the inequality structure for the youngest cohorts occur around specific ages. They start from lower values of the share of the permanent component compared with the older cohorts and record a sharp increase over the first 6 years of their career until they reach the age of 25, which is 1994 for the cohort born in 1969, 1995 for the cohort 
born in 1970 and 2000 for cohort born in 1974, surpassing the values recorded by the older cohorts. Further, they decrease sharply until they reach the age of 30 and increase slightly thereafter, with lower shares of the permanent component compared with the older cohorts.

\section{$\underline{\text { Earnings mobility }}$}

What are the implications for earnings mobility for each cohort over time? The answer is summarized in Figure 17, which plots the yearly evolution in earnings immobility ${ }^{15}$ by cohort. The evolution of earnings immobility resembles the evolution of the share of the persistent component. An increase in the profile implies a decrease in earnings mobility, meaning a decrease in the opportunity for low income men in a specific cohort to improve their position in the distribution of lifetime earnings.

The overall picture is that for all cohorts mobility decreased over the sample period, meaning that low wage men in all cohorts find it more difficult at the end of the sample period to improve their income position in the distribution of lifetime earnings compared with the beginning of the sample period.

The evolution was not monotonic. Similar with the structure of inequality, the immobility profiles differ considerably between the cohorts 1940-1968 and 1969-1975. The cohorts 1940 1968 recorded a sharp increase in earnings immobility until 1993, followed by a positive trend for the cohorts 1940-1963 and a negative trend for the cohorts 1964-1968 until 1997, and by an increase thereafter. Given that the changes in mobility occur at the same time for all cohorts represents a strong clue that the changes in the economy are the main triggers.

The youngest seven cohorts recorded an increase in earning immobility until age 25 , followed by a sharp decrease until age 30 and a slight increase thereafter. Unlike previous cohorts, the profiles of the youngest seven cohorts shift through time, with the main changes occurring around the same age, which indicate a strong age effect. Looking at the degree of immobility at age 25 , the shift indicates an increasing immobility over time. At the end of the sample earnings mobility appears to be higher for younger cohorts compared with older cohorts.

\subsubsection{Decomposition of the cross-sectional age-inequality profile}

\footnotetext{
${ }^{15}$ Immobility = permanent variance/transitory variance
} 
In order to see the evolution of the structure of inequality and earnings mobility over the lifecycle, we reveal the profiles of the two components and earnings immobility by age in 1988, 1993, 1998 and 2004. Here, the cohort and age effects are confounded.

\section{$\underline{\text { Absolute decomposition }}$}

Figure 18 illustrates the lifecycle profile of the permanent (left) and transitory (right) variance. In a cross-sectional view, in all years, permanent variance increases with age at a decreasing rate, which is consistent with the evidence of lifecycle earnings divergence provided earlier, showing that older cohorts experience a higher earnings persistency compared with younger cohorts. Similar results are found by Dickens (2000) and Ramos (1999, 2003) for UK, Cervini and Ramos (2006) for Spain, Capellari (2003) for Italy, and Sologon and O'Donoghue (2009b, 2009a, 2009c) for 14 EU countries.

The profile of the permanent component, however, changed over time. For people older than mid 30 s, the profile is higher the later the year, suggesting that the labour market structural changes and the increase in the educational attainment over time enhanced permanent differentials for these age groups. For men in their early 20s, permanent variance decreased slightly between 1988 and 1993. For men in their late 20s, permanent variance increased until 1993, and decreased until 1998 to a higher level than in 1988. For men in their early 30s, permanent variance increased until 1998 and decreased until 2004.

The transitory variance follows a similar inverted-U pattern over the lifecycle, but less steep than the permanent variance. The profile changed over time. In 1988, the transitory variance increased sharply until late 20s, and slightly until late 40s. In 1993 the profile increased sharply until mid 30s, then slowed down until mid 40s, and decreased slightly thereafter. In 1998 the profile increased sharply until mid 30s, and slightly thereafter. In 2004, the profile differentiates itself with a steep increase until early 30s, followed by a decrease around mid 30s and a slight increase thereafter.

For men in their early 20s the transitory variance increased between 1988 and 1993. For men in their mid 20s the transitory variance decreased between 1988 and 1998. For people in their late 20 s the profiles look similar. For men in their early 30s, the transitory variance increased between 1988 and 1993, decreased in 1998 and increased in 2004 to similar values as in 1993. For men older than mid 30s, the transitory variance increased until the 1990s, and decreased in 
2004 to values lower than in 1988. Therefore in 2004 compared with 1988 we observe an increased transitory variance for men in their early 30 s and a decreased transitory variance for older ages. Thus the maturation of the labour market brought a decrease in earnings instability.

Overall, we conclude that, in Luxembourg, earnings variance increases over the lifecycle due to an increase in both components. The permanent component records a sharper increase than the transitory component, and its increase is enhanced over time. Thus the labour market structural changes and the evolution of the education system over time enhanced the increase in the persistent component over the lifecycle.

\section{$\underline{\text { Relative decomposition }}$}

Further, Figure 19 illustrates the lifecycle evolution of the share of the permanent components in the overall variance in 1988, 1993, 1998 and 2004. The lifecycle profile of the structure of inequality reveals an increase in the share of the permanent component with age, in all years except 1998.

Over time, following the labour market structural changes, the lifecycle profile changed. In 1988 inequality became predominantly permanent (the share of the permanent component is higher than 50\%) after mid 40s, in 1993 after age 23, whereas in later years it was predominantly persistent for the entire age profile.

In 1988, the share of the persistent component increased sharply until mid 20s, stabilised until early 30s and intensified its increase thereafter, suggesting a higher persistency in earnings inequality the older the cohort. In 1993, the profile changed: it increased sharply until mid 20s, decreased slightly towards mid 30s, stabilised until mid 40s and increased thereafter to values lower than for mid 20s. Thus young cohorts appear to have a higher persistency than older cohorts and middle cohorts. The explanation might be the difference in the educational attainment between cohorts and the higher return to skills in the new economy. A similar trend is observed in 1998. Therefore, years 1993-1998 reflect the transition period between an industrial to a service economy. In 2004 the profile looks quite different: the share decreased for early 30s, increased sharply until early 40s and decreased slightly thereafter. Thus in 2004, the middle and oldest cohort have the highest persistency. 
Looking across age groups over time, for men in their early-mid 20s, the share of the permanent component increased over time. For those in their late 20s the share increased between 1988 and 1993, and decreased in 1998 to values above the ones in 1988. For men in their early 30s, the share increased until 1998 and decreased in 2004. For those older than 35, the share of the permanent component increased over time.

\section{Earnings mobility}

What are the implications for earnings mobility? The lifecycle immobility profiles for years 1988, 1993, 1998 and 2004 are illustrated in Figure 20. Overall, earnings immobility increases over the lifecycle in all years, except 1998. The trend in immobility follows closely the trend in the share of the permanent component. Thus, in 1988, earnings immobility was higher the older the age. In 1993 and 1998 immobility was the highest at younger ages, followed by mid career and older age. In 2004 immobility appears be the highest mid career, followed men in their 50s and their 30s.

For men in their early-mid 20s, immobility increased over time. For those in their late 20, earnings immobility increased between 1988 and 1993, and decreased in 1998 to values above the ones in 1988. For men in their early 30s, earnings immobility increased until 1998 and decreased in 2004. For those older than 35, immobility increased over time.

\subsubsection{Inequality decomposition by age-groups over time}

Finally, we perform the decomposition of inequality controlling for the age effect. This shows how the structure of inequality and earnings immobility evolved for people in a certain age group between 1988 and 2004 under the impact of the labour market structural changes. we follow Baker and Solon (2003) and perform the decomposition for 40 years old males, which is approximately the middle of the active career. The cohort and period effects are confounded, and the trend reveals the story for 40-year old men.

The absolute and relative inequality decomposition for men aged 40 is illustrated in Figure 21, which contains also the actual and predicted variances for the 40-year old men, reconfirming the high fit of the base model. In moving from year to year, all parameters change according to the specific period and birth cohort. 
The first thing to note is the increase in total variance, which duplicates the pattern seen in Figure 4. Consistent with the trends observed by cohort, the increase in the overall inequality was determined by an increase in permanent inequality. Split by sub-periods, the increase in the overall inequality between 1988 and 1992 was determined by an increase in both components, and by an increase in the permanent variance counteracted by a decrease in the transitory variance thereafter. Transitory inequality displays more variation compared with permanent inequality, evolving opposite to it: three spikes are observed in 1990, 1992 and 1994, followed by a monotonic decrease thereafter.

In 1988, the persistent component accounted for $46.5 \%$ of the inequality in hourly earnings. Its share decreased until 1990, increased until 1993 surpassing the transitory variance, decreased in 1994 to roughly $50 \%$, and increased thereafter reaching a value of over $70 \%$ in 2004 . Thus, after 1993, the permanent inequality had a dominant share in the overall inequality of men aged 40.

We also performed the decomposition for ages 30 and $50 .{ }^{16}$ The general trends are maintained, however some differences are noted. For age 50, the evolution of the two components was similar with age 40 , except that for age 50 the share of the permanent component in the overall inequality was higher than for the transitory inequality for most of the period. The share of the permanent component increased from below 50\% in 1990 to almost $70 \%$ in 2004.

For age 30, the trends display more noise compared with age 40 and 50: except for 1988-1992 and 2002, the persistent components dominated overall inequality. The share of the permanent component increased from around 40\% in 1988 to over 56\% 2004. The maximum persistency for the 30-year old was reached in 1996-1997, when the share of persistent inequality was of $60 \%$. Overall, the incidence of the transitory component is higher for men aged 30 than for those aged 40 and 50.

Following the labour market structural changes, the ranking between these age groups in terms of earnings persistency changed, sign that the impact of these changes differed by age groups. In the beginning of the sample period the highest persistency was observed for men aged 50, followed by those aged 40 and 30. In the middle of the sample period, the persistency became higher for men aged 30, followed by those aged 50 and 40. In 2004, earnings persistency was higher for age 40 , followed by age 50 and age 30 .

${ }^{16}$ Available on request 
What are the implications for earnings mobility for these age groups over time? The answer is summarized in Figure 22, which plots the pattern in earnings immobility ${ }^{17}$ for these age groups. Recall, an increase in the profile implies a decrease in earnings mobility, meaning a decrease in the opportunity for low income men to improve their position in the distribution of lifetime earnings.

Overall, the immobility ratio increased over the sample period, signalling decreasing earnings mobility for all age groups over the sample period. The immobility profiles over time, however, appear to differ by age groups, sign that the labour market structural changes influenced younger workers differently from older workers.

Men aged 40 and 50 exhibit similar profiles, with men aged 40 being more immobile than men aged 50 after $1996^{18}$. A turning point is observed in 1997, when both profiles intensified their increase until 2003, followed by a drop in immobility in 2004.

A noisier trend is observed for men aged 30, for whom immobility follows a hump-shaped pattern: men aged 30 appear to be more mobile than men aged 40 and 50 over the period 19881991 and after 1997. 1997 appears to be a turning point also for the immobility profile of men aged 30, which record a sharp drop in immobility until 2002, followed by a sharp increase thereafter. Thus the factors that determined a decrease in mobility for people aged 40 and 50 after 1997, determined an increase in mobility for people aged 30.

For comparison and to complete the picture of the impact of the labour market structural changes on earnings mobility for all age groups, we added the immobility profiles for ages 5 years apart, ranging from 20 to 55, displayed in Figure 23. The profile for age 20 records a slightly increasing trend over the sample period, being consistently lower than all other profiles. This suggests that the youngest group is the most mobile and the increase in immobility was much smaller compared with the other age groups. The profiles for ages 21 and 22, not shown in Figure $23^{19}$, evolve parallel with age 20 , showing a lower mobility the older the age.

The profile for age 25 is quite surprising. Starting from slightly higher values than age 30 in 1988, it records the largest increase until 1993, then a slight decrease until 1997 followed by a

\footnotetext{
${ }^{17}$ Immobility = permanent variance/transitory variance

${ }^{18}$ Except 2001

${ }^{19}$ Provided upon request from the author.
} 
sharp increase until 2000, surpassing the immobility ratios of all other profiles over the period 1991-2000. Thus the labour market structural changes increased earnings immobility for men aged 25 to a much larger extent compared with other age groups.

The profiles for ages 23-24, not shown in Figure $23^{20}$, evolve similar with age 25, but shifted backwards with 2 and 1 year. Thus immobility increased until 1996 for age 24, and 1995 for age 23 , at a lower rate compared with age 25 , and intensified their increase thereafter. Overall, for age range 20-25, earnings mobility is higher the younger the age.

The profiles for ages 26-29, not shown in Figure $23^{21}$, illustrate transition immobility profiles between age 25 and 30: they record a similar trend slightly lower the older the age until 1993, followed by a decrease, steeper and lasting one year longer the older the age, and finally a sharp increase parallel with the trend observed for age 25. Basically the profiles for ages 26-29 look like the profile for age 25, lower the older the age, with a decrease after 1997 longer with one year the further we move from age 25 , followed by a similar parallel increase thereafter.

The profiles for ages 31-39 represent a transition from the profile for age 30 to the profile for age 40: they evolve similar to age 30 recording lower values than the profile for age 30 until 1997, and surpassing it thereafter, at an increasing rate the younger the cohort. Similar with the profile for age 30, they start decreasing towards the end of the sample one year later for each age group, at a decreasing rate the older the age. Thus from age 30, the trends for each age group converges towards the profile for age 40 .

The profiles for ages 41-49 behave similar to the profile for age 40 . The profiles for ages 51-57 behave similar to the profile for age 50. Overall, the immobility around 40s is slightly higher than for 50s.

Thus these trends confirm the hump-shaped immobility profile observed in Figure 20.

In order to see whether the estimated changes over the sample period are likely to be due to real changes in the functioning of the labour market rather than to short term fluctuations in the business cycle, we follow Baker and Solon (2003) and apply least squares to estimate time-series regressions of the persistent and transitory components and earnings immobility on a linear trend

\footnotetext{
${ }^{20}$ Provided upon request.

${ }^{21}$ Provided upon request.
} 
and a variable that captures the business cycle - the growth rate in real GDP ${ }^{22}$. The results are reported in Table 3.

The point estimates indicate a strongly significant positive trend for the permanent component and earnings immobility, and a less strong significant negative trend for the transitory component. Thus permanent variance contributes positively to the upward trend in earnings inequality, whereas the transitory variance counteracts with the increase in the permanent component. The insignificant coefficient estimates of the GDP growth rate for the permanent component and the immobility index indicate that the permanent variance and earnings mobility are insensitive to the business cycle. Hence, the estimated changes in the persistent components and earnings immobility between 1988 and 2004 are due to changes in the functioning of the labour market. The estimated coefficient of the GDP growth rate for the transitory component indicates a significant cyclical sensitivity in the transitory variance.

To conclude, the changes that occurred in the labour market in this period intensified permanent differentials and decreased transitory differentials among men, thus decreasing their earnings mobility in a lifetime perspective.

As a last step we look at the implications of estimating the restricted model displayed in Table 2. This model assumes away age-specific innovation variances and age-related heteroskedasticity in the transitory shocks. The decomposition implied by the restricted model for men aged 40 is revealed in Figure 24.

Here are some major differences between Figure 21 and Figure 24. Unlike Figure 21, the restricted model predicts an absolute increase in both components over the sample period, with the permanent component increasing more than the transitory component. Moreover, except the beginning and the end of the sample period, the share of the transitory component is higher than the share of the permanent, with an average of over $50 \%$. The structure of inequality, however, looks similar in 2004 compared with 1988.

This information is formalized in the time-series regressions reported in Table 4. First, the estimates in the restricted model explain a lower share of the variation in the dependent variables and show that only the permanent variance plays a significant positive role in the trend increases

${ }^{22}$ The real GDP is expressed in constant prices 2004. Source: STATEC, IGSS 
in inequality. For the transitory component and earnings immobility the model predicts a positive trend, but insignificant. Moreover, none appears to be sensitive to the cyclical variations. For immobility, none of the explanatory variables are significantly different from zero.

Therefore, while the estimates from the more general model indicates that the persistent component determines the increase in overall inequality overcoming the negative effect of the transitory component, this simpler model imposing clearly false restrictions attributes the growth in inequality to both components, albeit insignificant for the transitory component.

\section{CONCLUDING REMARKS}

Starting with the late 1980s and intensifying after early 1990s, Luxembourg evolved from an industrial economy to an economy dominated by the tertiary sector, which relies heavily on the cross-border workforce. This paper explored the implications of these labour market structural changes for the structure of earnings inequality and earnings mobility.

Using 17 years of longitudinal earnings information drawn from the administrative data on the professional career, we decomposed Luxembourg's growth in earnings inequality into persistent and transitory components and explored the extent to which changes in cross-sectional earnings inequality in between 1988 and 2004 reflect changes in the transitory or permanent components of earnings.

Our results indicate that Luxembourg's increase in earnings inequality has steamed from an increase in the permanent component of earnings variation, whereas the transitory variance recorded a decrease. Moreover, earnings immobility increased over the sample period. Thus, Luxembourg's growth in earnings inequality reflects increasing long-run (permanent) differentials between individuals accompanied by decreasing earnings mobility, meaning decreasing opportunity for low wage individuals of improving their income position in a lifetime perspective.

While our focus has been to extend the research on earnings dynamics at the European level and to understand the driving factors behind the increase in earnings inequality in Luxembourg in the context of the labour market structural changes that occurred starting with the late 1980s, we also tried to bring a methodological advancement in modelling earnings dynamics. Thanks to the large size of our panel, we were able to estimate a more general model that incorporates most of 
the features identified by the previous research on earnings mobility from the US, Canada and Europe.

First, unlike previous studies, we were able to account for cohort and age effects in a more precise way by considering cohorts formed of individuals born in one year, not several years pulled together. This is a quite unique feature in the literature given the huge data requirements. To our knowledge, only one study had the luxury of capturing the true cohort and age effect, Dickens (2000b) for the UK. Moreover, the richness of our data allowed us to incorporate cohort loading factors both on the permanent and transitory component, a feature which is not so common. Most studies used the cohort shifters only on one component.

Second, for modelling the permanent component, we extended the random walk specification to incorporate age-specific innovation variances after age 20 until age 40, and a random effects model after age 40 with the distribution of the effects fixed at that implied by the random walk, a specification which was used previously only by Dickens (2000b). This model is consistent with the expectations steaming from many matching and human capital models, whereby human capital is accumulated for the first 20 year of labour market experiences, after which betweenindividual differences stop growing. we attempted to incorporate also the random growth specification, as persistent differences between individuals with respect to their human capital accumulation do exist. The specifications, however, leaded to identification problems in our data. Third, for modelling the transitory component, besides allowing for cohort specific initials transitory variances to accommodate cohort heterogeneity with respect to the accumulation of the transitory process until the start of the panel, we incorporated also age-related heteroskedastic transitory innovations to accommodate the lifecycle variation in the volatility of the transitory earnings innovations.

All these specifications, besides being economically plausible were found to be also statistically defensible. Specifying models that assume away these features when they are present in the data falsely attribute the non-stationarity that would be captured by these elements to the other sources of non-stationarity that remain in their models. Baker and Solon (2003) This statement is supported by the practical example carried out by estimating a restricted model, which imposes some restrictions that were rejected by our data. we find that imposing the restriction of no agespecific innovation variances in the random walk and no age-related heteroskedasticity in the 
transitory innovations exacerbates the importance of the transitory variance in explaining the trend in the overall inequality. The sensitivity of the predicted components to the different restrictions shows that when carrying out such a study one has to pay an extensive attention to the information provided by the autocovariance structure of earnings and to whether certain restrictions fit a specific data or not.

Whereas this exercise has identified the evolution of the two components over the sample period in Luxembourg, it has not identified the factors that might have triggered this evolution. This topic is extremely relevant and should be focused by future research. A good starting point is the approach taken by Sologon and O'donoghue (2009f), which tried to explain these trends in a comparative study at the EU level.

Another possible extension is to test statistically the impact of the labour market structural changes on the structure of earnings inequality and earnings mobility, by including also contextual variables, such as occupation shifters.

Another point for future research is to explore other measures of earnings mobility, as this topic is under researched at the EU level and in Luxembourg. Sologon and O'Donogue (2009e, 2009d) explored earnings mobility at the EU level and included also Luxembourg in their study. One point of interest would be to see how their results based on panel survey data compares with the results using administrative data. 


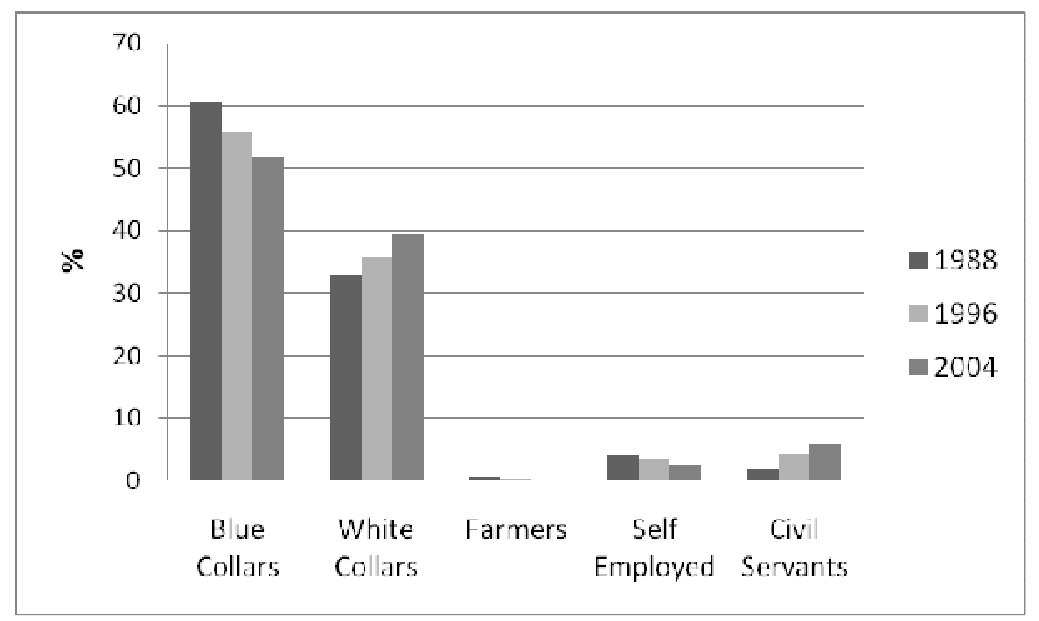

Figure 1. The evolution of the labour market structure by occupation status in Luxembourg in 1988, 1996 and 2004.

Note: Own calculations based on IGSS data. Vertical axis - share of workers by occupation status

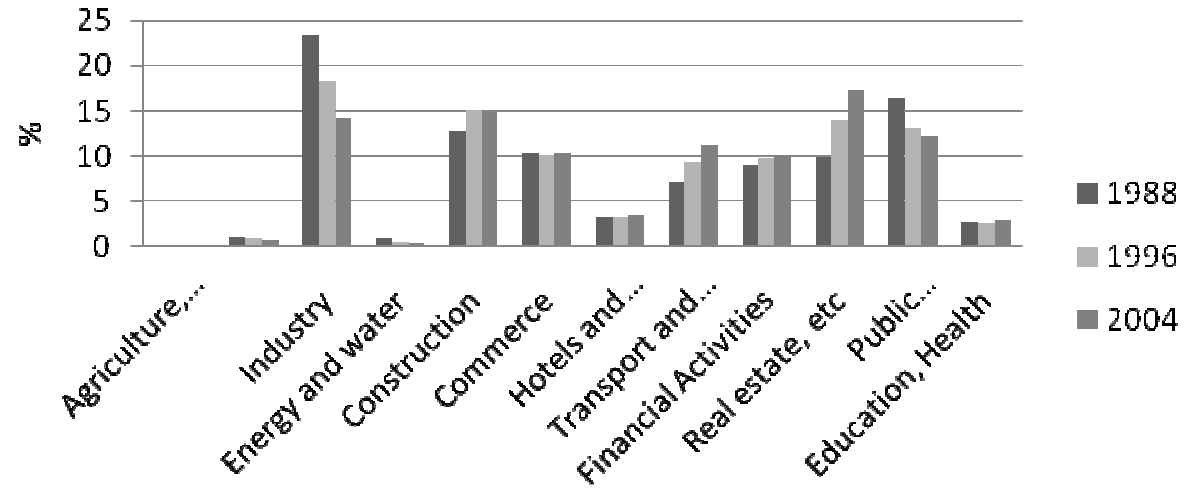

Figure 2. The evolution of the labour market structure by sector of activity status in Luxembourg in 1988, 1996 and 2004

Note: Own calculations based on IGSS data. Vertical axis - share of workers by sector of activity 


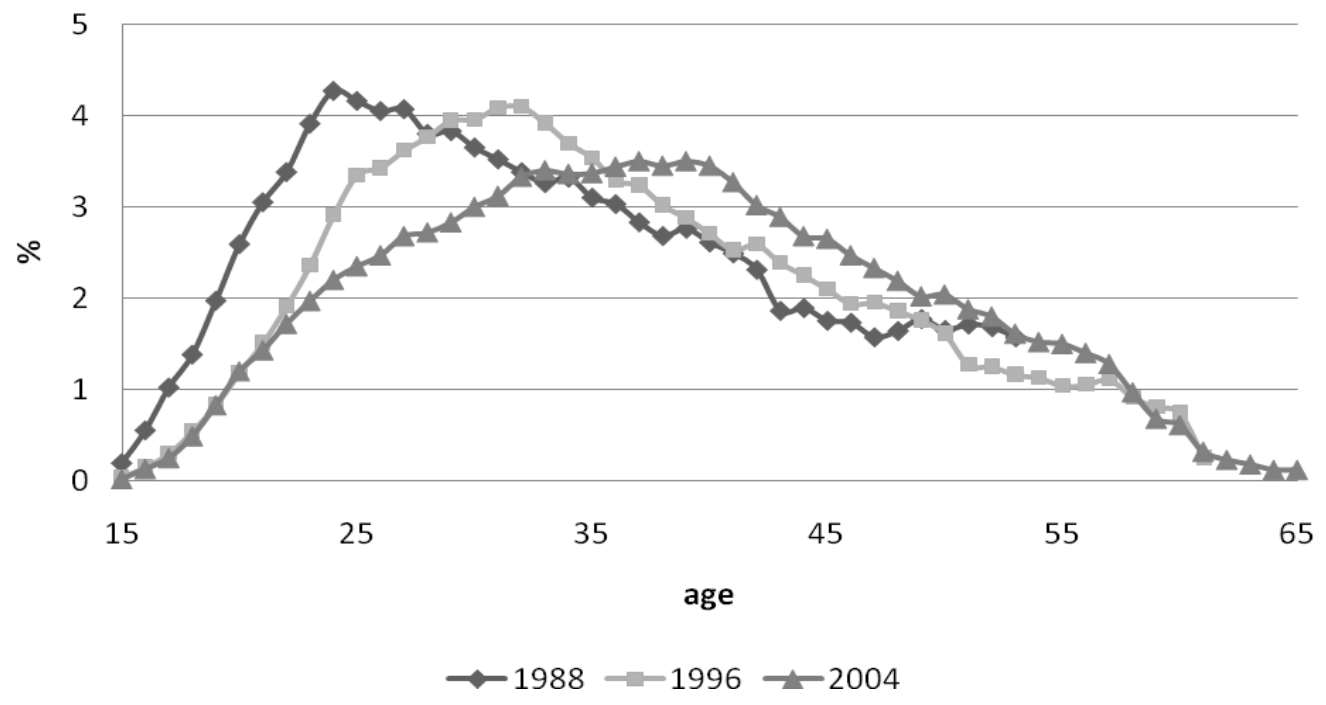

Note: Vertical axis - share of workers by age groups

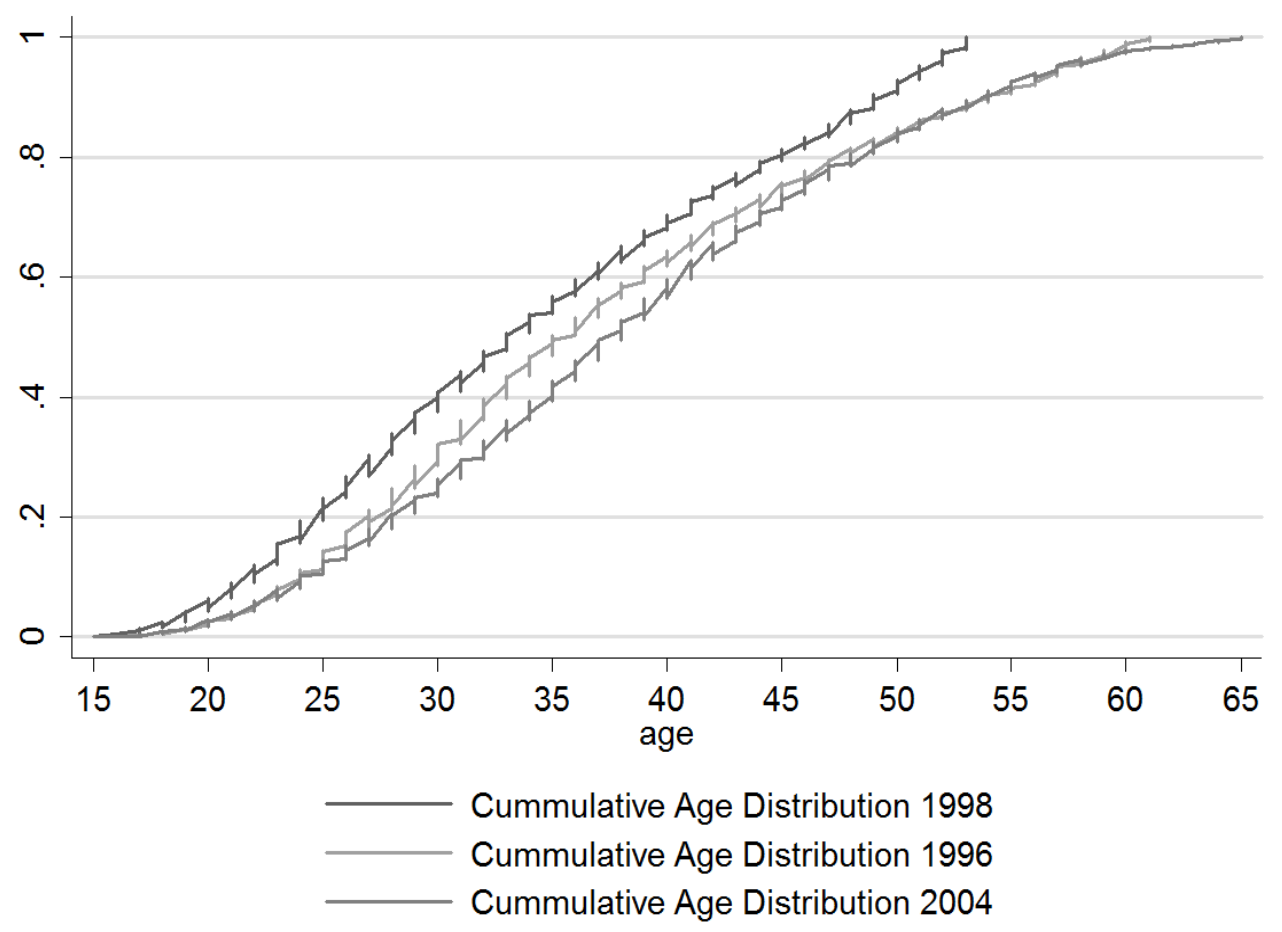

Figure 3. The evolution of the age structure of the active population in Luxembourg

Note: Own calculations based on IGSS data. Vertical axis - cumulative share of workers by age groups 


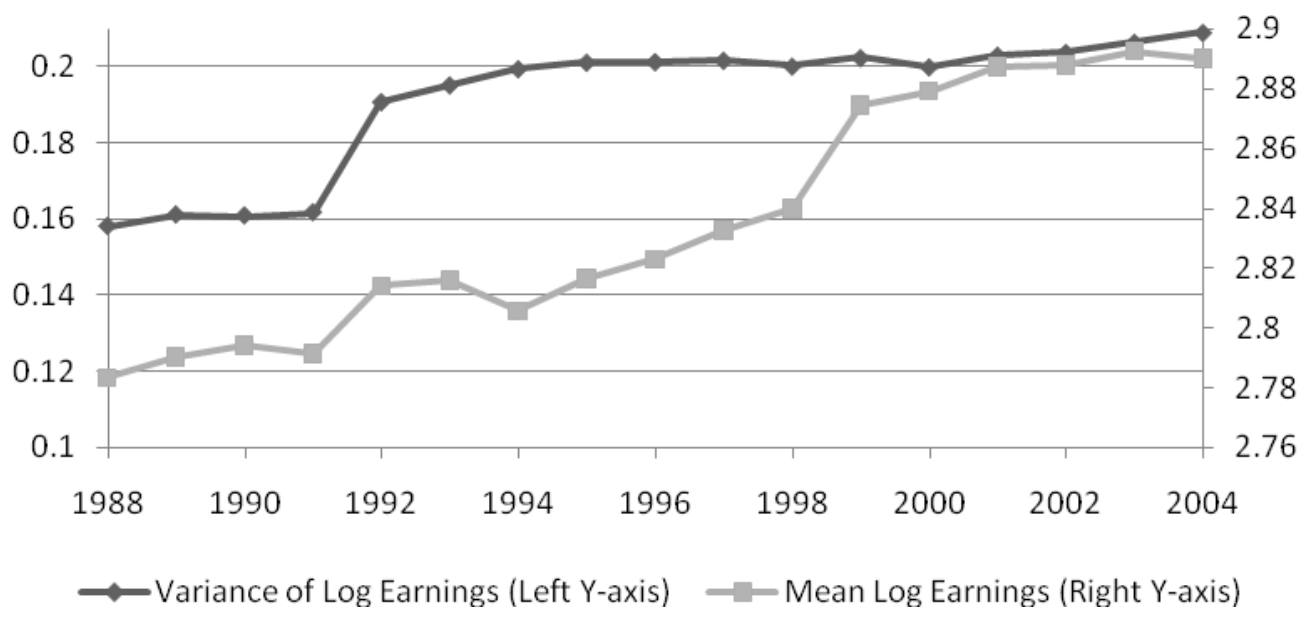

Figure 4. The variance and mean of log hourly earnings, 1988-2004

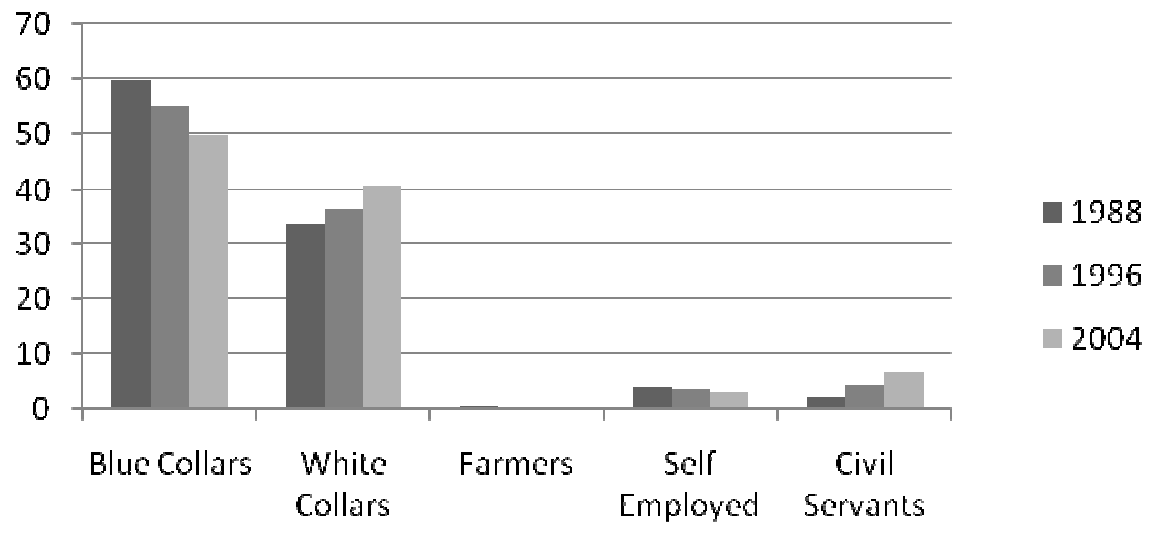

Figure 5. The evolution of the labour market structure by occupational status in the sample in 1988, 1996 and 2004.

Note: Vertical axis - share of workers by occupational status 


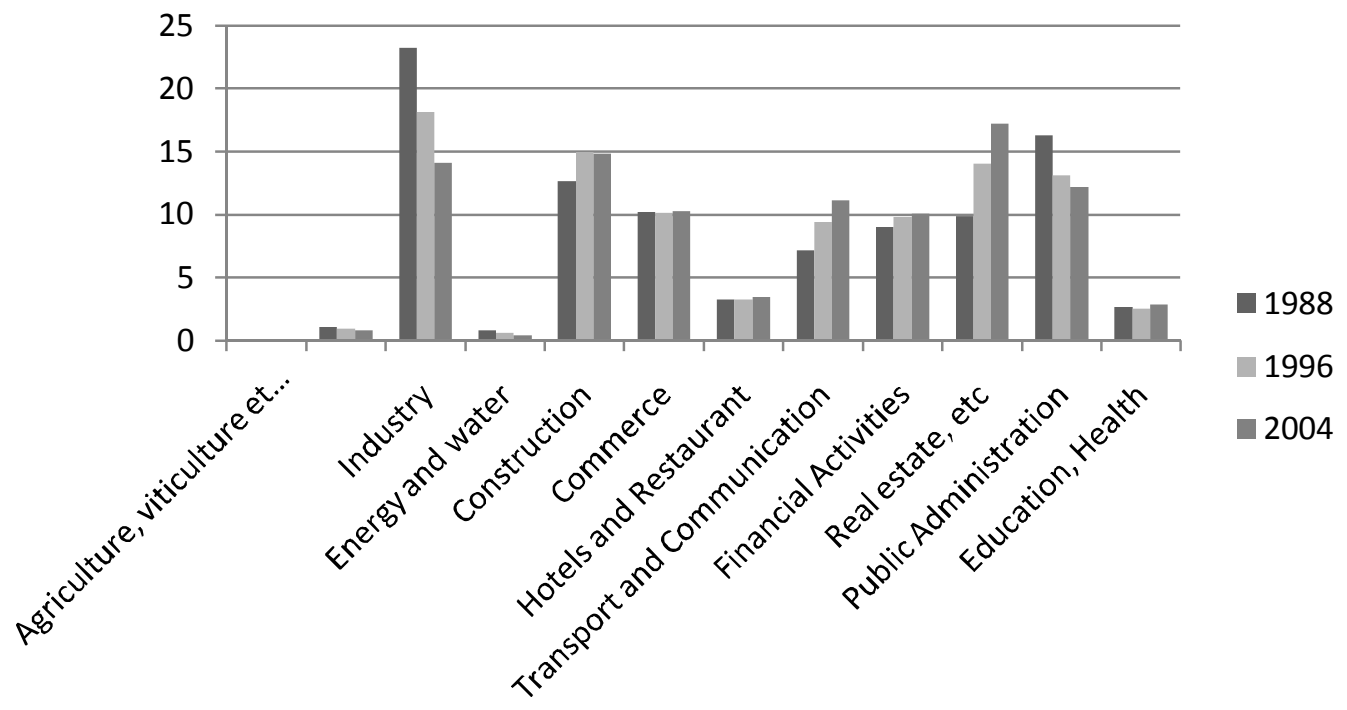

Figure 6. The evolution of the labour market structure by sector in the sample in 1988, 1996 and 2004.

Note: Vertical axis - share of workers by sector of activity 


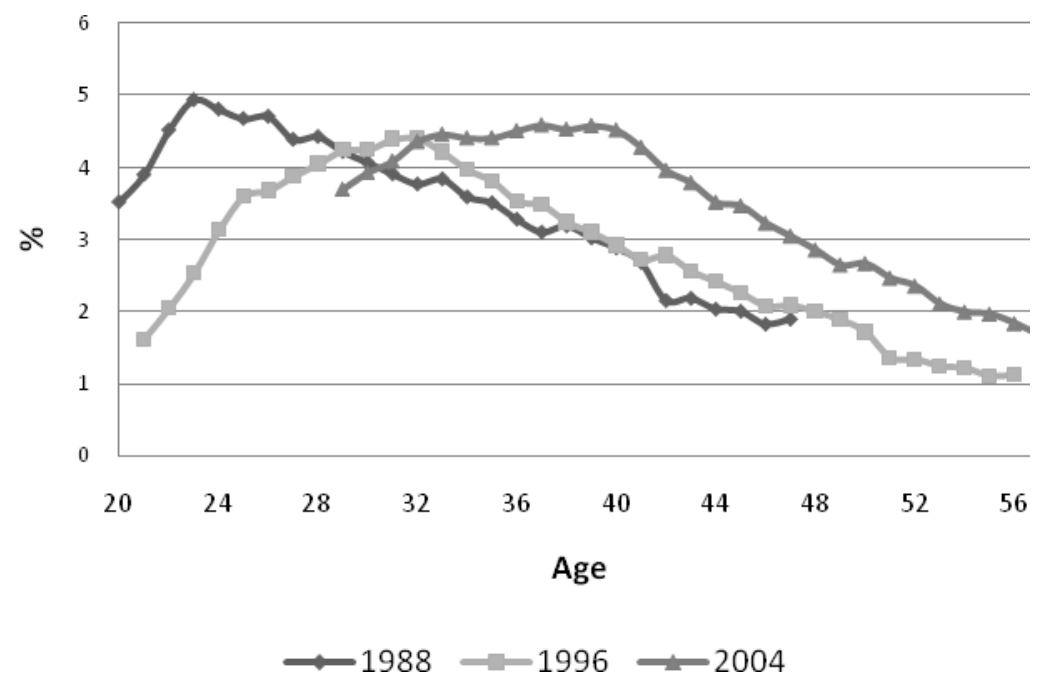

Note: Vertical axis - share of workers by age groups

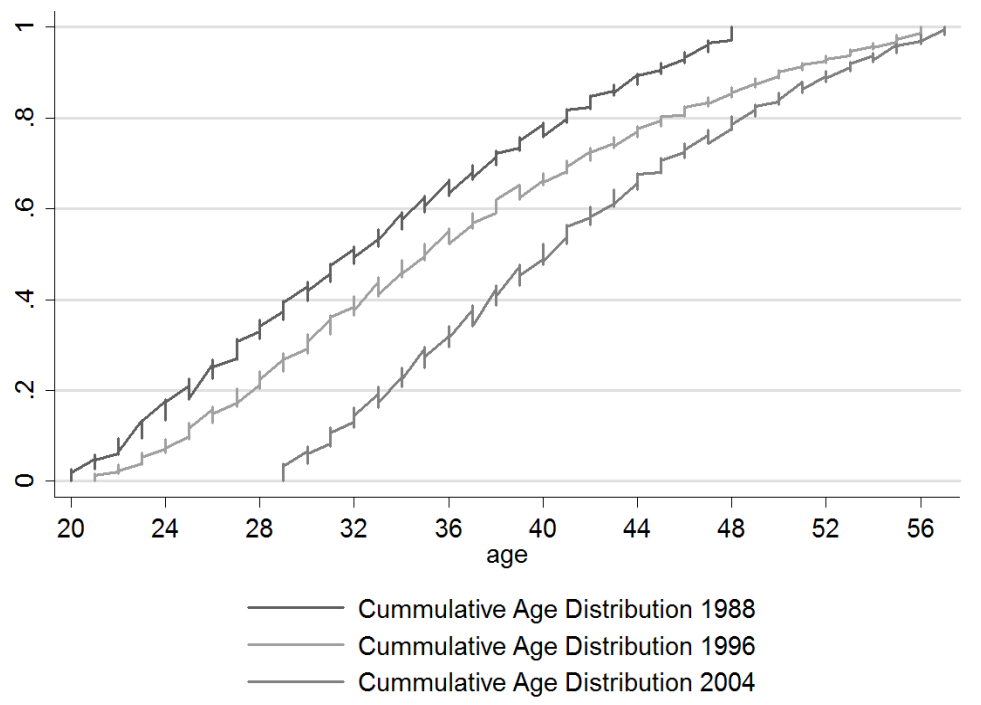

Figure 7. The evolution of the age structure of the active population in the sample

Note: Vertical axis - cummulative share of workers by age groups 

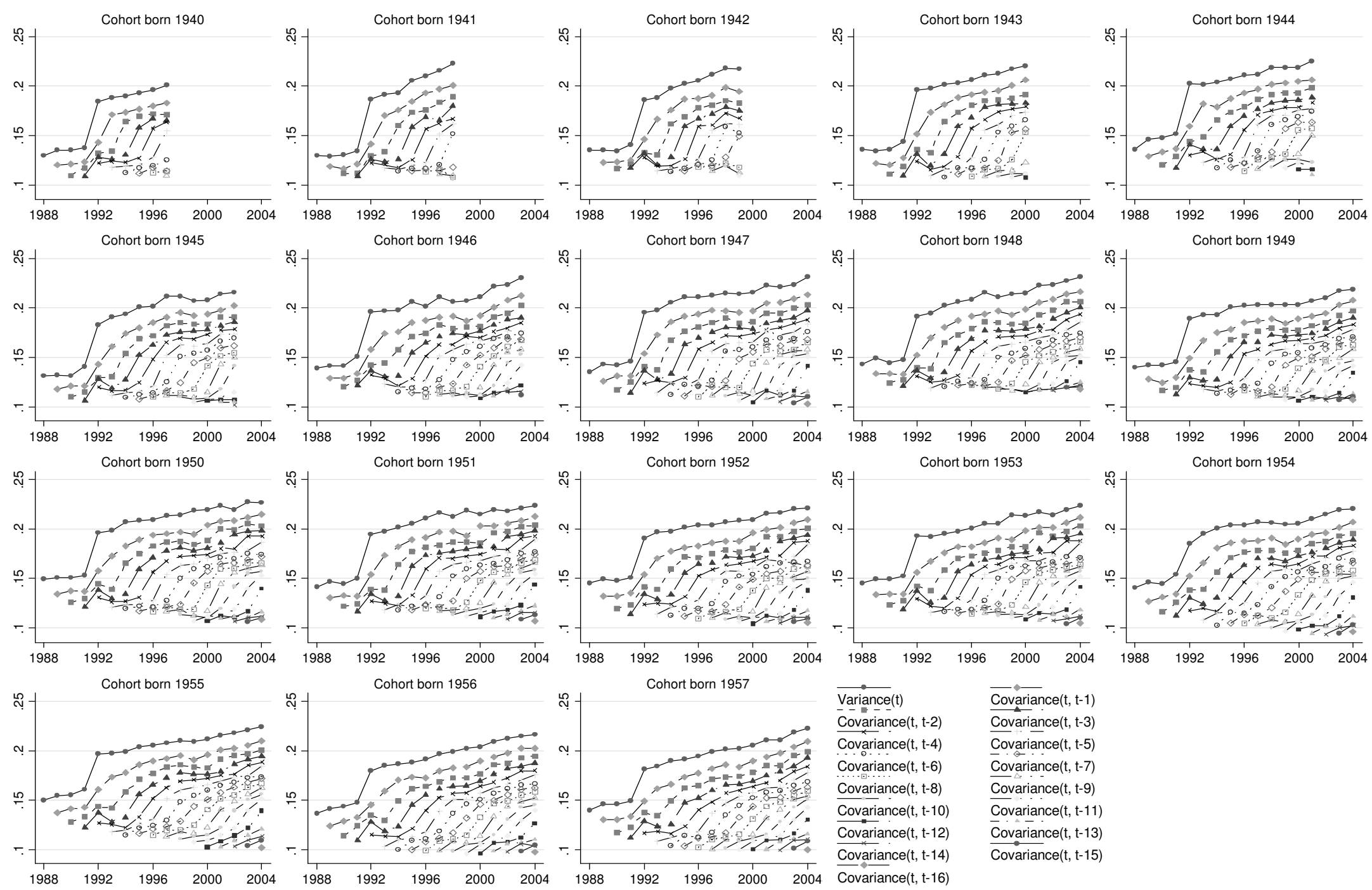

\begin{tabular}{l} 
Variance $(\mathrm{t})$ \\
Covariance $(\mathrm{t}, \mathrm{t}-2)$ \\
Covariance \\
Covariance $(\mathrm{t}, \mathrm{t}-4)$ \\
Covariance $(\mathrm{t}, \mathrm{t}-6)$ \\
Covariance $(\mathrm{t}, \mathrm{t}-8)$ \\
\hline Covariance $(\mathrm{t}, \mathrm{t}-10)$ \\
\hline Covariance $(\mathrm{t}, \mathrm{t}-12)$ \\
\hline Covariance $(\mathrm{t}, \mathrm{t}-14)$ \\
\hline Covariance $(\mathrm{t}, \mathrm{t}-16)$
\end{tabular}

Covariance(t, $\mathrm{t}-1)$ Covariance $(t, t-3)$ Covariance $(t, t-5)$ Covariance(t, t-7) Covariance(t, t-9) Covariance(t, t-11) Covariance $(\mathrm{t}, \mathrm{t}-13)$ Covariance(t, $\mathrm{t}-15)$

Figure 8. Autocovariance Structure of Earnings for Selected Cohorts: 1940 - 1975

Note: In the legend, $t$ stands for the each year displayed on the horizontal axis of each graph. 

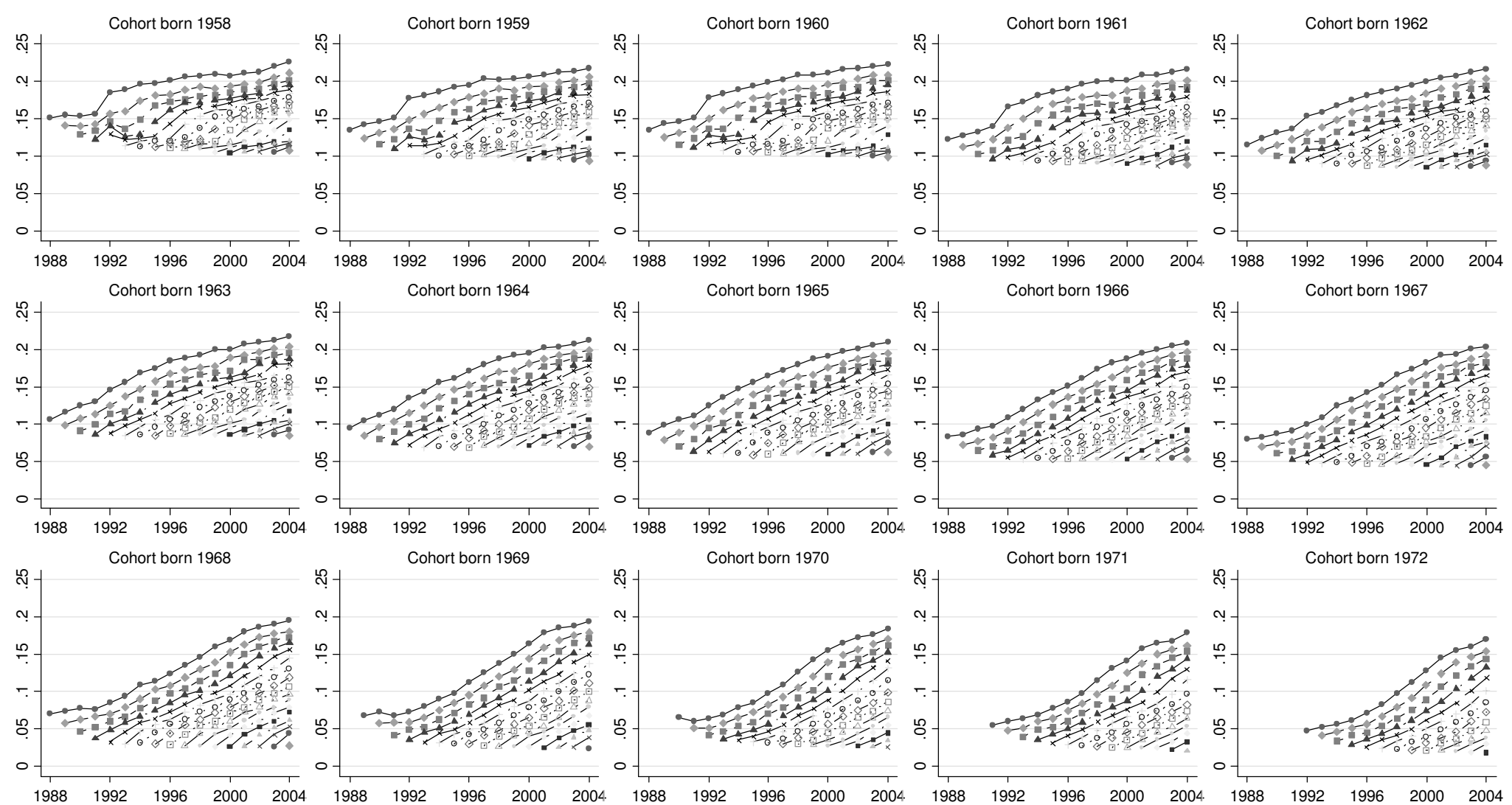

Cohort born 1972
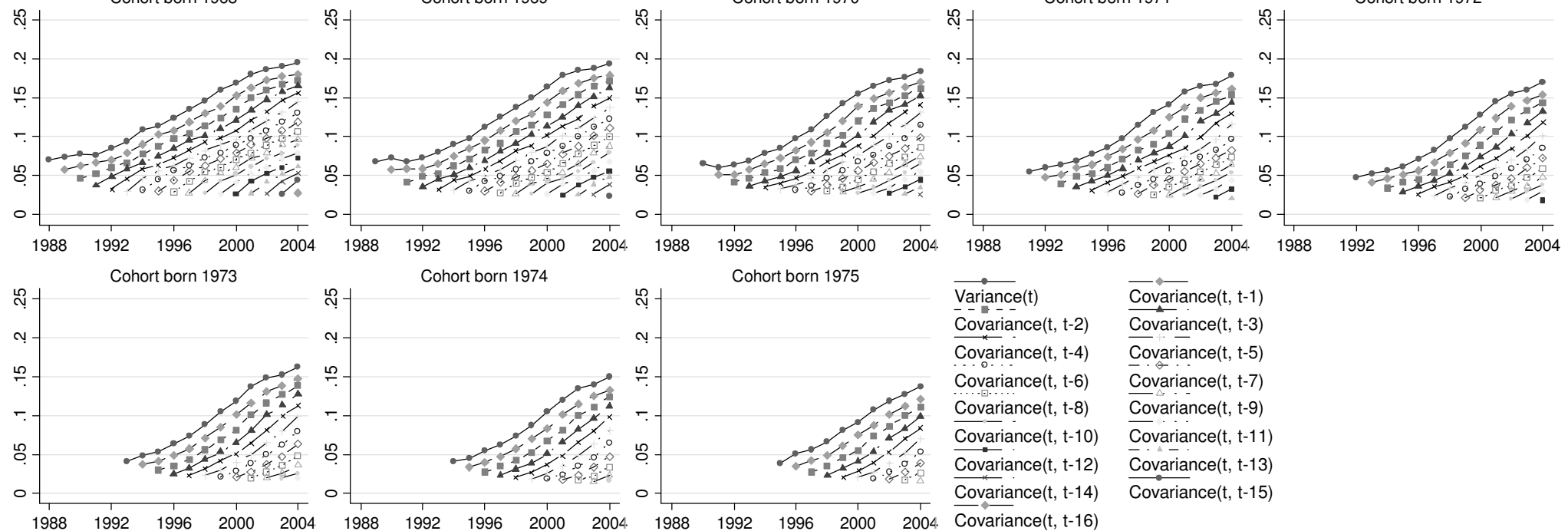

Figure 8 (Continued) 

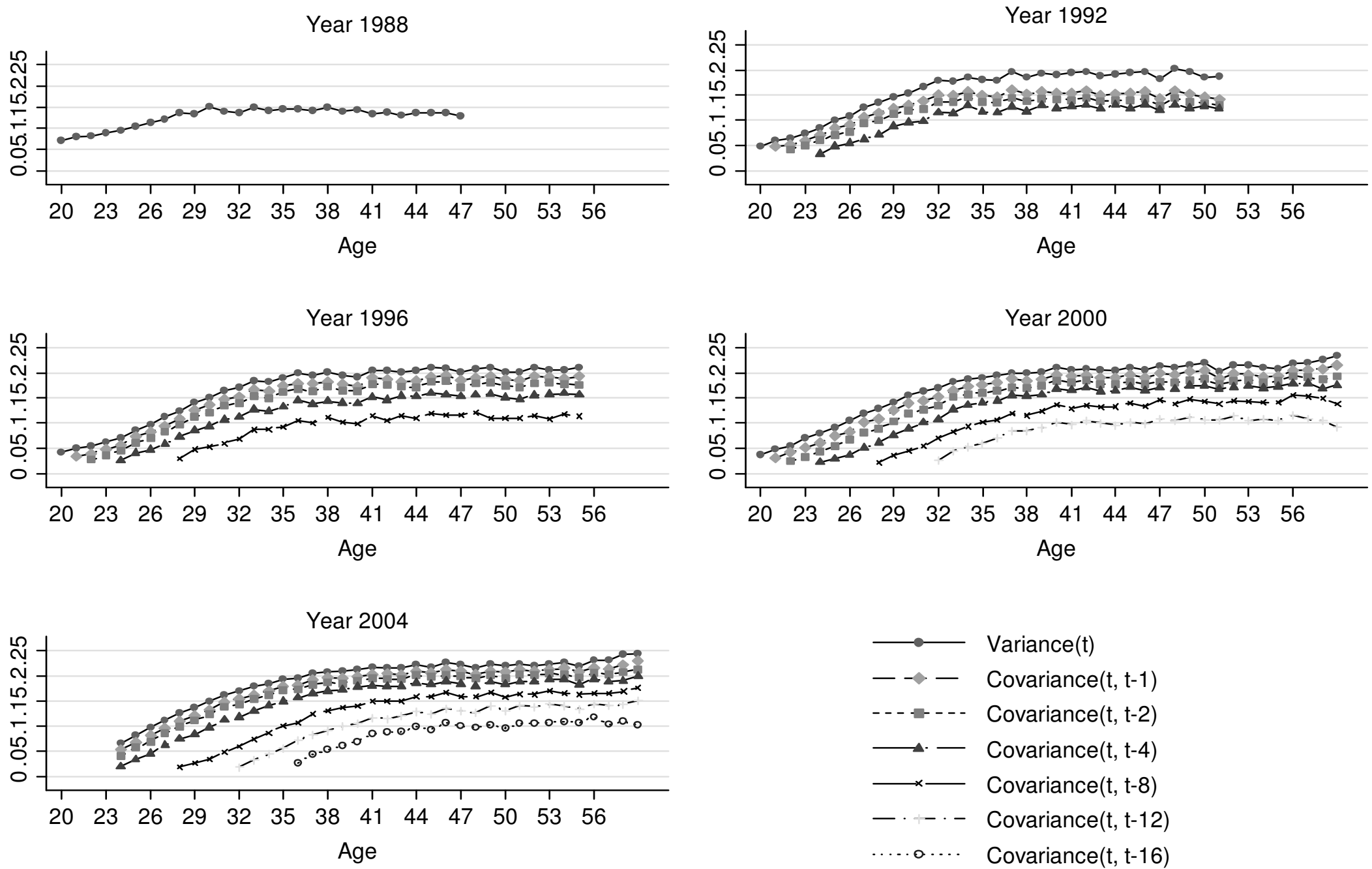

$$
\begin{array}{ll}
\longrightarrow- & \text { Variance }(\mathrm{t}) \\
\hdashline- & \text { Covariance }(\mathrm{t}, \mathrm{t}-1) \\
\hdashline- & \text { Covariance }(\mathrm{t}, \mathrm{t}-2) \\
\hdashline- & \text { Covariance }(\mathrm{t}, \mathrm{t}-4) \\
-\cdots- & \text { Covariance }(\mathrm{t}, \mathrm{t}-\mathrm{t}-12) \\
\cdots \cdots \cdots & \text { Covariance }(\mathrm{t}, \mathrm{t}-16)
\end{array}
$$

Figure 9. Lifecycle Autocovariances for Selected Years : 1988, 1992, 1996, 2000, 2004

Note: In the legend, $t$ stands for the each age displayed on the horizontal axis of each graph. 


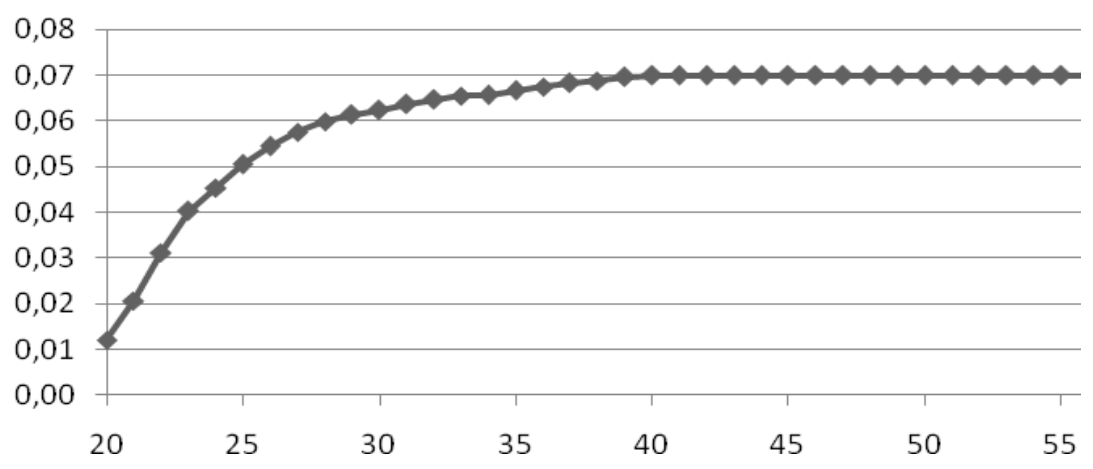

Figure 10. The pattern of the permanent component without time and cohort loading factors Note: Based on the parameters estimates displayed in Table 2 - Base Model.

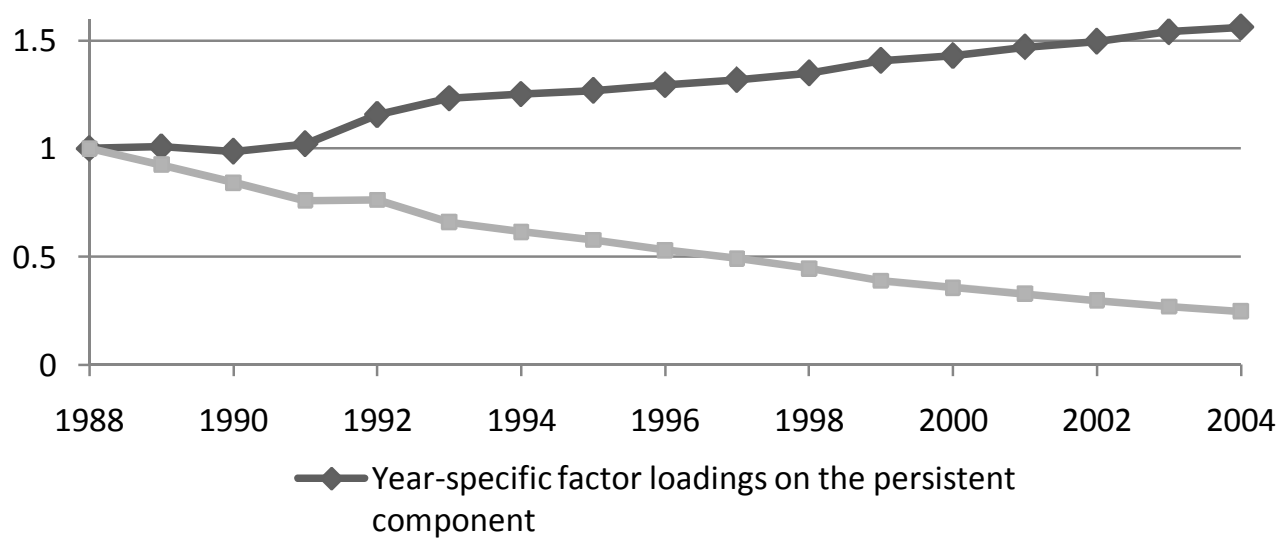

Figure 11. Year-specific factor loadings on the persistent and transitory components Note: Based on the parameters estimates displayed in Table 2 - Base Model.

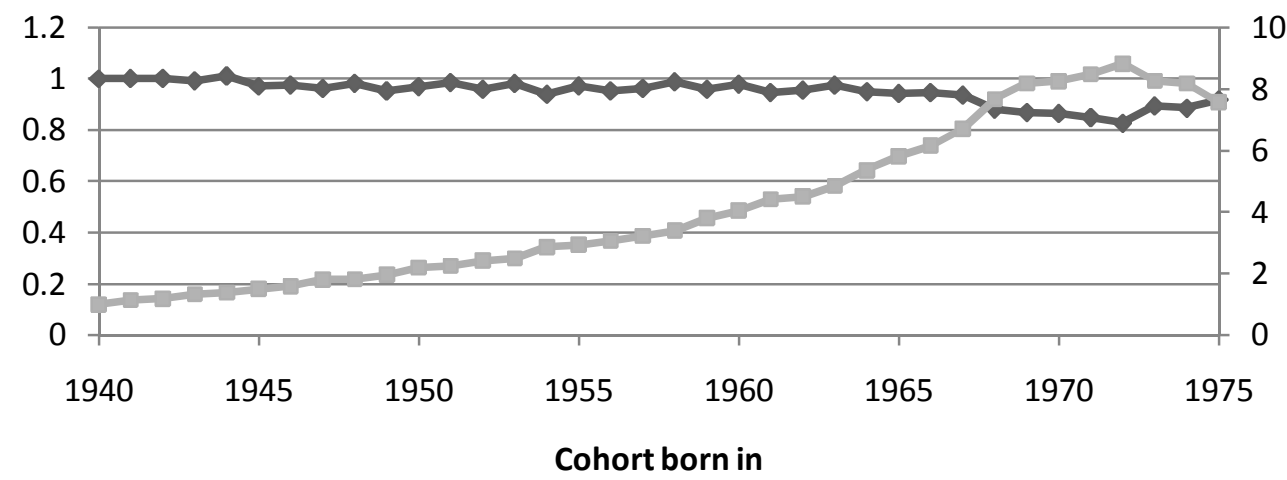

Cohort-specific factor loadings on the permanent component (left Y-axis)

-Cohort-specific factor loadings on the transitory component (right Y-axis)

Figure 12. Cohort-specific loading factors on the permanent and transitory components

Note: Based on the parameters estimates displayed in Table 2 - Base Model. 


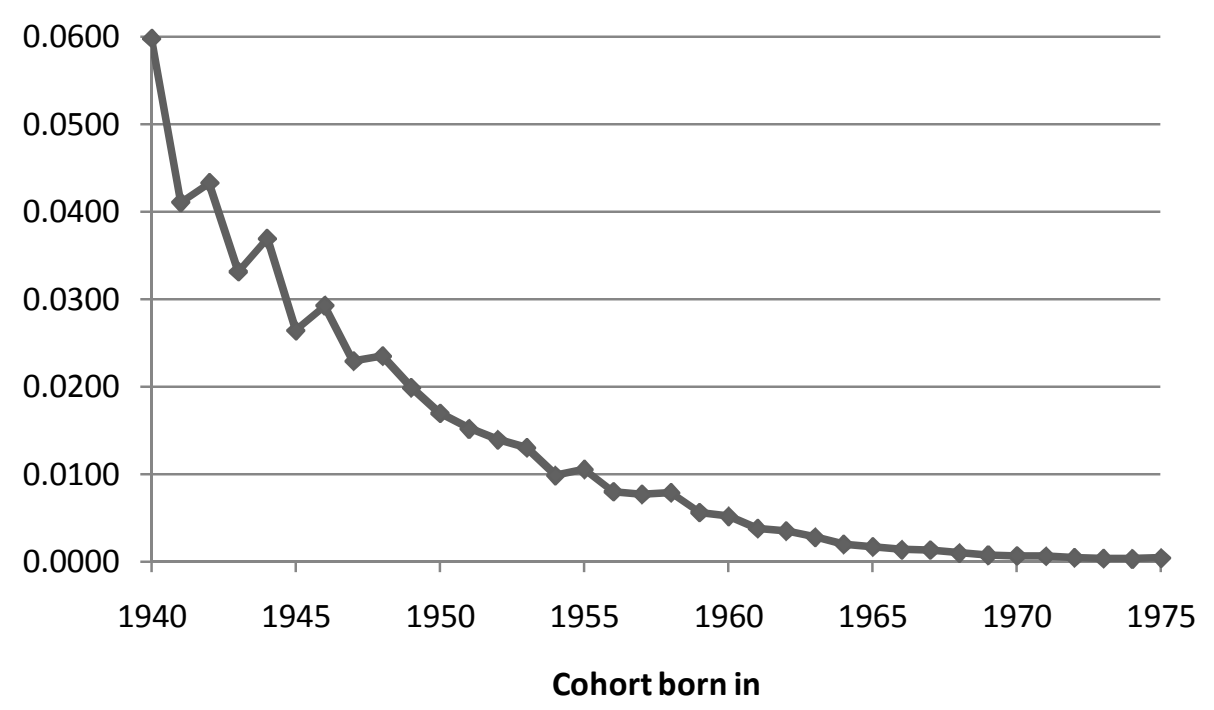

Figure 13. Cohort-specific initial transitory variances

Note: Based on the parameters estimates displayed in Table 2 - Base Model.

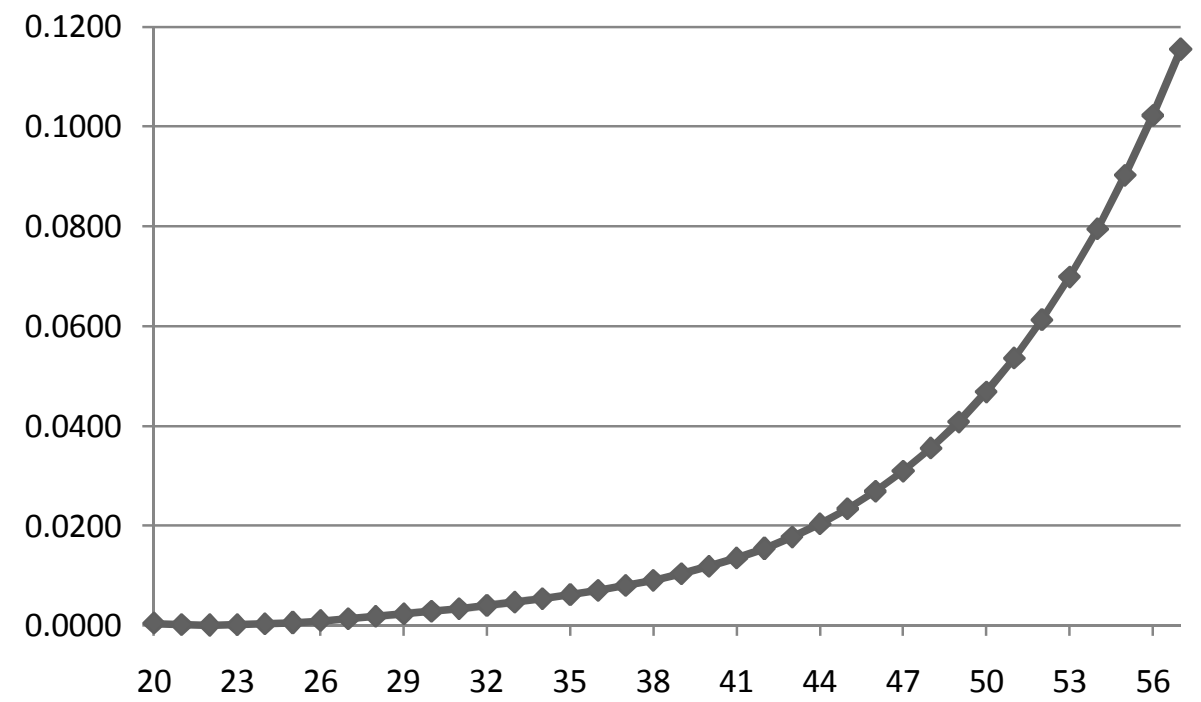

Figure 14. The age profile of the variance of the transitory innovation, base model Note: Based on the parameters estimates displayed in Table 2 - Base Model. 

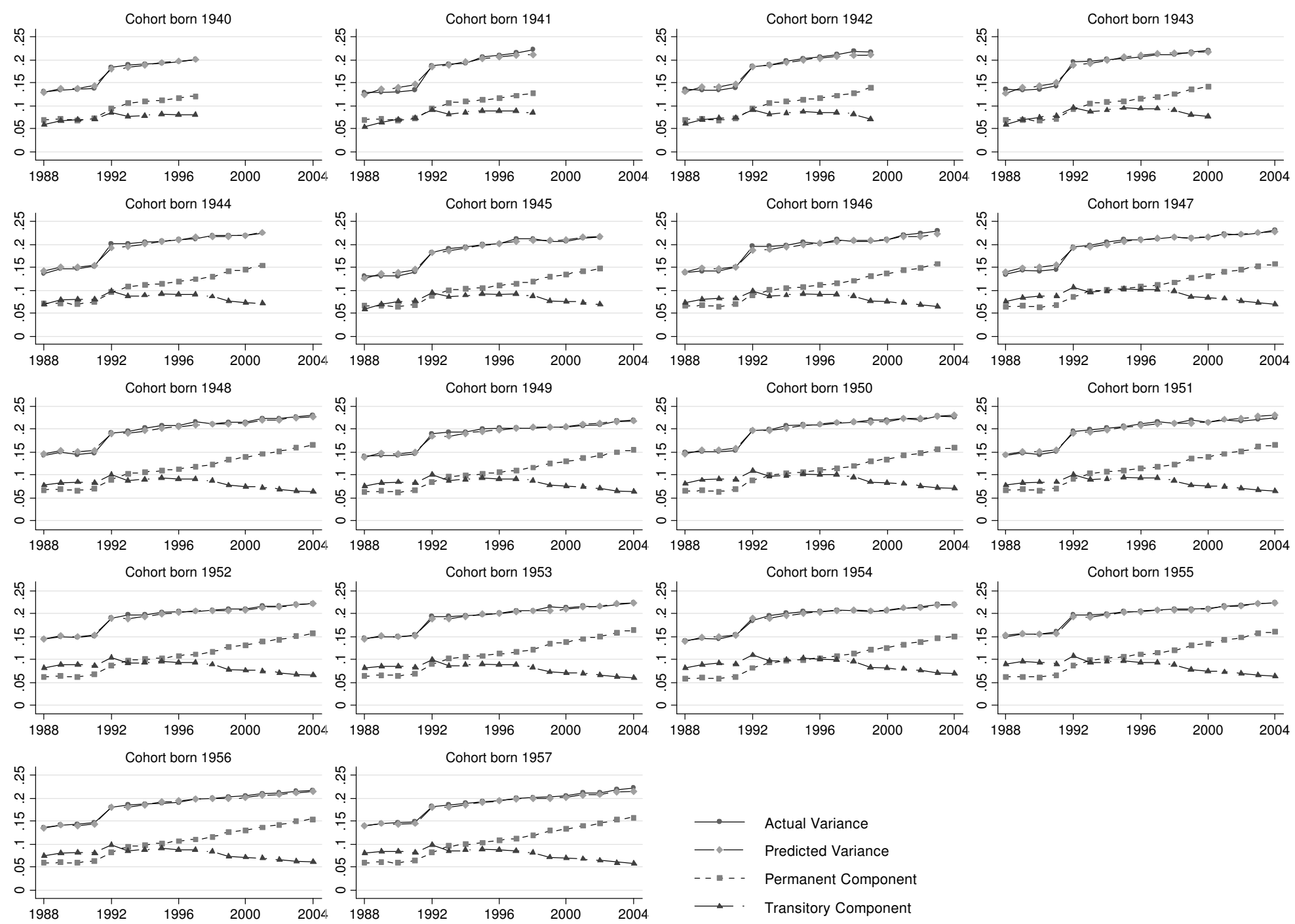

Figure 15. Actual and Predicted Variance of Earnings with Permanent and Transitory Predicted Components for Selected Cohorts: 1940-1975 

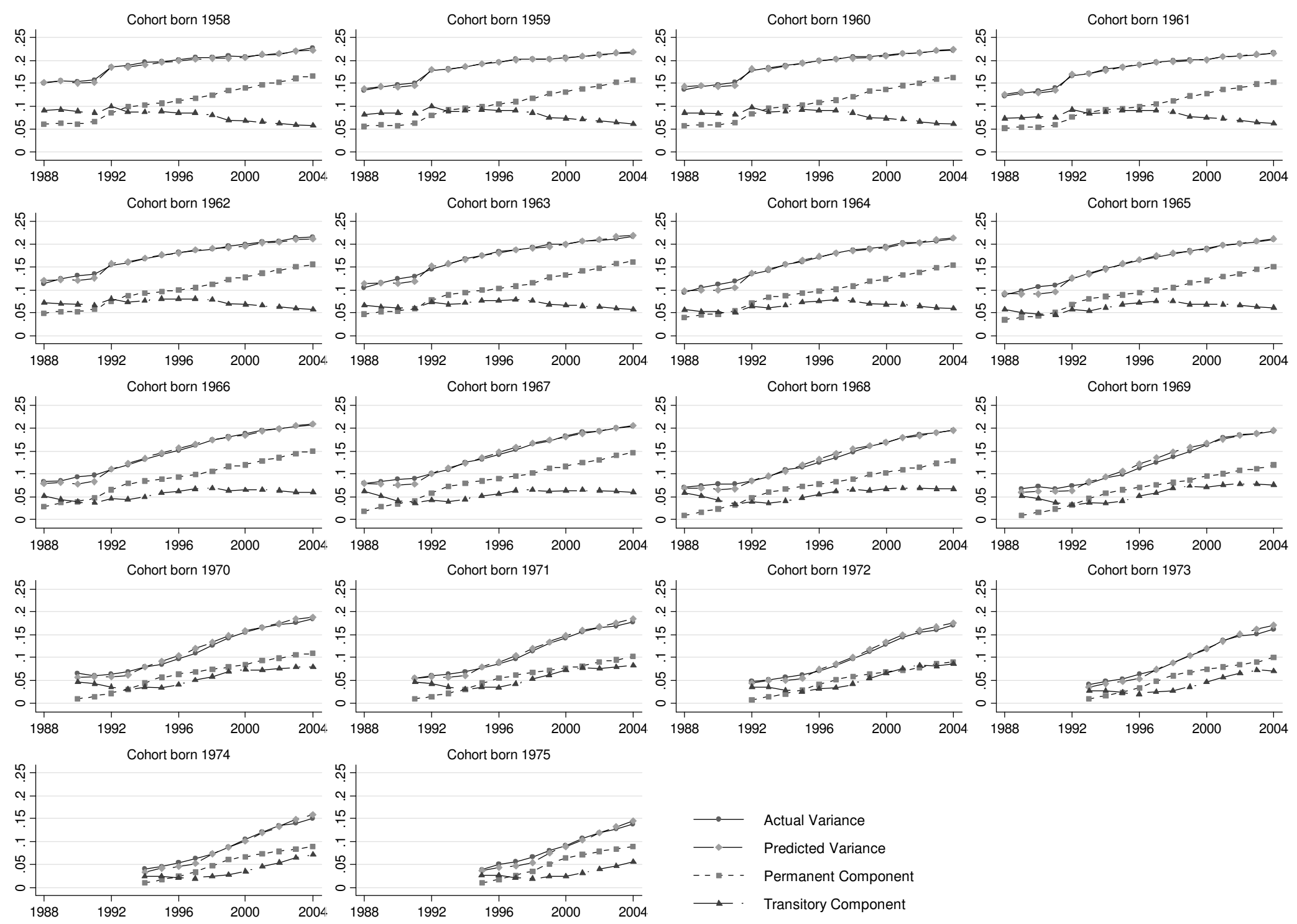

\section{Figure 15 (Continued)}



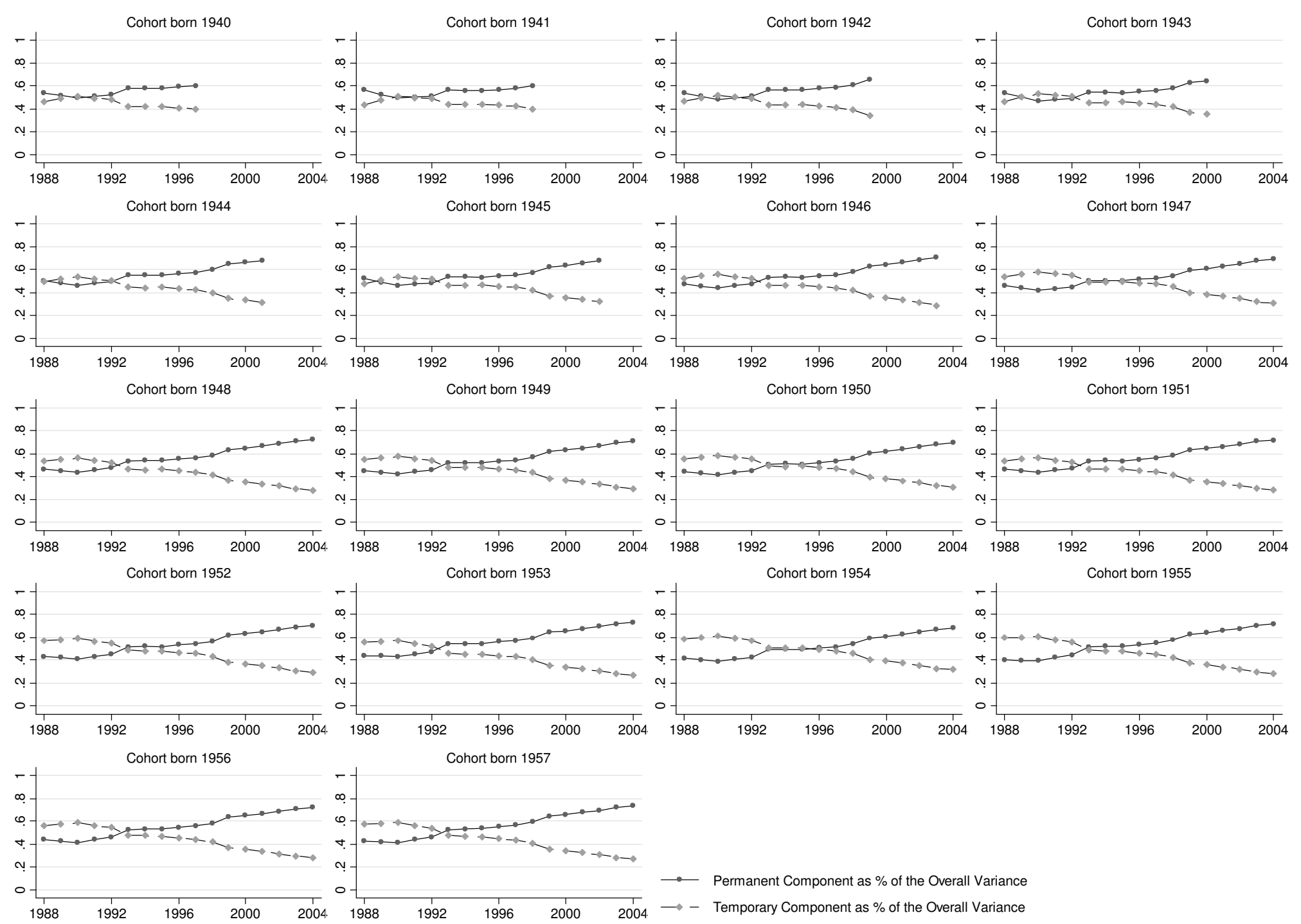

Figure 16. Predicted Permanent and Transitory Variance as \% of Predicted Overall Variance for Selected Cohorts: 1994-2001 

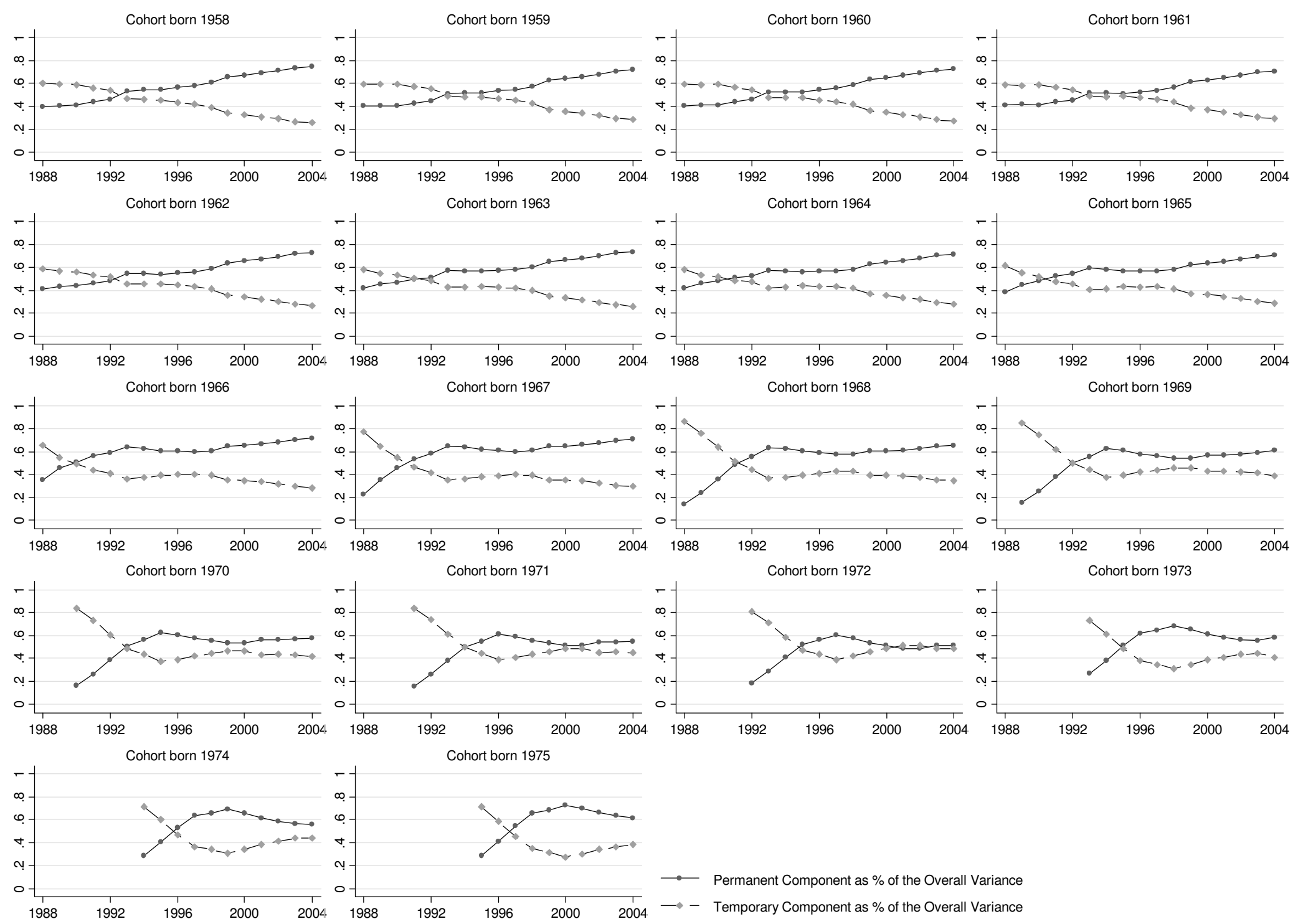

- Permanent Component as \% of the Overall Variance

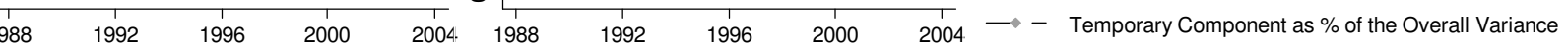

\section{Figure 16 (Continued)}



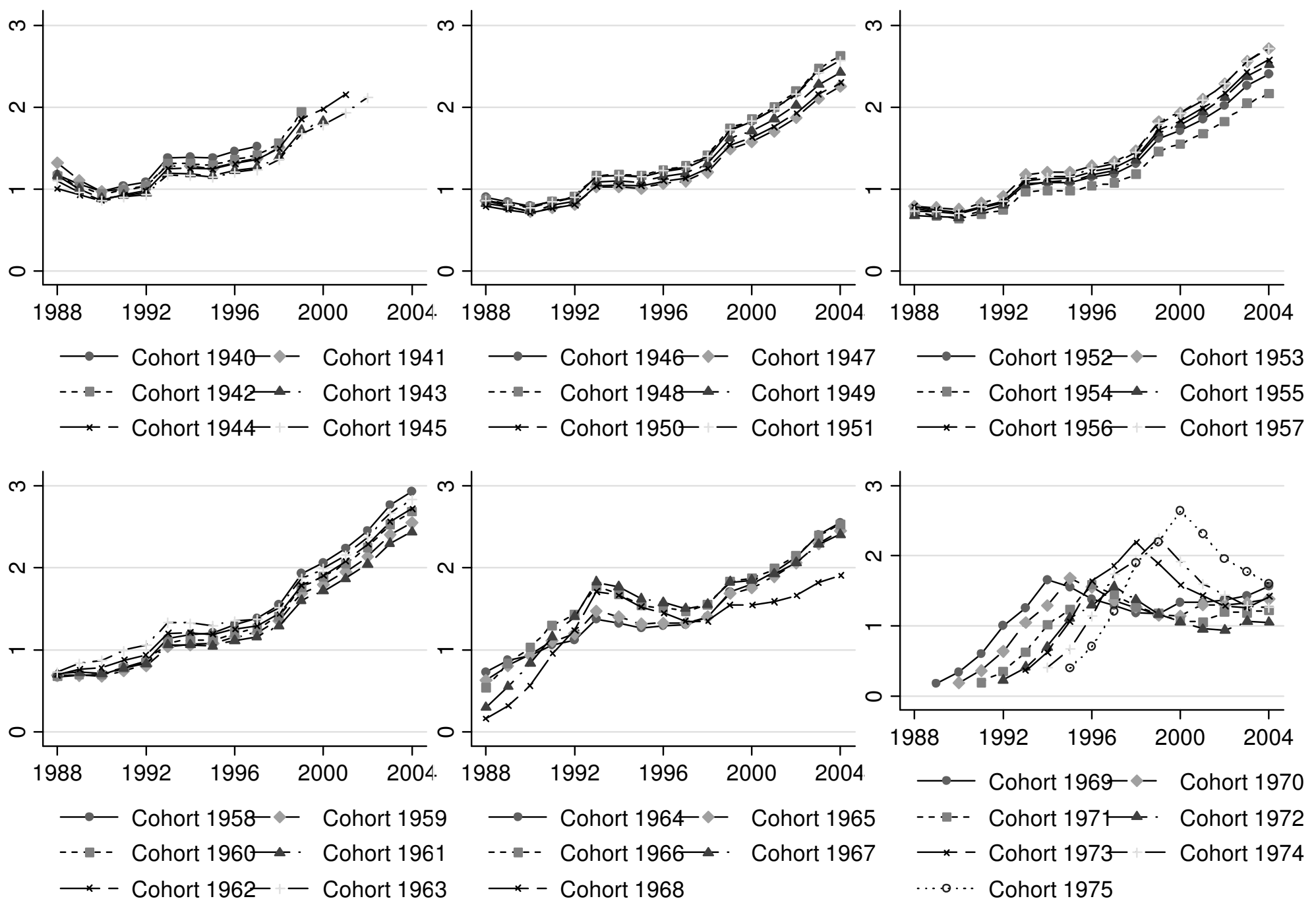

Figure 17. Earnings immobility for men by cohort over time - base model

Note: Each line plots the earnings immobility ratio by cohort over time 

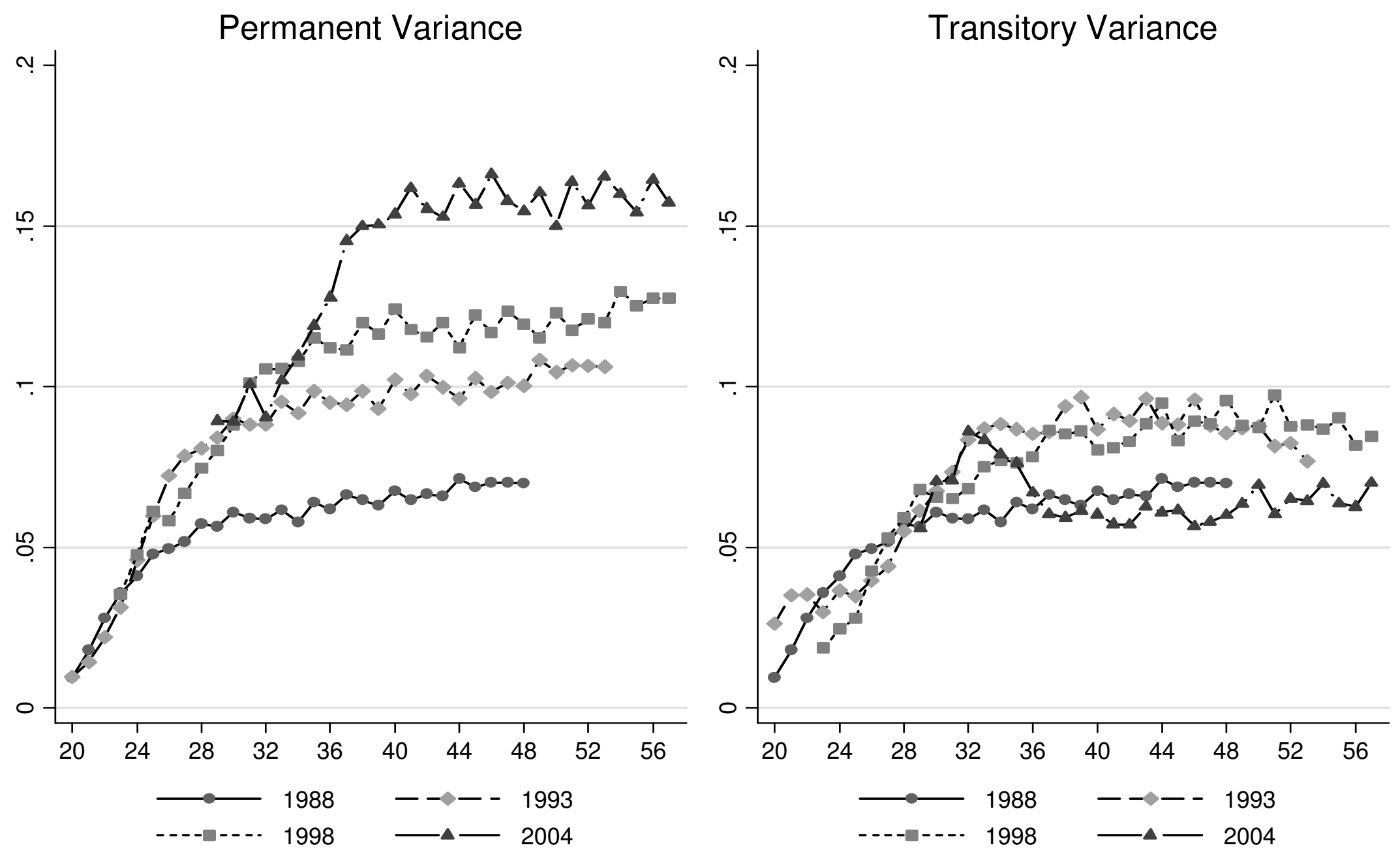

Figure 18. Cross-sectional age profile of the permanent and transitory variance for selected years

Note: vertical axis - permanent variance of log earnings (left), transitory variance of log earnings (right); horizontal axis - age; each line plots the permanent/transitory variance for ages 20-57 in selected years 


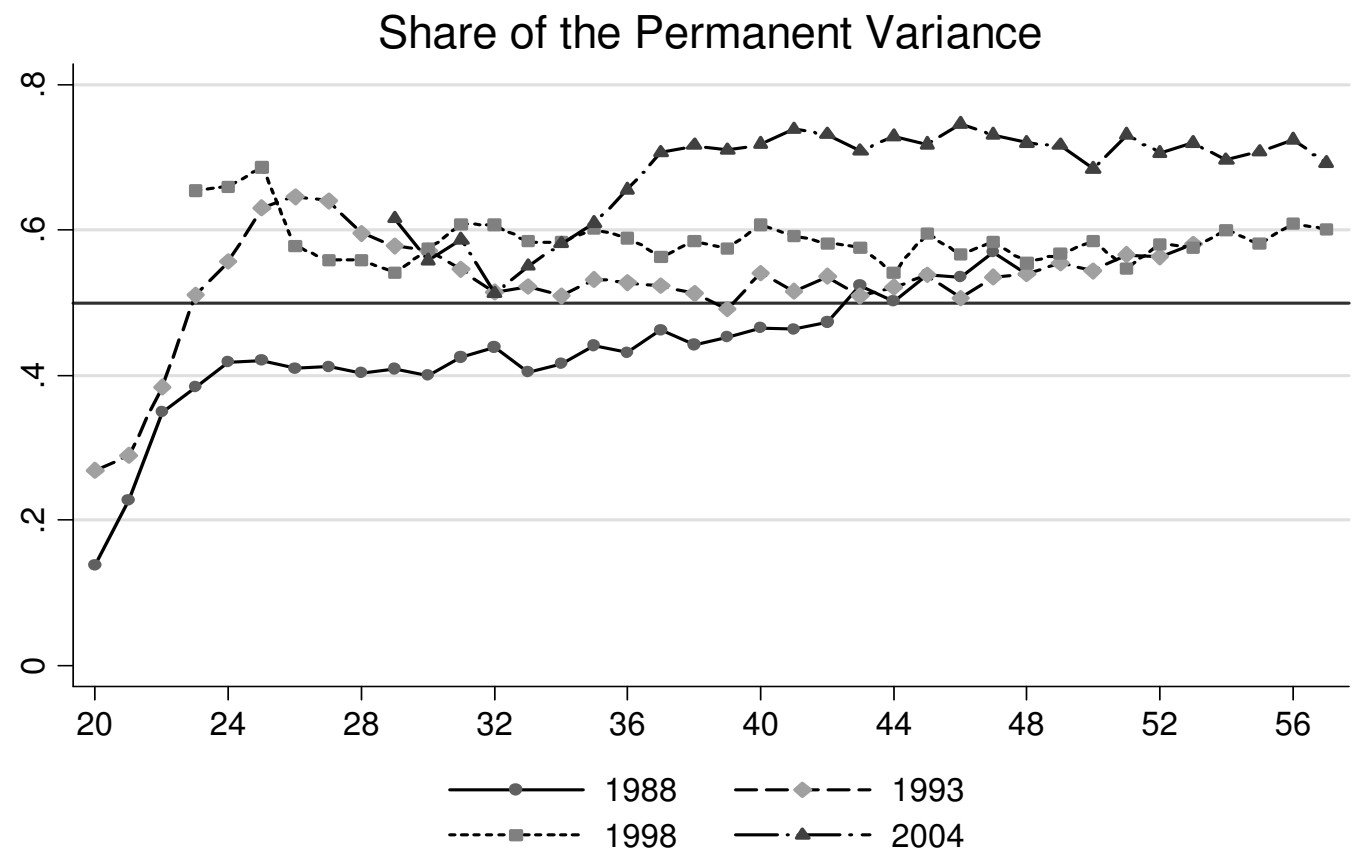

Figure 19. Cross-sectional age profile of the share of the permanent component from the overall variance for selected years: 1988, 1993, 1998, 2004

Note: vertical axis - share (\%) of the permanent component from the overall variance , horizontal axis - age

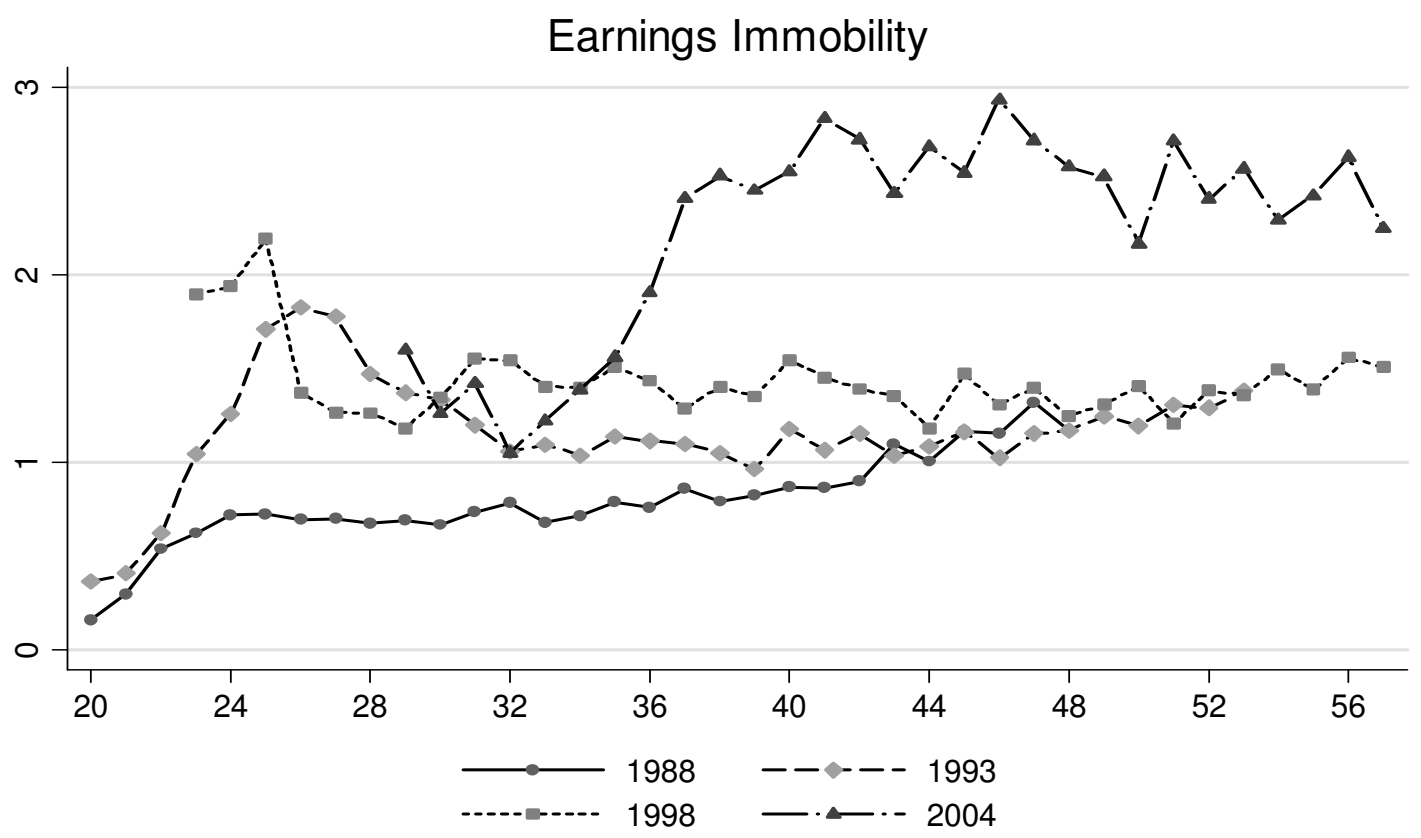

Figure 20. The cross-sectional age -immobility profile for selected years 1988, 1993, 1998, 2004 
Note: vertical axis - immobility ratio; each line plots the immobility ratio for ages $20-56$, in the selected years
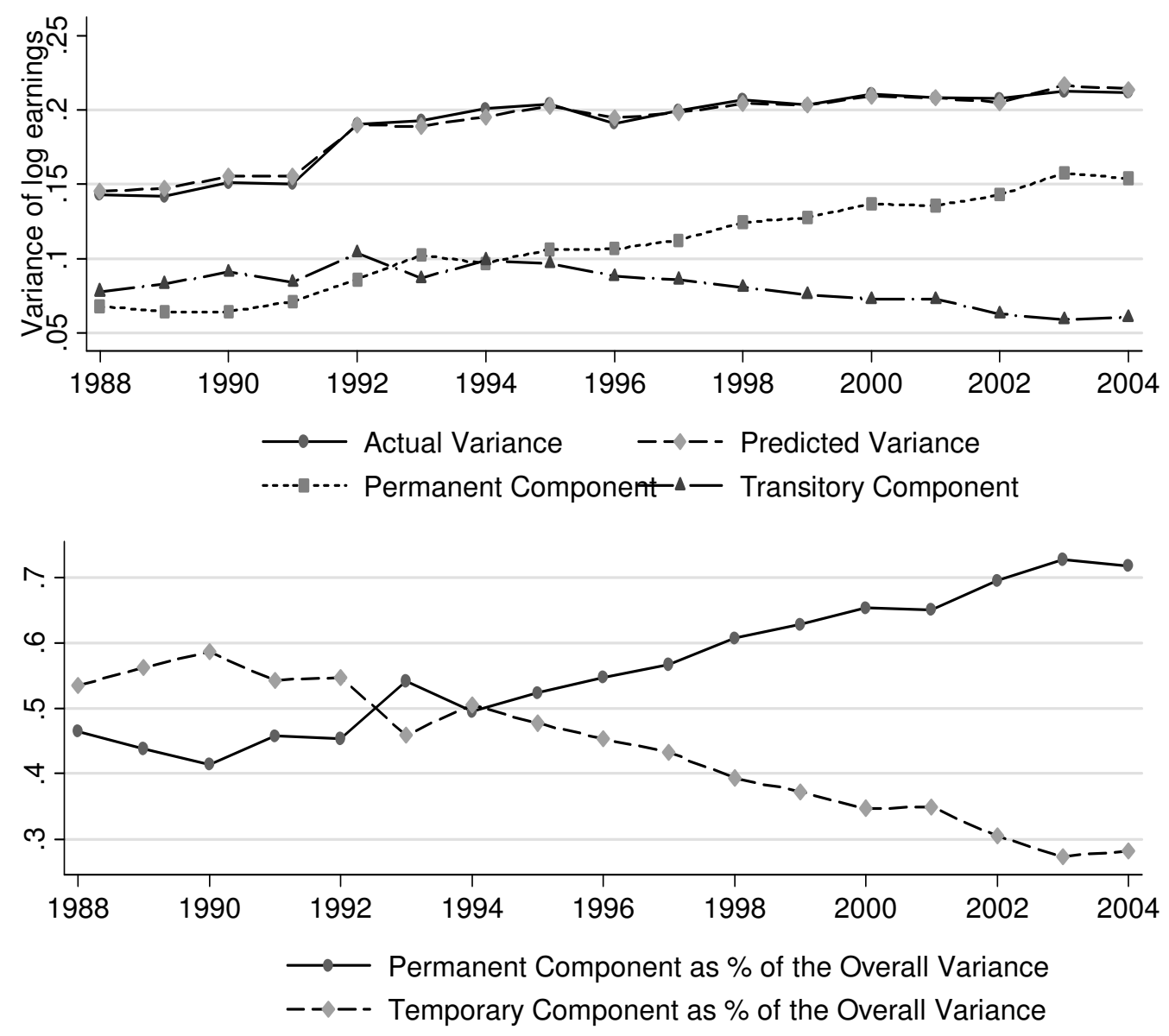

Figure 21. A decomposition of the variance of log hourly earnings for men, 40 years old: base model 


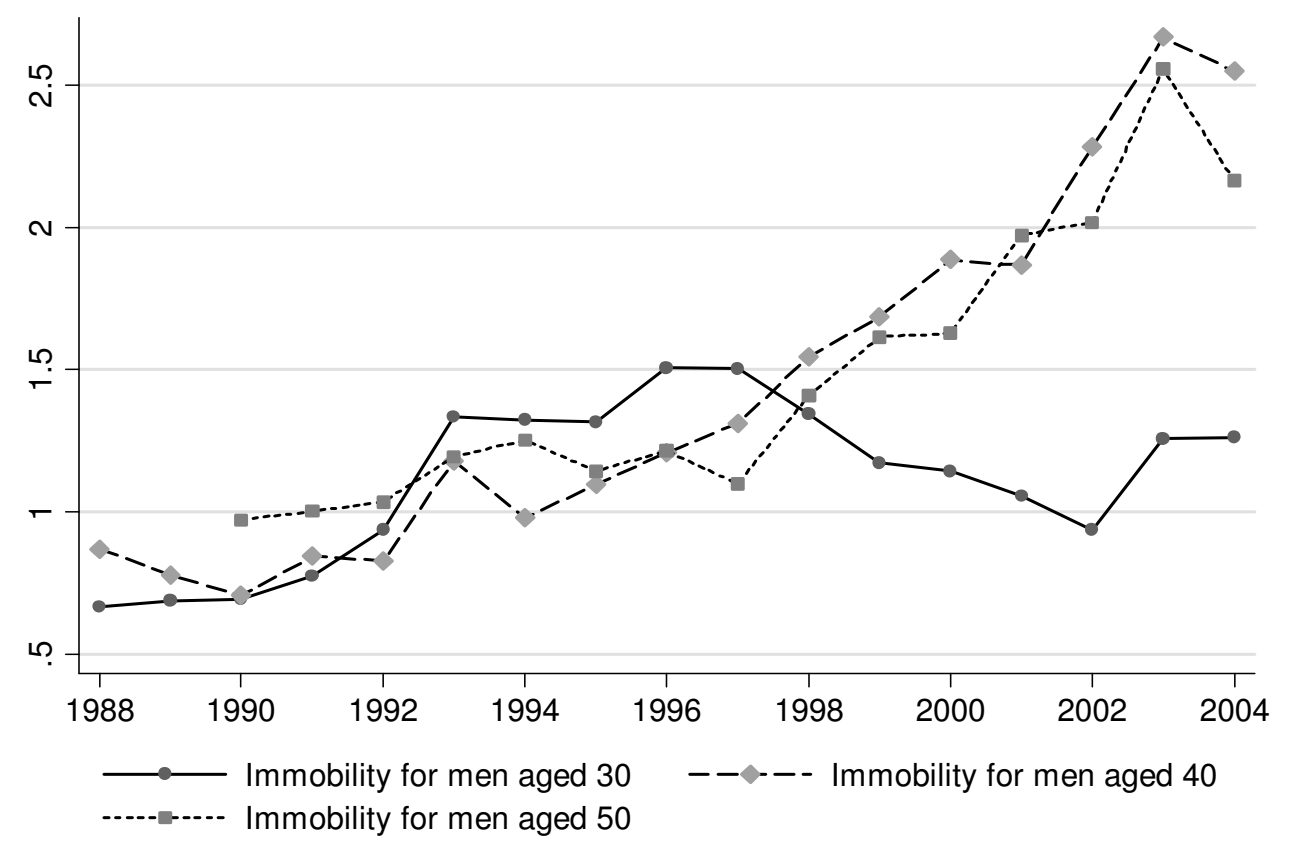

Figure 22. Earnings immobility for men of age 30, 40 and 50 - base model

Note: vertical axis - immobility ratio; each line plots the immobility ratio for men aged 30, 40 and 50 over time

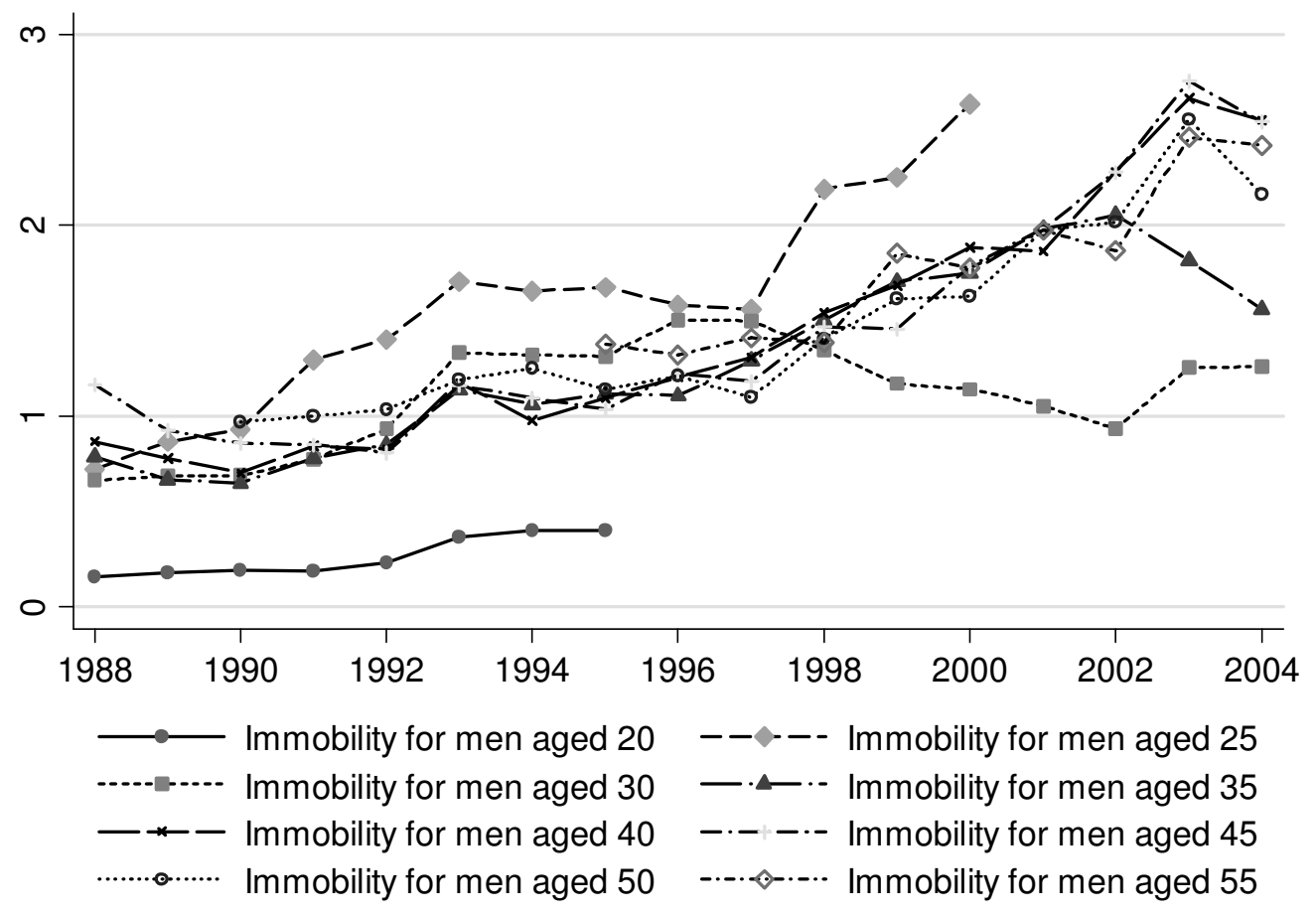

Figure 23. Earnings immobility for men of age 20, 25, 30, 35, 40, 45, 50, 55 - base model 
Note: vertical axis - immobility ratio; each line plots the immobility ratio for men aged 20, 25 , $30,35,40,45,50,55$ over time
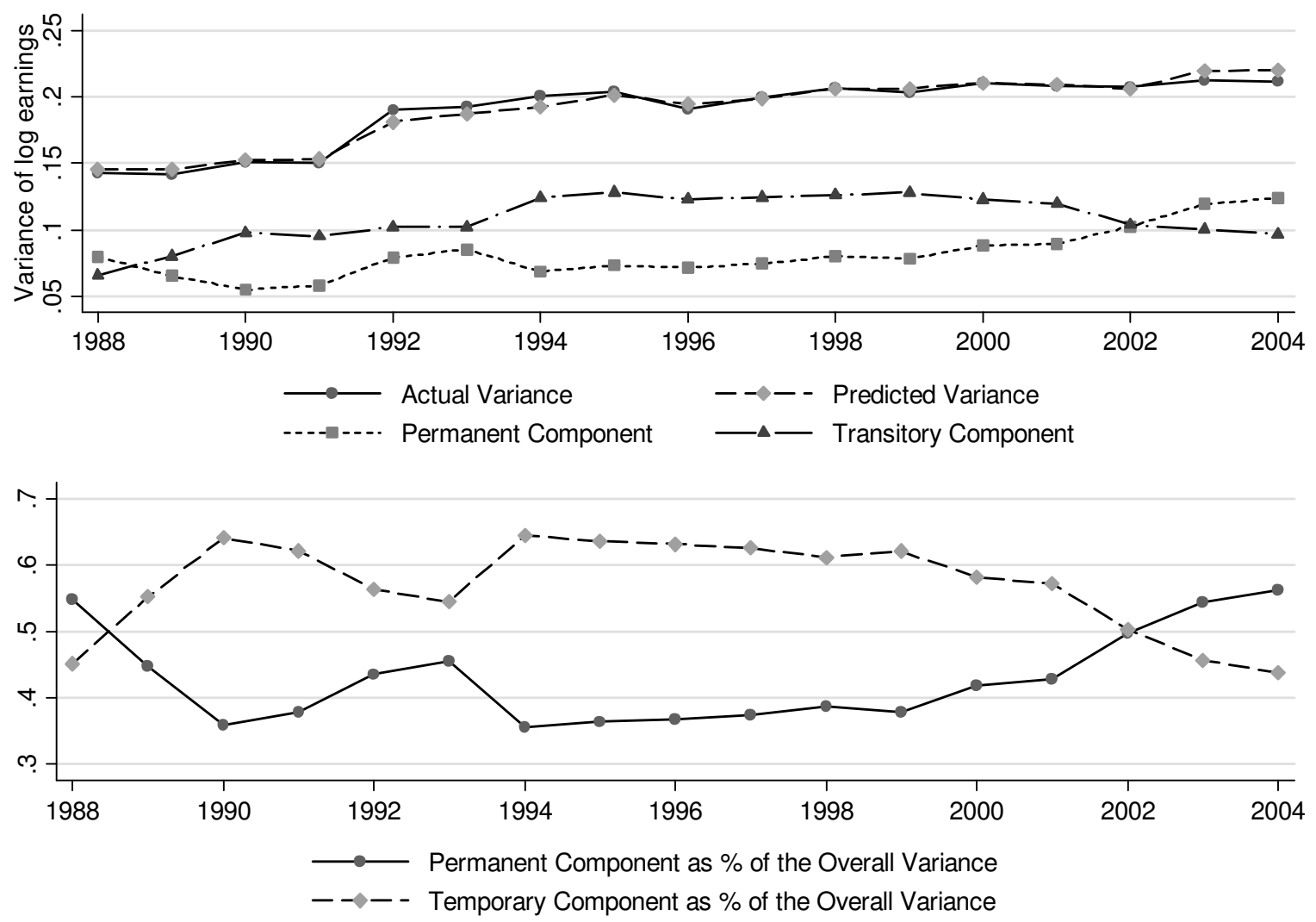

Figure 24. A decomposition of the variance of log hourly earnings for men, 40 years old: restricted model 
Table 1. Cohorts Included in the Working Sample

\begin{tabular}{|c|c|c|c|}
\hline Cohort born in & Sample Size & Years Observed & Ages Observed \\
\hline 1940 & 1862 & 1988-1997 & $48-57$ \\
\hline 1941 & 1878 & 1988-1998 & $47-57$ \\
\hline 1942 & 2288 & 1988-1999 & $46-57$ \\
\hline 1943 & 2495 & $1988-2000$ & $45-57$ \\
\hline 1944 & 2722 & $1988-2001$ & $44-57$ \\
\hline 1945 & 2864 & $1988-2002$ & $43-57$ \\
\hline 1946 & 3622 & $1988-2003$ & $42-57$ \\
\hline 1947 & 4161 & $1988-2004$ & $41-57$ \\
\hline 1948 & 4463 & $1988-2004$ & $40-56$ \\
\hline 1949 & 4725 & $1988-2004$ & $39-55$ \\
\hline 1950 & 4865 & $1988-2004$ & $38-54$ \\
\hline 1951 & 5120 & $1988-2004$ & $37-53$ \\
\hline 1952 & 5712 & $1988-2004$ & $36-52$ \\
\hline 1953 & 5901 & $1988-2004$ & $35-51$ \\
\hline 1954 & 6475 & $1988-2004$ & $34-50$ \\
\hline 1955 & 6564 & 1988-2004 & $33-49$ \\
\hline 1956 & 6974 & $1988-2004$ & $32-48$ \\
\hline 1957 & 7481 & $1988-2004$ & $31-47$ \\
\hline 1958 & 7828 & $1988-2004$ & $30-46$ \\
\hline 1959 & 8562 & $1988-2004$ & $29-45$ \\
\hline 1960 & 8840 & $1988-2004$ & $28-44$ \\
\hline 1961 & 9621 & $1988-2004$ & $27-43$ \\
\hline 1962 & 10004 & 1988-2004 & $26-42$ \\
\hline 1963 & 10771 & $1988-2004$ & $25-41$ \\
\hline 1964 & 11523 & $1988-2004$ & $24-40$ \\
\hline 1965 & 11671 & 1988-2004 & $23-39$ \\
\hline 1966 & 11754 & $1988-2004$ & $22-38$ \\
\hline 1967 & 11928 & $1988-2004$ & $21-37$ \\
\hline 1968 & 11929 & $1988-2004$ & $20-36$ \\
\hline 1969 & 11739 & 1989-2004 & $20-35$ \\
\hline 1970 & 11617 & $1990-2004$ & $20-34$ \\
\hline 1971 & 11657 & $1991-2004$ & $20-33$ \\
\hline 1972 & 11192 & 1992-2004 & $20-32$ \\
\hline 1973 & 10443 & $1993-2004$ & $20-31$ \\
\hline 1974 & 9843 & 1994-2004 & $20-30$ \\
\hline 1975 & 9186 & $1995-2004$ & $20-29$ \\
\hline Total & 270280 & & \\
\hline
\end{tabular}


Table 2. Error Component Model Estimates

\begin{tabular}{|c|c|c|c|c|c|c|}
\hline \multirow[b]{2}{*}{ Permanent Component } & \multicolumn{3}{|l|}{ Base model } & \multicolumn{3}{|c|}{$\begin{array}{l}\text { Restricted Model } \\
\text { Random Walk + ARMA }(1,1)\end{array}$} \\
\hline & Exp(Estimate) & Estimate & SE & Exp(Estimate) & Estimate & SE \\
\hline $\exp ($ estimate $)=\sigma_{\mu_{20}}^{2}$ & 0.0122 & -4.4103 & 0.0681 & & & \\
\hline $\exp ($ estimate $)=\sigma_{\pi}^{2}$ & & & & 0.0001 & -8.9471 & 0.0831 \\
\hline $\exp ($ estimate $)=\sigma_{\pi_{21}}^{2}$ & 0.0085 & -4.7702 & 0.0668 & & & \\
\hline $\exp ($ estimate $)=\sigma_{\pi_{22}}^{2}$ & 0.0106 & -4.5495 & 0.0589 & & & \\
\hline $\exp ($ estimate $)=\sigma_{\pi_{23}}^{2}$ & 0.0090 & -4.7058 & 0.0599 & & & \\
\hline $\exp ($ estimate $)=\sigma_{\pi_{24}}^{2}$ & 0.0052 & -5.2677 & 0.0616 & & & \\
\hline $\exp ($ estimate $)=\sigma_{\pi_{25}}^{2}$ & 0.0051 & -5.2853 & 0.0639 & & & \\
\hline $\exp ($ estimate $)=\sigma_{\pi_{26}}^{2}$ & 0.0039 & -5.5439 & 0.0653 & & & \\
\hline $\exp ($ estimate $)=\sigma_{\pi_{27}}^{2}$ & 0.0033 & -5.7284 & 0.0675 & & & \\
\hline $\exp ($ estimate $)=\sigma_{\pi_{28}}^{2}$ & 0.0023 & -6.0951 & 0.0744 & & & \\
\hline $\exp ($ estimate $)=\sigma_{\pi_{29}}^{2}$ & 0.0014 & -6.5711 & 0.1053 & & & \\
\hline $\exp ($ estimate $)=\sigma_{\pi_{30}}^{2}$ & 0.0011 & -6.8030 & 0.1501 & & & \\
\hline $\exp ($ estimate $)=\sigma_{\pi_{31}}^{2}$ & 0.0013 & -6.6765 & 0.1434 & & & \\
\hline $\exp ($ estimate $)=\sigma_{\pi_{32}}^{2}$ & 0.0011 & -6.8453 & 0.1868 & & & \\
\hline $\exp ($ estimate $)=\sigma_{\pi_{33}}^{2}$ & 0.0007 & -7.3006 & 0.2934 & & & \\
\hline $\exp ($ estimate $)=\sigma_{\pi_{34}}^{2}$ & 0.0003 & -8.0633 & 0.6885 & & & \\
\hline $\exp ($ estimate $)=\sigma_{\pi_{35}}^{2}$ & 0.0008 & -7.0832 & 0.2881 & & & \\
\hline $\exp ($ estimate $)=\sigma_{\pi_{36}}^{2}$ & 0.0010 & -6.9368 & 0.2537 & & & \\
\hline $\exp ($ estimate $)=\sigma_{\pi_{37}}^{2}$ & 0.0008 & -7.1521 & 0.3257 & & & \\
\hline $\exp ($ estimate $)=\sigma_{\pi_{38}}^{2}$ & 0.0005 & -7.6076 & 0.5160 & & & \\
\hline $\exp ($ estimate $)=\sigma_{\pi_{39}}^{2}$ & 0.0008 & -7.1649 & 0.3545 & & & \\
\hline $\exp ($ estimate $)=\sigma_{\pi_{40}}^{2}$ & 0.0004 & -7.9056 & 0.8928 & & & \\
\hline Time shifters $\lambda_{1,1988}=1$ & & & & & & \\
\hline$\lambda_{1,1989}$ & & 1.0079 & 0.0043 & & 0.9131 & 0.0049 \\
\hline$\lambda_{1,1990}$ & & 0.9881 & 0.0059 & & 0.8059 & 0.0069 \\
\hline$\lambda_{1,1991}$ & & 1.0219 & 0.0071 & & 0.7756 & 0.0074 \\
\hline$\lambda_{1,1992}$ & & 1.1567 & 0.0093 & & 0.9140 & 0.0092 \\
\hline
\end{tabular}




\begin{tabular}{|c|c|c|c|c|}
\hline$\lambda_{1,1993}$ & 1.2329 & 0.0121 & 0.8867 & 0.0099 \\
\hline$\lambda_{1,1994}$ & 1.2521 & 0.0136 & 0.8245 & 0.0096 \\
\hline$\lambda_{1,1995}$ & 1.2682 & 0.0149 & 0.7899 & 0.0095 \\
\hline$\lambda_{1,1996}$ & 1.2939 & 0.0161 & 0.7566 & 0.0095 \\
\hline$\lambda_{1,1997}$ & 1.3167 & 0.0174 & 0.7327 & 0.0098 \\
\hline$\lambda_{1,1998}$ & 1.3488 & 0.0185 & 0.7139 & 0.0099 \\
\hline$\lambda_{1,1999}$ & 1.4073 & 0.0202 & 0.7046 & 0.0101 \\
\hline$\lambda_{1,2000}$ & 1.4291 & 0.0214 & 0.6938 & 0.0107 \\
\hline$\lambda_{1,2001}$ & 1.4689 & 0.0229 & 0.6914 & 0.0114 \\
\hline$\lambda_{1,2002}$ & 1.4952 & 0.0242 & 0.6892 & 0.0124 \\
\hline$\lambda_{1,2003}$ & 1.5388 & 0.0258 & 0.6881 & 0.0134 \\
\hline$\lambda_{1,2004}$ & 1.5601 & 0.0266 & 0.6805 & 0.0142 \\
\hline \multicolumn{5}{|c|}{ Cohort shifters $\gamma_{1,1940}=1$} \\
\hline$\gamma_{1,1941}$ & 1.0011 & 0.0401 & 1.0361 & 0.0583 \\
\hline$\gamma_{1,1942}$ & 1.0016 & 0.0381 & 1.0559 & 0.0588 \\
\hline$\gamma_{1,1943}$ & 0.9924 & 0.0367 & 1.0867 & 0.0585 \\
\hline$\gamma_{1,1944}$ & 1.0100 & 0.0354 & 1.1290 & 0.0571 \\
\hline$\gamma_{1,1945}$ & 0.9708 & 0.0343 & 1.1188 & 0.0580 \\
\hline$\gamma_{1,1946}$ & 0.9763 & 0.0333 & 1.1563 & 0.0569 \\
\hline$\gamma_{1,1947}$ & 0.9616 & 0.0317 & 1.1600 & 0.0556 \\
\hline$\gamma_{1,1948}$ & 0.9831 & 0.0320 & 1.2381 & 0.0580 \\
\hline$\gamma_{1,1949}$ & 0.9519 & 0.0312 & 1.2255 & 0.0581 \\
\hline$\gamma_{1,1950}$ & 0.9695 & 0.0321 & 1.2742 & 0.0616 \\
\hline$\gamma_{1,1951}$ & 0.9857 & 0.0319 & 1.3615 & 0.0630 \\
\hline$\gamma_{1,1952}$ & 0.9583 & 0.0311 & 1.3482 & 0.0634 \\
\hline$\gamma_{1,1953}$ & 0.9808 & 0.0314 & 1.4439 & 0.0664 \\
\hline$\gamma_{1,1954}$ & 0.9390 & 0.0305 & 1.3903 & 0.0660 \\
\hline$\gamma_{1,1955}$ & 0.9709 & 0.0311 & 1.5023 & 0.0700 \\
\hline$\gamma_{1,1956}$ & 0.9530 & 0.0306 & 1.5502 & 0.0716 \\
\hline$\gamma_{1,1957}$ & 0.9628 & 0.0308 & 1.6323 & 0.0749 \\
\hline$\gamma_{1,1958}$ & 0.9878 & 0.0313 & 1.7380 & 0.0793 \\
\hline$\gamma_{1,1959}$ & 0.9592 & 0.0306 & 1.7389 & 0.0798 \\
\hline$\gamma_{1,1960}$ & 0.9791 & 0.0286 & 1.8759 & 0.0754 \\
\hline
\end{tabular}




\begin{tabular}{|c|c|c|c|c|c|c|}
\hline$\gamma_{1,1961}$ & & 0.9475 & 0.0279 & & 1.8959 & 0.0762 \\
\hline$\gamma_{1,1962}$ & & 0.9553 & 0.0282 & & 2.0361 & 0.0818 \\
\hline$\gamma_{1,1963}$ & & 0.9752 & 0.0290 & & 2.2006 & 0.0883 \\
\hline$\gamma_{1,1964}$ & & 0.9502 & 0.0284 & & 2.2670 & 0.0909 \\
\hline$\gamma_{1,1965}$ & & 0.9425 & 0.0284 & & 2.3467 & 0.0941 \\
\hline$\gamma_{1,1966}$ & & 0.9464 & 0.0287 & & 2.5782 & 0.1032 \\
\hline$\gamma_{1,1967}$ & & 0.9352 & 0.0285 & & 2.7112 & 0.1085 \\
\hline$\gamma_{1,1968}$ & & 0.8821 & 0.0271 & & 2.7789 & 0.1111 \\
\hline$\gamma_{1,1969}$ & & 0.8692 & 0.0267 & & 2.9177 & 0.1163 \\
\hline$\gamma_{1,1970}$ & & 0.8638 & 0.0265 & & 2.9631 & 0.1178 \\
\hline$\gamma_{1,1971}$ & & 0.8500 & 0.0261 & & 2.8585 & 0.1135 \\
\hline$\gamma_{1,1972}$ & & 0.8276 & 0.0255 & & 2.9451 & 0.1165 \\
\hline$\gamma_{1,1973}$ & & 0.8938 & 0.0273 & & 3.1080 & 0.1226 \\
\hline$\gamma_{1,1974}$ & & 0.8861 & 0.0270 & & 3.0035 & 0.1185 \\
\hline$\gamma_{1,1975}$ & & 0.9176 & 0.0278 & & 2.9632 & 0.1174 \\
\hline Transitory Component & & & & & & \\
\hline $\exp ($ estimate $)=\sigma_{0}^{2}$ & & & & & & \\
\hline $\exp ($ estimate $)=\sigma_{0,1940}^{2}$ & 0.0597 & -2.8182 & 0.1292 & 0.0334 & -3.3990 & 0.3236 \\
\hline $\exp ($ estimate $)=\sigma_{0,1941}^{2}$ & 0.0411 & -3.1928 & 0.1599 & 0.0253 & -3.6788 & 0.3853 \\
\hline $\exp ($ estimate $)=\sigma_{0,1942}^{2}$ & 0.0433 & -3.1406 & 0.1355 & 0.0362 & -3.3196 & 0.2597 \\
\hline $\exp ($ estimate $)=\sigma_{0,1943}^{2}$ & 0.0331 & -3.4075 & 0.1364 & 0.0333 & -3.4026 & 0.2468 \\
\hline $\exp ($ estimate $)=\sigma_{0,1944}^{2}$ & 0.0369 & -3.3000 & 0.1244 & 0.0468 & -3.0623 & 0.1692 \\
\hline $\exp ($ estimate $)=\sigma_{0,1945}^{2}$ & 0.0264 & -3.6340 & 0.1292 & 0.0412 & -3.1905 & 0.1757 \\
\hline $\exp ($ estimate $)=\sigma_{0,1946}^{2}$ & 0.0292 & -3.5322 & 0.1141 & 0.0545 & -2.9091 & 0.1235 \\
\hline $\exp ($ estimate $)=\sigma_{0,1947}^{2}$ & 0.0229 & -3.7765 & 0.1123 & 0.0571 & -2.8627 & 0.1066 \\
\hline $\exp ($ estimate $)=\sigma_{0,1948}^{2}$ & 0.0235 & -3.7510 & 0.1106 & 0.0635 & -2.7560 & 0.0971 \\
\hline $\exp ($ estimate $)=\sigma_{0,1949}^{2}$ & 0.0199 & -3.9187 & 0.1116 & 0.0678 & -2.6906 & 0.0907 \\
\hline $\exp ($ estimate $)=\sigma_{0,1950}^{2}$ & 0.0170 & -4.0770 & 0.1158 & 0.0704 & -2.6536 & 0.0838 \\
\hline $\exp ($ estimate $)=\sigma_{0,1951}^{2}$ & 0.0152 & -4.1881 & 0.1207 & 0.0727 & -2.6212 & 0.0840 \\
\hline $\exp ($ estimate $)=\sigma_{0,1952}^{2}$ & 0.0139 & -4.2731 & 0.1216 & 0.0800 & -2.5259 & 0.0775 \\
\hline $\exp ($ estimate $)=\sigma_{0,1953}^{2}$ & 0.0130 & -4.3393 & 0.1273 & 0.0845 & -2.4712 & 0.0768 \\
\hline
\end{tabular}




\begin{tabular}{|c|c|c|c|c|c|c|}
\hline $\exp ($ estimate $)=\sigma_{0,1954}^{2}$ & 0.0099 & -4.6196 & 0.1296 & 0.0828 & -2.4915 & 0.0705 \\
\hline $\exp ($ estimate $)=\sigma_{0,1955}^{2}$ & 0.0105 & -4.5522 & 0.1349 & 0.0976 & -2.3269 & 0.0707 \\
\hline $\exp ($ estimate $)=\sigma_{0,1956}^{2}$ & 0.0080 & -4.8270 & 0.1429 & 0.0903 & -2.4042 & 0.0717 \\
\hline $\exp ($ estimate $)=\sigma_{0,1957}^{2}$ & 0.0077 & -4.8647 & 0.1450 & 0.1005 & -2.2976 & 0.0697 \\
\hline $\exp ($ estimate $)=\sigma_{0,1958}^{2}$ & 0.0079 & -4.8412 & 0.1482 & 0.1161 & -2.1532 & 0.0699 \\
\hline $\exp ($ estimate $)=\sigma_{0,1959}^{2}$ & 0.0056 & -5.1777 & 0.1517 & 0.1060 & -2.2448 & 0.0680 \\
\hline $\exp ($ estimate $)=\sigma_{0,1960}^{2}$ & 0.0052 & -5.2634 & 0.1429 & 0.1156 & -2.1575 & 0.0504 \\
\hline $\exp ($ estimate $)=\sigma_{0,1961}^{2}$ & 0.0038 & -5.5767 & 0.1492 & 0.1072 & -2.2329 & 0.0502 \\
\hline $\exp ($ estimate $)=\sigma_{0,1962}^{2}$ & 0.0035 & -5.6525 & 0.1550 & 0.1150 & -2.1631 & 0.0500 \\
\hline $\exp ($ estimate $)=\sigma_{0,1963}^{2}$ & 0.0028 & -5.8699 & 0.1617 & 0.1147 & -2.1651 & 0.0499 \\
\hline $\exp ($ estimate $)=\sigma_{0,1964}^{2}$ & 0.0020 & -6.2214 & 0.1690 & 0.1002 & -2.3004 & 0.0498 \\
\hline $\exp ($ estimate $)=\sigma_{0,1965}^{2}$ & 0.0017 & -6.3801 & 0.1740 & 0.0961 & -2.3429 & 0.0499 \\
\hline $\exp ($ estimate $)=\sigma_{0,1966}^{2}$ & 0.0014 & -6.5932 & 0.1771 & 0.0944 & -2.3607 & 0.0502 \\
\hline $\exp ($ estimate $)=\sigma_{0,1967}^{2}$ & 0.0014 & -6.6023 & 0.1795 & 0.0959 & -2.3446 & 0.0508 \\
\hline $\exp ($ estimate $)=\sigma_{0,1968}^{2}$ & 0.0010 & -6.9092 & 0.1859 & 0.0826 & -2.4939 & 0.0514 \\
\hline $\exp ($ estimate $)=\sigma_{0,1969}^{2}$ & 0.0008 & -7.1767 & 0.1849 & 0.0744 & -2.5986 & 0.0515 \\
\hline $\exp ($ estimate $)=\sigma_{0,1970}^{2}$ & 0.0007 & -7.2768 & 0.1844 & 0.0698 & -2.6622 & 0.0513 \\
\hline $\exp ($ estimate $)=\sigma_{0,1971}^{2}$ & 0.0006 & -7.3486 & 0.1836 & 0.0614 & -2.7902 & 0.0509 \\
\hline $\exp ($ estimate $)=\sigma_{0,1972}^{2}$ & 0.0005 & -7.6823 & 0.1819 & 0.0506 & -2.9829 & 0.0506 \\
\hline $\exp ($ estimate $)=\sigma_{0,1973}^{2}$ & 0.0004 & -7.8563 & 0.1824 & 0.0451 & -3.0991 & 0.0503 \\
\hline $\exp ($ estimate $)=\sigma_{0,1974}^{2}$ & 0.0004 & -7.9512 & 0.1816 & 0.0405 & -3.2065 & 0.0502 \\
\hline $\exp ($ estimate $)=\sigma_{0,1975}^{2}$ & 0.0004 & -7.7175 & 0.1824 & 0.0452 & -3.0968 & 0.0503 \\
\hline$\rho$ & & 0.9640 & 0.0052 & & 0.9508 & 0.0018 \\
\hline$\theta$ & & -0.2060 & 0.0037 & & -0.2700 & 0.0024 \\
\hline $\exp ($ estimate $)=\sigma_{\varepsilon}^{2}$ & & & & 0.0442 & -3.1180 & 0.0514 \\
\hline$\beta_{0}$ & & 0.0004 & 0.0001 & & & \\
\hline$\beta_{1}$ & & -0.0004 & 0.0000 & & & \\
\hline$\beta_{2}$ & & 0.0001 & 0.0000 & & & \\
\hline$\beta_{3}$ & & $\begin{array}{l}-6.01 \mathrm{E}- \\
06\end{array}$ & $\begin{array}{l}6.47 \mathrm{E}- \\
07\end{array}$ & & & \\
\hline$\beta_{4}$ & & $\begin{array}{l}1.54 \mathrm{E}- \\
07\end{array}$ & $\begin{array}{l}1.37 \mathrm{E}- \\
08\end{array}$ & & & \\
\hline
\end{tabular}




Time shifters $\lambda_{2,1988}=1$
$\lambda_{2,1989}$
$\lambda_{2,1990}$
$\lambda_{2,1991}$
$\lambda_{2,1992}$
$\lambda_{2,1993}$
$\lambda_{2,1994}$
$\lambda_{2,1995}$
$\lambda_{2,1996}$
$\lambda_{2,1997}$
$\lambda_{2,1998}$
$\lambda_{2,1999}$
$\lambda_{2,2000}$
$\lambda_{2,2001}$
$\lambda_{2,2002}$
$\lambda_{2,2003}$
$\lambda_{2,2004}$
Cohort shifters
$\gamma_{2,1941}$
$\gamma_{2,1942}$
$\gamma_{2,1943}=1$
$\gamma_{2,1944}$
$\gamma_{2,1945}$
$\gamma_{2,1946}$
$\gamma_{2,1947}$
$\gamma_{2,1948}$
$\gamma_{2,1949}$
$\gamma_{2,1950}$
$\gamma_{2,1951}$

\begin{tabular}{|c|c|c|c|}
\hline 0.9258 & 0.0058 & 0.9911 & 0.0038 \\
\hline 0.8420 & 0.0089 & 0.9716 & 0.0056 \\
\hline 0.7603 & 0.0110 & 0.9400 & 0.0067 \\
\hline 0.7626 & 0.0135 & 0.9151 & 0.0078 \\
\hline 0.6603 & 0.0139 & 0.9010 & 0.0086 \\
\hline 0.6153 & 0.0145 & 0.9211 & 0.0090 \\
\hline 0.5781 & 0.0151 & 0.9217 & 0.0091 \\
\hline 0.5310 & 0.0153 & 0.9200 & 0.0092 \\
\hline 0.4925 & 0.0155 & 0.9152 & 0.0094 \\
\hline 0.4466 & 0.0152 & 0.9015 & 0.0096 \\
\hline 0.3898 & 0.0143 & 0.8815 & 0.0099 \\
\hline 0.3579 & 0.0140 & 0.8622 & 0.0107 \\
\hline 0.3293 & 0.0138 & 0.8504 & 0.0116 \\
\hline 0.2990 & 0.0134 & 0.8208 & 0.0127 \\
\hline 0.2710 & 0.0131 & 0.8060 & 0.0142 \\
\hline 0.2487 & 0.0129 & 0.7886 & 0.0155 \\
\hline 1.1373 & 0.0521 & 1.0572 & 0.0363 \\
\hline 1.1860 & 0.0543 & 1.0323 & 0.0358 \\
\hline 1.3352 & 0.0592 & 1.0617 & 0.0359 \\
\hline 1.3868 & 0.0601 & 1.0368 & 0.0337 \\
\hline 1.5069 & 0.0667 & 1.0411 & 0.0347 \\
\hline 1.5928 & 0.0696 & 1.0246 & 0.0330 \\
\hline 1.8069 & 0.0782 & 1.0661 & 0.0328 \\
\hline 1.8197 & 0.0835 & 1.0163 & 0.0322 \\
\hline 1.9607 & 0.0915 & 1.0130 & 0.0314 \\
\hline 2.1941 & 0.1079 & 1.0598 & 0.0333 \\
\hline 2.2548 & 0.1154 & 1.0201 & 0.0317 \\
\hline 2.4227 & 0.1302 & 1.0230 & 0.0314 \\
\hline 2.4951 & 0.1423 & 0.9973 & 0.0315 \\
\hline 2.8690 & 0.1709 & 1.0538 & 0.0322 \\
\hline
\end{tabular}




\begin{tabular}{|c|c|c|c|c|c|}
\hline$\gamma_{2,1955}$ & 2.9363 & 0.1853 & & 1.0216 & 0.0324 \\
\hline$\gamma_{2,1956}$ & 3.0621 & 0.2029 & & 0.9973 & 0.0316 \\
\hline$\gamma_{2,1957}$ & 3.2217 & 0.2222 & & 0.9817 & 0.0313 \\
\hline$\gamma_{2,1958}$ & 3.3996 & 0.2435 & & 0.9753 & 0.0317 \\
\hline$\gamma_{2,1959}$ & 3.8064 & 0.2785 & & 1.0066 & 0.0314 \\
\hline$\gamma_{2,1960}$ & 4.0505 & 0.2903 & & 0.9904 & 0.0247 \\
\hline$\gamma_{2,1961}$ & 4.4171 & 0.3283 & & 0.9923 & 0.0248 \\
\hline$\gamma_{2,1962}$ & 4.5102 & 0.3462 & & 0.9466 & 0.0237 \\
\hline$\gamma_{2,1963}$ & 4.8457 & 0.3850 & & 0.9424 & 0.0236 \\
\hline$\gamma_{2,1964}$ & 5.3518 & 0.4412 & & 0.9490 & 0.0238 \\
\hline$\gamma_{2,1965}$ & 5.8114 & 0.4960 & & 0.9544 & 0.0240 \\
\hline$\gamma_{2,1966}$ & 6.1591 & 0.5430 & & 0.9070 & 0.0229 \\
\hline$\gamma_{2,1967}$ & 6.7065 & 0.6104 & & 0.8898 & 0.0225 \\
\hline$\gamma_{2,1968}$ & 7.6686 & 0.7202 & & 0.8706 & 0.0220 \\
\hline$\gamma_{2,1969}$ & 8.1754 & 0.7665 & & 0.8558 & 0.0217 \\
\hline$\gamma_{2,1970}$ & 8.2511 & 0.7724 & & 0.8524 & 0.0216 \\
\hline$\gamma_{2,1971}$ & 8.4753 & 0.7908 & & 0.8900 & 0.0224 \\
\hline$\gamma_{2,1972}$ & 8.8249 & 0.8197 & & 0.8773 & 0.0221 \\
\hline$\gamma_{2,1973}$ & 8.2619 & 0.7680 & & 0.8924 & 0.0225 \\
\hline$\gamma_{2,1974}$ & 8.1837 & 0.7567 & & 0.9057 & 0.0228 \\
\hline$\gamma_{2,1975}$ & 7.5667 & 0.6990 & & 0.9082 & 0.0228 \\
\hline SSR & 0.0644 & & 0.0773 & & \\
\hline$\chi^{2}$ & $5390.3708(\mathrm{df}=166)$ & & 7541.0155 & & \\
\hline BIC & $1.9311 \mathrm{E}-05$ & & $2.2095 \mathrm{E}-05$ & & \\
\hline
\end{tabular}


Table 3. Wald tests of model restrictions in the base model

\begin{tabular}{|c|c|c|c|}
\hline Restriction & $\chi^{2}$ & $\begin{array}{l}\text { Degrees of } \\
\text { freedom }\end{array}$ & P-value \\
\hline $\begin{array}{l}\text { (1) } \sigma_{\pi_{21}}^{2}=\sigma_{\pi_{22}}^{2}=\ldots=\sigma_{\pi_{40}}^{2}=0 \\
\text { (no random walk) }\end{array}$ & 10326.6302 & 31 & 0.0001 \\
\hline $\begin{array}{l}\text { (2) } \sigma_{\pi_{21}}^{2}=\sigma_{\pi_{22}}^{2}=\ldots=\sigma_{\pi_{40}}^{2}=\sigma_{\pi}^{2} \\
\text { (no age-specific innovation variance) }\end{array}$ & 2463.3344 & 21 & 0.0001 \\
\hline $\begin{array}{l}\text { (3) } \beta_{1}=0, \beta_{2}=0, \beta_{3}=0, \beta_{4}=0 \\
\text { (no age-related heteroskedastic transitory shocks) }\end{array}$ & 2963.499 & 4 & 0.0001 \\
\hline
\end{tabular}

Table 4. Trend and cyclical variation of the persistent and transitory components, base and restricted model

\begin{tabular}{llllll}
\hline Dependent Variable & Linear trend & \multicolumn{2}{l}{ Real GDP growth rate } & Adjusted R2 \\
\cline { 2 - 5 } Base Model & Est & SE & Est & SE & \\
\cline { 3 - 5 } Permanent Variance & 0.0060 & 0.0003 & -0.0235 & 0.0504 & $96.80 \%$ \\
Transitory Variance & -0.0022 & 0.0004 & -0.1947 & 0.0740 & $61.05 \%$ \\
Immobility & 0.1217 & 0.011 & 1.8663 & 1.9257 & $88.75 \%$ \\
& & & & & \\
Restricted Model & & & & & \\
\hline Permanent Variance & 0.0029 & 0.0006 & -0.0504 & 0.1106 & $58.49 \%$ \\
Transitory Variance & 0.0015 & 0.0009 & -0.1193 & 0.1526 & $15.54 \%$ \\
Immobility & 0.0149 & 0.013 & 0.5118 & 2.2663 & $8.72 \%$ \\
\hline
\end{tabular}

Note: OLS estimates, sample period 1988-2004 (T=16) 
Abowd, John M., and Card, David. 1989. On the covariance structure of earnings and hours changes. Econometrica, 57(2), 411-445.

Anderson, T. W., and Hsiao, Cheng. 1982. Formulation and estimation of dynamic models using panel data. Journal of Econometrics.

Atkinson, Anthony, B., Bourguignon, Francois, and Morrisson, C. (Eds.). (1992). Empirical studies of earnings mobility: Suisse : Harwood Academic Publishers.

Baker, Michael. 1997. Growth-rate heterogeneity and the covariance structure of life-cycle earnings. Journal of Labor Economics, 15(2), 338-375.

Baker, Michael, and Solon, Gary. 2003. Earnings dynamics and inequality among Canadian men, 1976-1992: evidence from longitudinal income tax records. Journal of Labor Economics, 21(2), 289-321.

Cappellari, Lorenzo. 2003. The dynamics and inequlaity of Italian men's earnings. The Journal of Human Resources, XXXIX.

Cervini, Morilla, and Ramos, Xavier. 2006. Permanent and Transitory Earnings Inequlaity in Spain, 1993-2000. Paper presented at the EALE 2006.

Clark, Todd E. 1996. Small sample properties of estimators of non-linear models of covariance structure. Journal of Business and Economic Statistics, 14, 367-373.

Dickens, Richard. 1999. Caught in a trap? Wage mobility in Great Britain: 1975-1994. Economica(67), 477-497.

Dickens, Richard. 2000. The evolution of individual male earnings in Great Britain: 1975-95. The Economic Journal, 110(460), 27-49.

Freeman, Richard B. 1975. Overinvestment in college training? Journal of human resources, 10, 287-311.

Friedman, Milton, and Kuznets, Simon. 1954. Income from independent professional practice. New York, NBER

Gustavsson, Magnus. 2004a. Changes in Permanent and Transitory Earnings Inequality in Sweden: 1991:1999". In "Empirical Essays on Earnings Inequality": Ph.D. Dissertation, Uppsala University.

Gustavsson, Magnus. 2004b. Trends in the transitory variance of earnings: evidence from Sweden 1960-1990 and a comparison with the United States. Uppsala University Working Papers, No. 11.

Hause, John C. 1977. The covariance structure of earnings and on-the-job training hypothesis. Annals of Economic and Social Measurement, 335-366.

Hause, John C. 1980. The fine structure of earnings and the on-the-job training hypothesis. Econometrica, 48(4), 1013-1029.

Kalwij, Adriaan, and Alessie, Rob. 2003. Permanent and transitory wage inequality of British men, 1975-2001: year, age and cohort effect. Journal of Applied Econometrics, 22, 10631093.

Katz, Lawrence F. 1994. Comments and discussion. Brookings Papers on Economic Activity(2), 255-261. 
Katz, Lawrence F., and Autor, David H. 1999. Changes in the wage structure and earnings inequality. In Handbook of Labor Economics (Vol. 3): Elsevier Science B.V.

Leamer, Edward E. 1983. Let's take the con out of econometrics. American Economic Review, 74(March), 31-43.

Lillard, Lee A., and Weiss, Y. 1979. Components of variation in panel earnings data: American scientists 1960-70. Econometrica, 47(2), 437-454.

Lillard, Lee A., and Willis, R. 1978. Dynamic aspects of earnings mobility. Econometrica, 46(5), 985-1012.

MaCurdy, Thomas E. 1981. Time series models applied to panel data. Stanford University.

MaCurdy, Thomas E. 1982. The use of time series processes to model the error structure of earnings in a longitudinal data analysis. Journal of Econometrics, 18(1), 83-114.

Mincer, Jacob. 1957. A study of income distribution. Columbia University.

Mincer, Jacob. 1958. Investment in human capital and personal income distribution. Joournal of Political Economy, 66(4), 281-302.

Mincer, Jacob. 1962. On-the-job training: costs, returns and some implications. Journal of Political Economy, 70(5, Part 2), S50-S79.

Mincer, Jacob. 1974. Schooling, experience and earnings. New York: NY: NBER.

Moffitt, Robert, and Gottschalk, Peter. 1995. Trends in the covariance structure of earnings in the United States: 1969-1987. Paper presented at the Working Papers in Economics, No. 355.

Moffitt, Robert, and Gottschalk, Peter. 1998. Trends in the variances of permanent and transitory earnings in the U.S. and their relation to earnings mobility. Boston College Working Papers, No. 444.

Moffitt, Robert, and Gottschalk, Peter. 2002. Trends in the transitory variance of earnings in the United States. The Economic Journal, 112(478), C68-C73.

Moffitt, Robert, and Gottschalk, Peter. 2008. Trends in the transitory variance of male earnings in the U.S., 1970-2004. Boston College Working Papers, No. 697.

Ramos, Xavier. 1999. Anatomy of earnings mobility in Britain: evidence from BHPS, 1991-1995. Working Papers of the ESRC Research Centre on Micro-social Change(99-11).

Ramos, Xavier. 2003. The covariance structure of earnings in Great Britain, 1991-1999. Economica, vol. 70(278), 353-374.

Rodrik, Dani. 1997. Has international integration gone too far? Washington, DC.

Sologon, Denisa M., and O'Donoghue, Cathal. 2009a. Earnings dynamics and inequality among men across 14 EU countries: evidence from ECHP. IZA Working Series, No. 4012(February).

Sologon, Denisa M., and O'Donoghue, Cathal. 2009b. Earnings dynamics and inequality in EU countries, 1994-2001. MGSOG Working Series(June).

Sologon, Denisa M., and O'Donoghue, Cathal. 2009c. Earnings dynamics and inequality in EU: 1994-2001. SOEPpapers on Multidisciplinary Panel Data Research, No. 184(April).

Sologon, Denisa M., and O'Donoghue, Cathal. 2009d. Equalizing or disequalizing lifetime earnings differentials? Earnings mobility in the EU: 1994-2001. MGSOG Working Series(November). 
Sologon, Denisa M., and O'Donoghue, Cathal. 2009e. Increased Opportunity to Move Up the Economic Ladder? Earnings Mobility in EU: 1994-2001. IZA Working Series, No. 4311(July).

Sologon, Denisa M., and O'Donoghue, Cathal. 2009f. Policy, Institutional Factors and Earnings Mobility. IZA Working Series, No. 4151(May). 


\section{Figures}

Figure 1. The evolution of the labour market structure by occupation status in Luxembourg in 1988, 1996 and 2004.

Figure 2. The evolution of the labour market structure by sector of activity status in Luxembourg

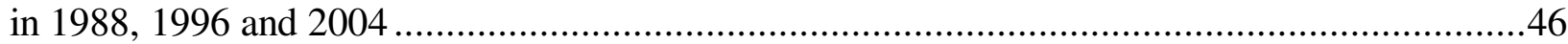

Figure 3. The evolution of the age structure of the active population in Luxembourg ................47

Figure 4. The variance and mean of log hourly earnings, 1988-2004 ......................................48

Figure 5. The evolution of the labour market structure by occupational status in the sample in

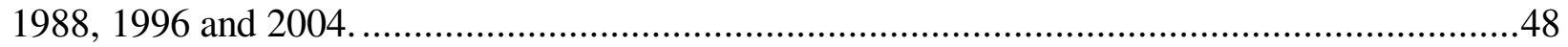

Figure 6. The evolution of the age structure of the active population in the sample....................50

Figure 7. Autocovariance Structure of Earnings for Selected Cohorts: 1940 - 1975...................51

Figure 8. Lifecycle Autocovariances for Selected Years : 1988, 1992, 1996, 2000, 2004............53

Figure 9. The pattern of the permanent component without time and cohort loading factors ......54

Figure 10. Year-specific factor loadings on the persistent and transitory components .................54

Figure 11. Cohort-specific loading factors on the permanent and transitory components ............54

Figure 12. Cohort-specific initial transitory variances............................................................55

Figure 13. The age profile of the variance of the transitory innovation, base model ...................55

Figure 14. Actual and Predicted Variance of Earnings with Permanent and Transitory Predicted

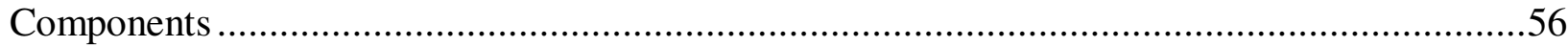

Figure 15. Predicted Permanent and Transitory Variance as \% of Predicted Overall Variance for

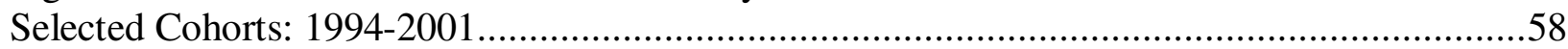

Figure 16. Earnings immobility for men by cohort over time - base model.............................60

Figure 17. Cross-sectional age profile of the permanent and transitory variance for selected years

Figure 18. Cross-sectional age profile of the share of the permanent component from the overall variance for selected years: 1988, 1993, 1998, 2004. . .62 Figure 19. The cross-sectional age -immobility profile for selected years 1988, 1993, 1998, 2004

Figure 20. A decomposition of the variance of log hourly earnings for men, 40 years old: base

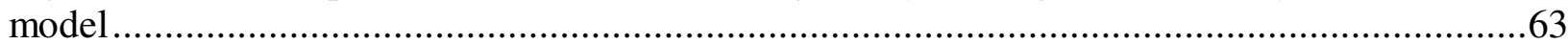

Figure 21. Earnings immobility for men of age 30, 40 and 50 - base model ...........................64

Figure 22. Earnings immobility for men of age 20, 25, 30, 35, 40, 45, 50, 55 - base model .......64 Figure 23. A decomposition of the variance of log hourly earnings for men, 40 years old: restricted model.

\section{Tables}

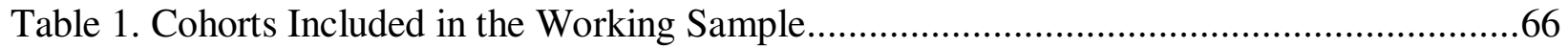

Table 2. Error Component Model Estimates .........................................................................67

Table 3. Wald tests of model restrictions in the base model .....................................................73

Table 4. Trend and cyclical variation of the persistent and transitory components, base model..73 